\title{
Busca indexada de padrões em textos comprimidos
}

\author{
Lennon de Almeida Machado
}

\author{
DISSERTAÇÃO APRESENTADA \\ $\mathrm{AO}$ \\ Instituto DE MatemáticA E Estatística \\ DA \\ Universidade DE SÃo PAUlo \\ PARA \\ OBTENÇÃO DO TÍTULO \\ DE \\ Mestre EM CiênCIAS \\ Programa: Ciências da Computação \\ Orientador: Prof. Dr. Alair Pereira do Lago
}

São Paulo, janeiro de 2010 


\section{Agradecimentos}

Gostaria de agradecer primeiramente a Deus, o Criador e Salvador, por ter tido misericórdia de todos, sendo eu mais um a compartilhar de suas promessas:

"Porque Deus amou o mundo de tal maneira que deu o seu Filho unigênito para que todo aquele que nele crê não pereça, mas que tenha a vida eterna." - João 3:16 (Bíblia - tradução por João Ferreira de Almeida),

Também descrita em:

"Disse-lhe Jesús: Eu sou o caminho, e a verdade e a vida. Ninguém vem ao Pai, senão por mim" - João 14:6 (Bíblia - tradução por João Ferreira de Almeida).

Graças e Ele encontrei pessoas preciosas que me ajudaram e ajudam em minha caminhada nesta vida. A começar por minha esposa, Cristina, e minha filha, Bruna, elas são a alegria de minha vida, razão pela qual tudo vale a pena! Cris com seu bom coração, sabendo quando calar e quando falar, sempre me dando direção, me consolando em minhas dores (e foram muitas!), trazendo de volta minha confiança por vezes abalada, compartilhando alegrias e tristezas, sonhos e desilusões, mas principalmente nosso amor. Bruna com sua alegria, sempre feliz, procurando juntar a todos; não tem como ficar triste com ela por perto ou mesmo longe, pois sempre tem algum brinquedo colocado por ela na minha bolsa e ao olhá-lo, as lembranças de você brincando me animam. Quem é pai compreende melhor muitas coisas, em especial as palavras de Deus. E aproveito para agradecer a meu pai, Antonio Carlos, e minha mãe, Ana Maria, por todo amor, carinho e dedicação com que criaram a mim, meu irmão Harrison e minha irmã Polianna. Pai, obrigado por sempre ter sido o alicerce de casa. Mãe, obrigado por ter dedicado sua vida a cuidar de nós. Harri e Poli, obrigado por terem me divertido tanto, brincamos e brigamos muito, mas sempre nos respeitamos. Também agradeço a meus sobrinhos Lara, Beatriz e Vinícus, meus sogros Wilson e Cleuza e minha cunhada Meire, vocês completam a felicidade das pessoas que amo, trazendo mais alegria.

Agradeço ao BuscaPé por sua confiança em mim depositada. Estamos juntos há mais de nove anos, aprendi muito desde junho de 2000 e continuo a aprender até hoje. Agradeço aos diretores Romero Rodrigues, Rodrigo Borges, Ronaldo Takahashi e Mario Letelier, a meu ex-colega de classe e gerente Eduardo Akira, a meus funcionários Alex Soares, Andrea Paiva, Daniel Mezzatto, Daniel Nakazato, Danilo Brandão e Paulo Passaia e ex-funcionários Daniel Ribeiro e Rodrigo Lisboa. Em especial, agradeço ao Rodrigo Borges que proporcionou o encontro entre o professor Alair e eu, me apoiou neste mestrado e patrocinou minha ida ao SIGIR 2005 para entrarmos em contato com a comunidade científica de recuperação de informação e a meus funcionários que sempre foram $110 \%$ responsáveis, atingindo todas as metas propostas e me ajudando a multiplicar o tempo escasso.

Agradeço aos professores Alair e Yoshiharu que ajudaram a desenferrujar meu lado científico adormecido por mais de cinco anos. Yoshi, obrigado por ter se lembrado daquele aluno politécnico que ficava feliz com os desafios feitos nas aulas, e mais feliz com os Ferrero-Rocher ganhos, muito mais que os bombons, o que valeu foi ter deixado sólidos em mim os conceitos que formam as 
bases da Ciência da Computação. Alair, é difícil te chamar assim, mais difícil ainda é te agradecer, que professor aceitaria um aluno tão enferrujado e atarefado asism? Poucos, pouquíssimos! Sua paciência e obstinação em ajudar me impressionam, se um dia eu tiver $1 \%$ delas já ficarei feliz. Obrigado por ter sido pai, amigo e professor, além de me aturar desde junho de 2005!

Agradeço aos funcionários do IME, em especial da secretaria, pois os procurei várias vezes, principalmente com problemas de prazos, mas todos sempre se mostraram empenhados em me ajudar a resolver os problemas. Em especial agradeço ao Pinho, ao Emerson, à Alessandra (Leka) e à Adenilza, pois foram os que mais sofreram comigo.

Agradeço aos amigos que conheci ao longo de minha vida e que tanto me ajudaram, os politécnicos: Fabricio Ferreira, Karin Strauss, Leonardo Martucci, Marcel Smetana, Luiz Ceze, Marcelo Yamashita, Leo Brodskyn, Luiz Papa e Marcelo Mazur; os massoterapeutas, que sempre deram um jeito em mim: Zilton, Fátima e Regina; os mauaenses e baroneses (como eu): André Mobile, Vladimir, Schunk, Apolo e Odair; os professores do SENAI Anchieta: Jediael e Benício e a coordenadora Satiko.

Enfim, agradeço a todas as demais pessoas que não nomeei aqui, mas que compartilharam momentos de suas vidas comigo. Sem todos vocês não conseguiria chegar até onde hoje estou, nem ser como hoje sou.

A todos, meu muito obrigado! 


\section{Resumo}

A busca de palavras em uma grande coleção de documentos é um problema muito recorrente nos dias de hoje, como a própria utilização dos conhecidos "motores de busca" revela.

Para que as buscas sejam realizadas em tempo que independa do tamanho da coleção, é necessário que a coleção seja indexada uma única vez. O tamanho destes índices é tipicamente linear no tamanho da coleção de documentos.

A compressão de dados é outro recurso bastante utilizado para lidar com o tamanho sempre crescente da coleção de documentos.

A intenção deste estudo é aliar a indexação utilizada nas buscas à compressão de dados, verificando alternativas às soluções já propostas e visando melhorias no tempo de resposta das buscas e no consumo de memória utilizada nos índices.

A análise das estruturas de índice com os algoritmos de compressão mostra que arquivo invertido por blocos em conjuntos com compressão Huffman por palavras é uma ótima opção para sistemas com restrição de consumo de memória, pois proporciona acesso aleatório e busca comprimida.

Neste trabalho também são propostas novas codificações livres de prefixo a fim de melhorar a compressão obtida e capaz de gerar códigos auto-sincronizados, ou seja, com acesso aleatório realmente viável. A vantagem destas novas codificações é que elas eliminam a necessidade de gerar a árvore de codificação Huffman através dos mapeamentos propostos, o que se traduz em economia de memória, codificação mais compacta e menor tempo de processamento.

Os resultados obtidos mostram redução de $7 \%$ e $9 \%$ do tamanho dos arquivos comprimidos com tempos de compressão e descompressão melhores e menor consumo de memória.

Palavras-chave: busca indexada de textos comprimidos, compressão de dados, compressão Huffman, códigos-prefixos. 


\section{Abstract}

Pattern matching over a big document collection is a very recurrent problem nowadays, as the growing use of the search engines reveal.

In order to accomplish the search in a period of time independent from the collection size, it is necessary to index the collecion only one time. The index size is typically linear in the size of document collection.

Data compression is another powerful resource to manage the ever growing size of the document collection.

The objective in this assignment is to ally the indexed search to data compression, verifying alternatives to the current solutions, seeking improvement in search time and memory usage.

The analysis on the index structures and compression algorithms indicates that joining the block inverted files with Huffman word-based compression is an interesting solution because it provides random access and compressed search.

New prefix free codes are proposed in this assignment in order to enhance the compression and facilitate the generation of self-sinchronized codes, furthermore, with a truly viable random access. The advantage in this new codes is that they eliminate the need of generating the Huffman-code tree through the proposed mappings, which stands for economy of memory, compact encoding and shorter processing time.

The results demonstrate gains of $7 \%$ and $9 \%$ in the compressed file size, with better compression and decompression times and lower memory consumption.

Keywords: indexed search in compressed texts, data compression, Huffman coding, prefix code. 


\section{Sumário}

Lista de Abreviaturas $\quad$ xi

Lista de Símbolos $\quad$ xiii

Lista de Figuras $\quad$ xv

Lista de Tabelas $\quad$ xvii

1 Introdução $\quad 1$

1.1 Organização do Trabalho . . . . . . . . . . . . . . . . . . . . . . . . 2

2 Estruturas de Indexação $\quad 3$

2.1 Árvore de Sufixos . . . . . . . . . . . . . . . . . . . . . 3

2.2 Vetor de Sufixos . . . . . . . . . . . . . . . . . . . 4

2.3 Arquivo Invertido . . . . . . . . . . . . . . . . . . . 4

2.4 Arquivo Invertido por Blocos . . . . . . . . . . . . . . . . 5

2.5 Comparação das Estruturas de Índices . . . . . . . . . . . . . . . . . . . . 6

$\begin{array}{lll}3 & \text { Algoritmos de Compressão } & \mathbf{7}\end{array}$

3.1 Tipos de Compressão . . . . . . . . . . . . . . . . . . . . . . . 7

4 Compressão Ziv-Lempel 9

4.1 Busca em Textos Comprimidos . . . . . . . . . . . . . . . . . . . 11

4.2 Busca Exata . . . . . . . . . . . . . . . . . . . . . 11

4.3 Busca Aproximada . . . . . . . . . . . . . . . . . . 12

5 Compressão Huffman $\quad 17$

5.1 Utilizando Bytes como Unidade de Informação . . . . . . . . . . . . . . . . . . 21

5.2 Descompressão e Acesso Aleatório . . . . . . . . . . . . . . . . . . . . 22

5.3 Huffman Dinâmico . . . . . . . . . . . . . . . . . . . . . . 23

5.4 Compressão Utilizando Super-Alfabetos . . . . . . . . . . . . . . . . . . . . 24

6 Comparativo das Estratégias de Compressão 25

6.1 Comparação entre Huffman e Ziv-Lempel . . . . . . . . . . . . . . . . . . . 25

6.2 Comparativo entre Variantes da Compressão Huffman . . . . . . . . . . . . . . . . 25

7 Proposta de Novas Codificações Livres de Prefixo $\quad 27$

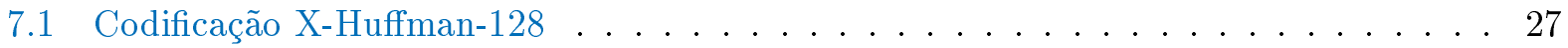

7.2 Atribuição dos Códigos às Palavras do Vocabulário . . . . . . . . . . . . . . . . . 30 
7.3 Codificação X-Huffman-F . . . . . . . . . . . . . . . . . 32

7.4 Codificação X-Huffman-V . . . . . . . . . . . . . . . . . 35

7.5 Otimização da Compressão Huffman . . . . . . . . . . . . . . . . . . 37

8 Resultados Experimentais - Codificações $\quad 39$

8.1 Descrição dos Experimentos . . . . . . . . . . . . . . . . . . . . . . 41

8.2 Experimento $100 \mathrm{k} / 500 \mathrm{k} \ldots \ldots \ldots \ldots \ldots \ldots$

8.3 Experimento $3 \mathrm{M} / 240 \mathrm{M} \ldots \ldots \ldots \ldots \ldots \ldots \ldots$

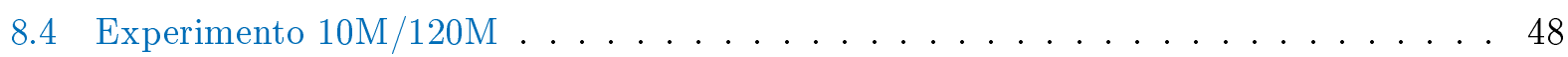

8.5 Análise dos Experimentos . . . . . . . . . . . . . . . . 55

9 Resultados Experimentais - Compressor Xhuff $\quad \mathbf{5 7}$

9.1 Experimento Comparativo de Xhuff, gzip e bzip2 . . . . . . . . . . . . 57

10 Conclusão $\quad \mathbf{5 9}$

10.1 Trabalhos Futuros . . . . . . . . . . . . . . . . . 60

A Listagens dos Programas em C das Codificações Propostas $\quad 63$

A.1 Codificação X-Huffman-F . . . . . . . . . . . . . . . . . . . . 63

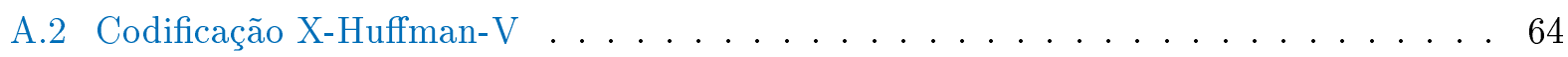

$\begin{array}{ll}\text { B Suporte das Codificações Propostas para } 64 \text { bits } & 67\end{array}$

B.1 Codificação X-Huffman-128 . . . . . . . . . . . . . . . . . 67

B.2 Codificação X-Huffman-F . . . . . . . . . . . . . . . . . 67 67

B.3 Codificação X-Huffman-V . . . . . . . . . . . . . . . . . . 69

$\begin{array}{ll}\text { C Otimização da compressão para X-Huffman-V } & \mathbf{7 3}\end{array}$

$\begin{array}{ll}\text { Referências Bibliográficas } & \mathbf{7 7}\end{array}$ 


\title{
Lista de Abreviaturas
}

\author{
AC Algoritmo de Busca Multi-Padrão de Alfred Aho e Margaret Corasick. \\ BWT Transformação de Burrows-Wheeler (Burrows-Wheeler Transform). \\ DMC Compressão Dinâmica Markov (Dynamic Markov Compression). \\ H-128 Codificação Huffman em base 128. \\ H-2 Codificação Huffman em base 2. \\ H-256 Codificação Huffman em base 256 . \\ LZ77 Algoritmo de Compressão de Abraham Lempel e Jacob Ziv de 1977. \\ LZ78 Algoritmo de Compressão de Abraham Lempel e Jacob Ziv de 1978. \\ LZW LZ78 estendido por A. T. Welch. em 1984. \\ MIT Massachusetts Institute of Technology. \\ MSN MicroSoft Network. \\ PPM Predição por Casamento Parcial (Prediction by Partial Matching). \\ UNIX Uniplexed Information and Computing Service. \\ URL Uniform Resource Locator. \\ WSJ Wall Street Journal. \\ XH-128 Exxtensão da Codificação Huffman 128. \\ XH-F Exxtensão da Codificação Huffman com divisão Fixa de códigos. \\ XH-V Exxtensão da Codificação Huffman com divisão Variável de códigos.
}




\section{Lista de Símbolos}

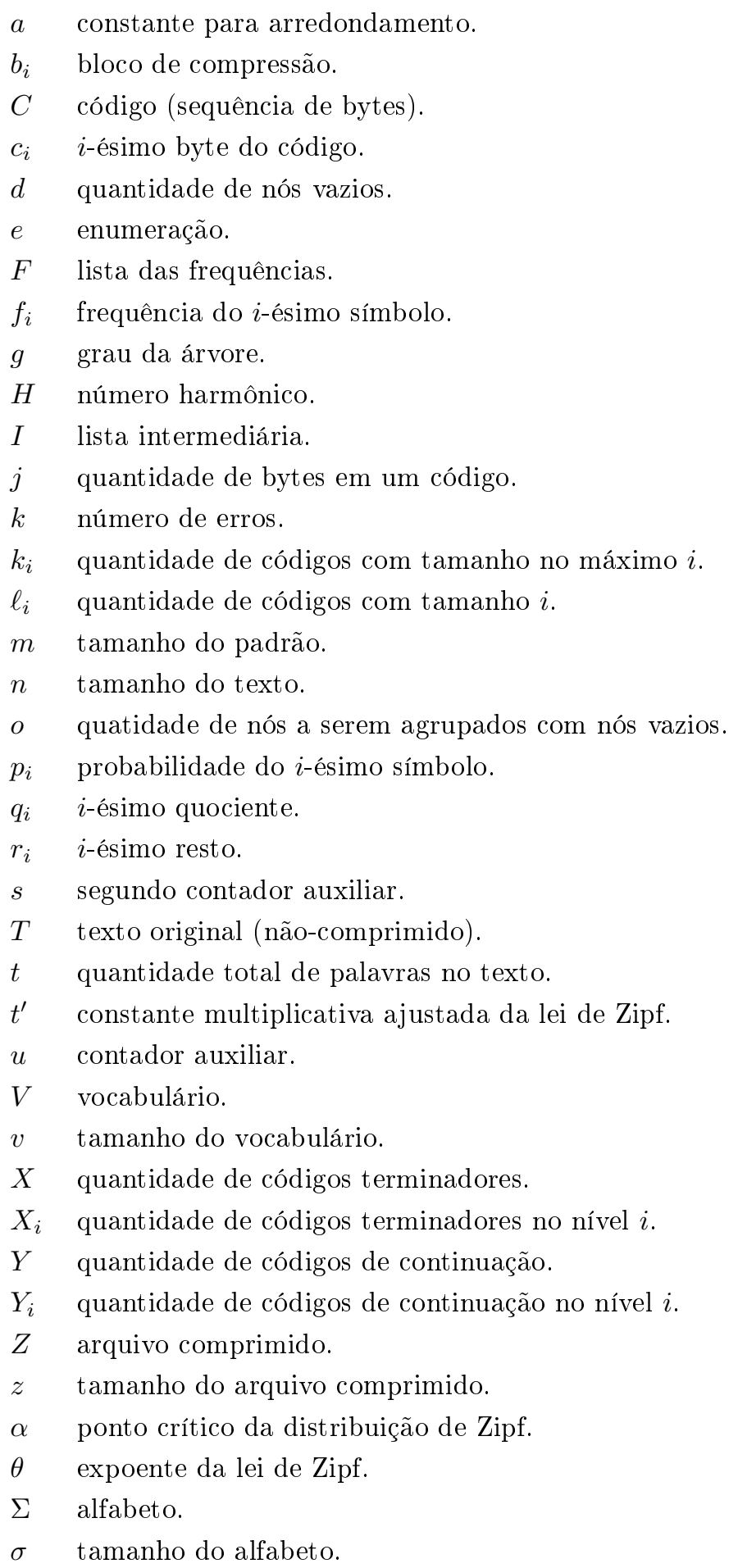




\section{Lista de Figuras}

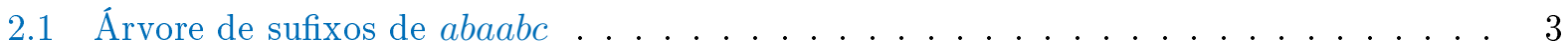

2.2 Exemplo de um arquivo invertido. Cada par de números representa o identificador do documento e a frequência da palavra no documento em questão . . . . . . . . . . 4

4.1 Exemplo após primeira iteração do algoritmo de compressão LZ78. . . . . . . . . . . 10

4.2 Exemplo após segunda iteração do algoritmo de compressão LZ78. . . . . . . . . . . 10

4.3 Exemplo após terceira iteração do algoritmo de compressão LZ78. . . . . . . . . . . . 10

4.4 Exemplo após quarta iteração do algoritmo de compressão LZ78. . . . . . . . . . . . 10

4.5 Exemplo após quarta iteração do algoritmo de compressão LZ78. . . . . . . . . . . . . 11

4.6 Busca aproximada em arquivo comprimido com Ziv-Lempel. Figura com resultados experimentais extraída de $\left(\mathrm{NKT}^{+} 01\right) \ldots \ldots \ldots \ldots \ldots \ldots$

5.1 Código Huffman de compressão para exemplo de texto analisado em (BYRN99) e (dMNZBY00). O texto é comprimido com 23 bits. . . . . . . . . . . . 18

5.2 Exemplo após primeira iteração do Algoritmo de Huffman . . . . . . . . . . . . . . . . . . . . . 18

5.3 Exemplo após segunda iteração do Algoritmo de Huffman . . . . . . . . . . . . . . . 19

5.4 Exemplo após terceira iteração do Algoritmo de Huffman . . . . . . . . . . . . . 19

5.5 Exemplo após quarta iteração do Algoritmo de Huffman . . . . . . . . . . . . . . . 20

5.6 Exemplo após quinta iteração do Algoritmo de Huffman . . . . . . . . . . . . . . 20

5.7 Exemplo de texto analisado em (BYRN99) e (dMNZBY00) comprimido segundo código Huffman descrito na figura 5.6. O texto aqui é comprimido com 22 bits . . . . 21

5.8 Exemplos de descompressão Huffman binária a partir de pontos arbitrários do texto

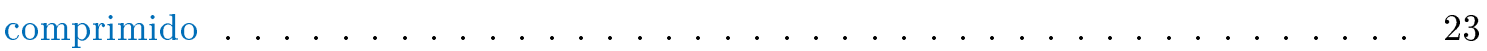

5.9 Durante a busca em textos comprimidos podem-se encontrar ocorrências fantasmas de palavras. Dependendo do ponto inicial da descompressão, pode-se obter "palavra real" ou "fantasma". . . . . . . . . . . . . . . . . . . . . . . . . .

7.1 Esquema da árvore gerada com a divisão de códigos terminadores e de continuação em 128 segundo o mapeamento $M$. Todos os grupos de 256 nós filhos de um mesmo nó pai foram agrupados, por nível, em um único retângulo para melhor visualização.

7.2 Primeiro esquema com a divisão de $X$ códigos terminadores e de $Y$ códigos de continuação. Todos os grupos de 256 nós filhos de um mesmo nó pai foram agrupados, por nível, em um único retângulo para melhor visualização. . . . . . . . . . . . . 32 
7.3 Esquema de codificação X-Huffman-F com a divisão de $X$ códigos terminadores e $Y$ códigos de continuação, sem o problema do prefixo "0x00". Todos os grupos de 256 nós filhos de um mesmo nó pai foram agrupados, por nível, em um único retângulo para melhor visualização. . . . . . . . . . . . . . . . . . . . . 32

7.4 Esquema da árvore gerada com a divisão de códigos terminadores e de continuação em valores arbitrários para cada nível, sem o problema do prefixo "0x00". Todos os grupos de 256 nós filhos de um mesmo nó pai foram agrupados, por nível, em um único retângulo para melhor visualização.

8.1 Comparação das distribuições de Zipf geradas sem e com a correção proposta para $v=5.000, t=25.000$ e $\theta=1,5 \ldots \ldots \ldots \ldots \ldots \ldots$

8.2 Detalhe da comparação das distribuições de Zipf geradas sem e com a correção proposta, para os 500 primeiros valores, para $v=5.000, t=25.000$ e $\theta=1,5 . \ldots$. . . 41

8.3 Resultados para texto com 500.000 palavras e vocabulário de 100.000 palavras. . . . 45

8.4 Razões para texto com 500.000 palavras e vocabulário de 100.000 . . . . . . . . . . . 46

8.5 Resultados para texto das descrições das ofertas do site BuscaPé com 240.000.000 palavras e vocabulário de 3.000 .000 palavras. . . . . . . . . . . . . . . . 49

8.6 Razões para texto das descrições das ofertas do site BuscaPé com 240.000.000 palavras e vocabulário de 3.000 .000 palavras. . . . . . . . . . . . . . . . . 50

8.7 Resultados para texto das URLs das ofertas do site BuscaPé com 120.000.000 palavras e vocabulário de 10.000 .000 palavras. . . . . . . . . . . . . . . . 53

8.8 Razões para texto das URLs das ofertas do site BuscaPé com 120.000.000 palavras e vocabulário de 10.000 .000 palavras. . . . . . . . . . . . . . . . . 54

C.1 Diagonal da superfície do tamanho do arquivo por $\left(X_{1}, X_{2}\right)$ para $v=5.000, t=$

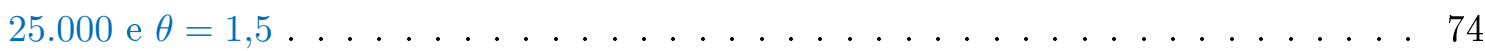

C.2 Visualização plana da superfície do tamanho do arquivo por $\left(X_{1}, X_{2}\right)$ para $v=5.000$,

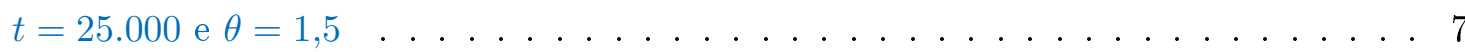

C.3 Visualização tridimensional da superfície do tamanho do arquivo por $\left(X_{1}, X_{2}\right)$ para

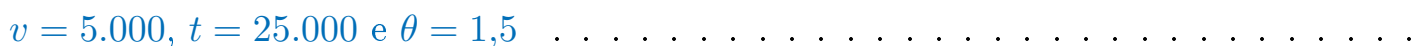




\section{Lista de Tabelas}

2.1 Vetor de sufixos de $a b a a b c \ldots \ldots \ldots \ldots \ldots \ldots \ldots \ldots$

2.2 Comparação de estruturas para vocabulário de arquivo invertido . . . . . . . . . 5

2.3 Comparação das Estruturas de Indexação . . . . . . . . . . . . . . . . . . . 6

4.1 Tempos de Compressão/Descompressão e Taxa de Compressão com diferentes variantes ZL. Dados extraídos de (NT00) . . . . . . . . . . . . . . . . 12

5.1 Tabela comparativa entre métodos de compressão. Dados obtidos de (dMNZBY00) para o arquivo WSJ. . . . . . . . . . . . . . . 22

6.1 Comparação entre diversos tipos de codificação Huffman. . . . . . . . . . . . . . . 26

7.1 Quantidade total de códigos até o nível $i\left(k_{i}\right)$ em função de $X \ldots \ldots \ldots$. . . . . 34

8.1 Tamanho do arquivo comprimido para texto com 500.000 palavras e vocabulário de 100.000 palavras. . . . . . . . . . . . . . . . . . 4 44

8.2 Valores ótimos para texto com 500.000 palavras e vocabulário de 100.000 palavras. . 44

8.3 Razões para texto com 500.000 palavras e vocabulário de 100.000 palavras. . . . . . 47

8.4 Tamanho do arquivo comprimido para texto das descrições das ofertas do site BuscaPé com 240.000.000 palavras e vocabulário de 3.000.000 palavras. A linha em negrito representa os dados reais. . . . . . . . . . . . . . . . . 48

8.5 Valores ótimos para texto das descrições das ofertas do site BuscaPé com 240.000.000 palavras e vocabulário de 3.000 .000 palavras. A linha em negrito representa os dados reais. . . . . . . . . . . . . . . . . . . . . 48

8.6 Razões para texto das descrições das ofertas do site BuscaPé com 240.000.000 palavras e vocabulário de 3.000 .000 palavras. A linha em negrito representa os dados reais. . . . . . . . . . . . . . . . . . . . 51

8.7 Tamanho do arquivo comprimido para texto das URLs das ofertas do site BuscaPé com 120.000.000 palavras e vocabulário de 10.000.000 palavras. A linha em negrito representa os dados reais. . . . . . . . . . . . . . . . . . . 52

8.8 Valores ótimos para texto das URLs das ofertas do site BuscaPé com 120.000.000 palavras e vocabulário de 10.000 .000 palavras. A linha em negrito representa os dados reais. . . . . . . . . . . . . . . . . . . . . 52

8.9 Razões para texto das URLs das ofertas do site BuscaPé com 120.000.000 palavras e vocabulário de 10.000 .000 palavras. A linha em negrito representa os dados reais. . 55

8.10 Comparação das codificações com relação aos resultados dos experimentos. . . . . . . 56

9.1 Comparação das compressões xhuff, gzip e bzip2 . . . . . . . . . . . . . . 57 
xviii LISTA DE TABELAS 


\section{Capítulo 1}

\section{Introdução}

Os buscadores, ou "motores de busca" (search engines), estão cada vez mais presentes no cotidiano. Atualmente, é possível buscar: informações genéricas em sites como Google, Yahoo! e MSN ${ }^{1}$; preços no BuscaPé e Bondfaro ${ }^{2}$; viagens no Kayak e BuscaPé Viagens ${ }^{3}$; lojas no E-Bit ${ }^{4}$; artigos novos e usados no Mercado Livre e Que Barato! $!^{5}$; amigos no Orkut ${ }^{6}$ ou ofertas de emprego no LinkedIn $^{7}$; enfim, a cada dia são apresentados novos serviços que visam ajudar seus usuários a encontrar as informações que eles desejam.

Por trás de todos estes exemplos, sempre existe um buscador apoiado em um tipo de indexação. O índice é uma estrutura de dados que visa apoiar a busca de forma que o tempo de resposta independa ao máximo do tamanho da coleção de documentos. Cada tipo de índice possui vantagens e desvantagens com relação a: memória primária (RAM); memória secundária (disco); tempo de resposta das consultas; escalabilidade e atualização do índice.

Dependendo da quantidade de dados e da estrutura de dados escolhida o uso de memória primária ou secundária pode ser muito alto. Contudo, existem estratégias conhecidas de compactação, que podem ajudar certos tipos de índices a obterem melhores resultados, em especial no consumo de memória. Conforme diversos relatos, são observadas melhorias até mesmo no tempo de resposta, provavelmente devido a menores transferências de dados do disco e de melhor utilização da memória cache.

Neste presente estudo, procurou-se estudar a associação da indexação à compressão a fim de se obter ganhos em algumas das estratégias conhecidas de indexação. São revistos resultados diversos no assunto, bem como são propostas melhorias em alguns destes. É desejável que os documentos indexados sejam sempre mantidos em sua forma comprimida e só sejam descomprimidos para enviar a resposta ao usuário final.

As principais contribuições deste trabalho são as novas formas de codificação livre de prefixos propostas, já que estas codificações proporcionam compressão tão boa quanto as já existentes, mas também duas delas são auto-sincronizadas, ou seja, possibilitam a busca com acesso aleatório em um arquivo comprimido e introduzem um mínimo de sobrecarga e de perda de compressão.

\footnotetext{
${ }^{1}$ Sites: http://www.google.com/, http://www.yahoo.com/ e http://www.msn.com/

${ }^{2}$ Sites: http://www.buscape.com.br/ e http://www.bondfaro.com.br/

${ }^{3}$ Sites: http://www.kayak.com/ e http://www.buscapeviagens.com.br/

${ }^{4}$ Site: http://www.ebit.com.br/

${ }^{5}$ Sites: http://www.mercadolivre.com.br/ e http://www.quebarato.com.br/

${ }^{6}$ Site: http://www.orkut.com/

${ }^{7}$ Site: http://www.linkedin.com/
} 


\subsection{Organização do Trabalho}

No capítulo 2 são descritas as principais estruturas utilizadas na indexação da coleção de documentos. De forma geral, pode-se descrever quatro tipos de índices utilizados na indexação: árvore de sufixos; vetor de sufixos; arquivo invertido e arquivo invertido por blocos. As duas primeiras estruturas são índices completos, ou seja, encontram ocorrências de quaisquer segmentos do texto. As duas últimas estruturas são índices incompletos: não indexam todas as ocorrências de segmentos dos textos, já que só encontram ocorrências de segmentos que coincidam com uma palavra. Nas seções de 2.1 a 2.4 descreve-se cada uma destas estruturas e na seção 2.5 é feita uma comparação delas.

No capítulo 3, são introduzidos os conceitos básicos relativos aos algoritmos de compressão.

No capítulo 4, estuda-se em detalhes a compressão Ziv-Lempel, também são analisadas as soluções de busca exata, seção 4.2, e busca aproximada, seção 4.3, em textos comprimidos.

No capítulo 5 estuda-se em detalhes a compressão Huffman e formas alternativas para melhorar seu desempenho e modificações para que seja possível o acesso aleatório e a busca em textos comprimidos nesta compressão.

No capítulo 6 realiza-se a comparação entre as estratégias de compressão e entre as variantes de compressão Huffman, já que, conforme será visto, esta compressão se adequa muito bem a um sistema de recuperação de informação compartilhando o mesmo vocabulário no caso de se utilizar arquivo invertido (ou arquivo invertido por blocos) e compressão por palavras.

No capítulo 7 propõem-se novas codificações livres de prefixo de forma a reduzir o consumo de memória, com relação à compressão Huffman usual, pois nas codificações propostas não há a necessidade da geração da árvore canônica, com isto a complexidade da compressão e descompressão diminuem e há uma melhora da compressão obtida, em especial nas codificações auto-sincronizadas que possibilitam o acesso aleatório do texto comprimido.

No capítulo 8 são apresentados os resultados de três experimentos realizados, uma simulação inicial e dois outros experimentos com dados reais das descrições e URLs das ofertas do site BuscaPé. Ao final deste capítulo é feita a análise dos resultados obtidos em todos estes os experimentos.

No capítulo 9 são apresentados os resultados do compressor protótipo Xhuff implementado e a comparação dos resultados com os compressores consagrados gzip e bzip2.

No capítulo 10 são apresentadas as conclusões finais e expõem-se sugestões e idéias para futuras melhorias e formas de utilização dos conceitos estudados neste trabalho. 


\section{Capítulo 2}

\section{Estruturas de Indexação}

Este capítulo descreve as principais estruturas de indexação que podem ser utilizadas em diferentes sistemas de recuperação de informação. Em todas as estruturas supõe-se um texto $T$ de tamanho $n$, composto por uma sequência de símbolos pertencentes ao alfabeto $\Sigma$ cujo tamanho é $\sigma$. Este texto $T$, que pode ser a concatenação de uma grande coleção de documentos, páginas da Internet, ou diversas descrições de ofertas, é previamente indexado e o conjunto das palavras distintas deste texto é seu vocabulário $V$, cujo tamanho é $v$. Após a indexação são realizadas várias buscas no mesmo texto e $m$ é o tamanho do padrão a ser buscado.

\section{1 Árvore de Sufixos}

A árvore de sufixos é uma estrutura de dados que contém todos os sufixos de uma palavra. Através dela pode-se verificar se uma sequência qualquer ocorre ou não no texto, não necessariamente começando no início de uma palavra, o que é uma característica de um índice completo. Ademais, concatenando-se toda a coleção de documentos é possível construir uma árvore de sufixos generalizada que representa toda a coleção. Há uma vasta literatura tratando do assunto, em inglês o livro utilizado em biologia computacional Algorithms On Strings, Trees And Sequences (Gus07). E em português, pode-se encontrar o livro Tópicos em algoritmos sobre sequências (dLS03), de onde foi tirado o exemplo da árvore de sufixos de $a b a a b c$ visto na figura 2.1.

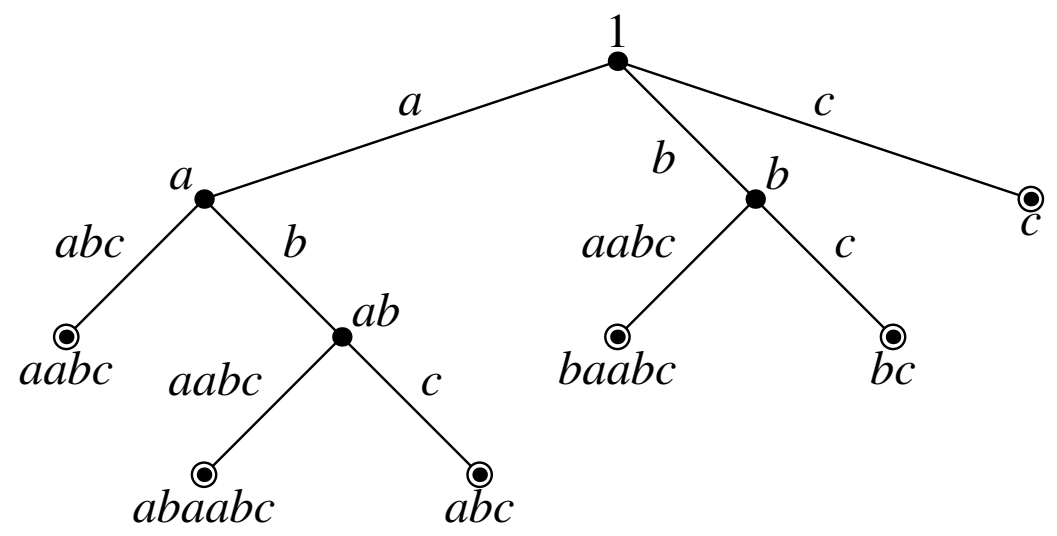

Figura 2.1: Árvore de sufixos de abaabc

O grande mérito desta estrutura é a rapidez na busca. A busca é realizada em tempo $O(m)$. Como para verificar a existência do padrão são necessárias $m$ comparações, então este algoritmo é ótimo. Porém o consumo de memória para armazenar tal estrutura é considerável, normalmente cerca de $10 n$ na implementação de Stefan Kurtz (Kur99), a mais compacta de que se tem conhecimento, com a restrição de que o tamanho máximo do texto seja $2^{27}-1$ bytes, ou seja, aproximadamente 
128MB, no caso de computadores com arquitetura de 32 bits.

\subsection{Vetor de Sufixos}

O vetor de sufixos é uma representação compacta da árvore de sufixos, obtida ordenando lexicograficamente um vetor de índices relativos aos sufixos. Visa principalmente diminuir o consumo de memória utilizando cerca de $4 n$ bytes para a estrutura de dados. Mantém a capacidade de busca de um índice completo como a árvore de sufixos, mas o tempo de consulta da ocorrência de um padrão é aumentado de $O(m)$ para $O(m \log n)$. Neste caso, o algoritmo é similar à busca binária em um vetor.

Exemplo a partir da árvore de 2.1 para "abaabc":

\begin{tabular}{|c|c|l|}
\hline $\begin{array}{c}\text { Posição } \\
\text { do Vetor }\end{array}$ & $\begin{array}{c}\text { Índice } \\
\text { no texto }\end{array}$ & Sufixo \\
\hline 1 & 3 & aabc \\
\hline 2 & 1 & abaabc \\
\hline 3 & 4 & abc \\
\hline 4 & 2 & baabc \\
\hline 5 & 5 & bc \\
\hline 6 & 6 & c \\
\hline
\end{tabular}

Tabela 2.1: Vetor de sufixos de abaabc

Apesar de reduzir o consumo de memória em $60 \%$ com relação à árvore de sufixos, este consumo de memória ainda é inviável para coleções grandes. Com isto, a seguir serão analisadas estruturas de índices incompletos, ou seja, nestes índices só são encontradas ocorrências de palavras completas ou de prefixos destas palavras.

\subsection{Arquivo Invertido}

A principal característica do arquivo invertido é manter, para cada palavra distinta da coleção de documentos, uma lista de todos os documentos que contém a palavra bem como a frequência da mesma no documento, esta lista é denominada lista de ocorrências. Na figura 2.2 há um exemplo de um arquivo invertido.

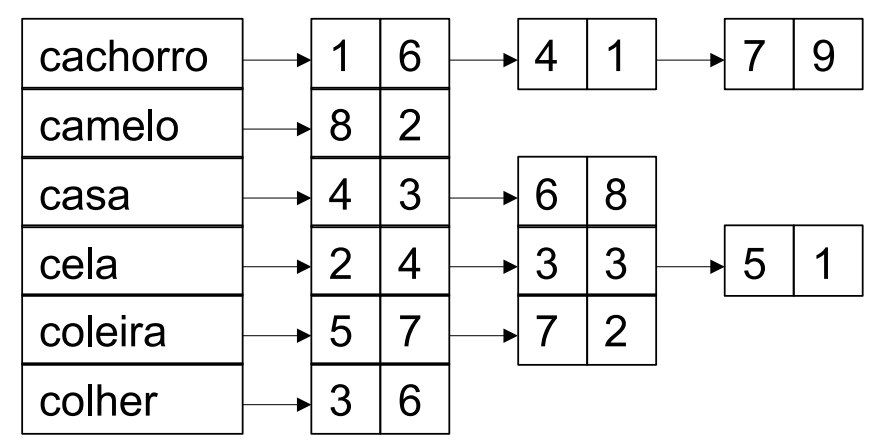

Figura 2.2: Exemplo de um arquivo invertido. Cada par de números representa o identificador do documento e a frequência da palavra no documento em questão

As listas de ocorrências de um arquivo invertido contêm o ID (identificador) do documento na coleção e a quantidade de ocorrências da palavra neste documento, além de um ponteiro para o próximo elemento da lista. 
A escolha da estrutura do vocabulário influencia diretamente o tempo de construção do índice, o tempo de busca de uma palavra, a quantidade de memória utilizada e os tipos de busca que podem ser realizadas. O menor consumo de memória é proporcionado pelas tabelas de espalhamento, a qual também permite a atualização dinâmica do índice, porém não é possível fazer buscas por prefixos neste índice. Os vários tipos de árvores (binárias, balanceadas, digitais e B-árvore) possibilitam a atualização dinâmica do índice e a busca por prefixos de palavras, porém aumentam o consumo de memória. Finalmente o vetor de ponteiros tem o menor consumo de memória e também proporciona a busca por prefixos de palavras, mas sua atualização dinâmica é extremamente custosa.

\begin{tabular}{|c|c|c|c|c|}
\hline Estrutura & $\begin{array}{c}\text { Tempo de } \\
\text { Busca }\end{array}$ & $\begin{array}{c}\text { Consumo de } \\
\text { Memória }\end{array}$ & $\begin{array}{c}\text { Atualização } \\
\text { Dinâmica }\end{array}$ & $\begin{array}{c}\text { Busca por } \\
\text { Prefixos }\end{array}$ \\
\hline $\begin{array}{c}\text { Árvore } \\
\text { Binária }\end{array}$ & $O(m \log v)$ & Alto & Sim & Sim \\
\hline $\begin{array}{c}\text { Árvore } \\
\text { Digital }\end{array}$ & $O(m \sigma)$ & Alto & Sim & Sim \\
\hline B-Ârvore & $O\left(m \log _{B} v\right)$ & Alto & Sim & Sim \\
\hline $\begin{array}{c}\text { Tabela de } \\
\text { Espalhamento }\end{array}$ & $\mathbf{O}(\mathbf{m})$ & Médio & Sim & Não \\
\hline $\begin{array}{c}\text { Vetor de } \\
\text { Ponteiros }\end{array}$ & $O(m \log v)$ & Baixo & Não & Sim \\
\hline
\end{tabular}

Tabela 2.2: Comparação de estruturas para vocabulário de arquivo invertido

O tempo de busca do padrão no vocabulário é a primeira etapa para encontrar as ocorrências dele no texto. Depois de encontrar a palavra no vocabulário é necessário percorrer a lista de ocorrências $L$ que tem tamanho $l$. Portanto o tempo total de busca $t_{t}$ é a soma do tempo de busca da palavra no vocabulário $t_{v}$ com o tempo para percorrer a lista de ocorrências $t_{l}$.

$$
t_{t}=t_{v}+t_{l}
$$

\subsection{Arquivo Invertido por Blocos}

$\mathrm{O}$ arquivo invertido por blocos é uma variante do arquivo invertido que visa reduzir o consumo de memória tratando um bloco inteiro de documentos como se fosse um único documento. Ao invés de manter a lista de ocorrência das palavras em cada documento, divide-se a coleção em blocos e a lista passa a referenciá-los. Com isto, diversas ocorrências da mesma palavra em documentos presentes no mesmo bloco são colapsadas em apenas uma referência, o que diminui o tamanho das listas de ocorrência. Porém, na busca, para verificar qual o documento exato da ocorrência é necessário buscar a palavra no bloco em questão. Com isto o tempo total de busca passa a ter mais uma parcela, o tempo de busca do padrão no bloco $t_{b}$

$$
t_{t}=t_{v}+t_{l}+t_{b}
$$

note que $t_{v}$ é exatamente o mesmo com relação ao Arquivo Invertido (2.3), pois o vocabulário não se altera, porém $t_{l}$ diminui.

Existem estratégias para aproveitar esta varredura e realizar buscas aproximadas, tais como a apresentada por Baeza-Yates e Navarro (BYN97). 


\subsection{Comparação das Estruturas de Índices}

A tabela 2.3 compara as estruturas de indexação apresentadas. Os campos em negrito indicam os melhores valores para cada fator em consideração.

\begin{tabular}{|c|c|c|c|c|}
\hline Estrutura & $\begin{array}{l}\text { Tempo de } \\
\text { Inserção }\end{array}$ & $\begin{array}{l}\text { Consumo de } \\
\text { Memória }\end{array}$ & $\begin{array}{c}\text { Flexibilidade } \\
\text { de Busca }\end{array}$ & $\begin{array}{l}\text { Tempo de } \\
\text { Resposta }\end{array}$ \\
\hline $\begin{array}{l}\text { Árvore de } \\
\text { Sufixos }\end{array}$ & Constante & $\begin{array}{c}\text { Muito Grande } \\
\sim 10 n\end{array}$ & Grande & $\begin{array}{c}\text { Muito } \\
\text { Rápido }\end{array}$ \\
\hline $\begin{array}{l}\text { Vetor de } \\
\text { Sufixos }\end{array}$ & Logarítmico & $\begin{array}{c}\text { Grande } \\
\sim 4 n \\
\end{array}$ & Grande & Rápido \\
\hline $\begin{array}{l}\text { Arquivo } \\
\text { Invertido }\end{array}$ & Constante & $\begin{array}{l}\text { Médio } \\
\sim 0,5 n\end{array}$ & Média & Médio \\
\hline $\begin{array}{l}\text { Arquivo } \\
\text { Invertido } \\
\text { por Blocos }\end{array}$ & Constante & $\begin{array}{c}\text { Pequeno } \\
<0,5 n\end{array}$ & Média & Lento \\
\hline
\end{tabular}

Tabela 2.3: Comparação das Estruturas de Indexação

De todos os métodos de indexação, os índices incompletos como o índice invertido e o arquivo invertido por blocos possuem o menor consumo de memória. Ainda assim, há aplicações em que pode ser necessário um consumo menor, face ao tamanho da coleção e a necessidade de manter todo o índice em memória primária. A compactação dos documentos é o recurso a ser utilizado para reduzir o consumo de memória. Neste caso pode-se comprimir a coleção de documentos como um todo ou comprimir os documentos um a um; no caso do arquivo invertido por blocos também é possível comprimir os documentos que compõem o bloco. Também é importante que seja possível realizar as buscas e descomprimir o texto a partir de um ponto qualquer do texto comprimido. 


\section{Capítulo 3}

\section{Algoritmos de Compressão}

Compressão consiste em representar os dados originais com menos bits ou bytes. Desta forma é possível buscar um equilíbrio entre a economia de memória e o gasto extra de processamento para descomprimir os dados. Este equilíbrio cada vez mais se transforma em ganho, pois a velocidade dos processadores aumenta em um ritmo maior que a taxa de transferência dos discos rígidos e das memórias RAM. Como a compressão diminui a demanda destes dispositivos de armazenamento às custas de processamento, esta economia pode se transformar em ganhos no tempo de execução das aplicações.

A fim de analisar os algoritmos de compressão, define-se que a taxa de compressão é a divisão do tamanho dos dados comprimidos pelo tamanho dos dados originais.

\subsection{Tipos de Compressão}

Os algoritmos de compressão podem ser divididos em duas classes: estatístico ou dicionário.

Os algoritmos estatísticos estimam a probabilidade de ocorrência dos símbolos a fim de representar os mais frequentes com códigos mais curtos. A conversão destas probabilidades em bits ou bytes é denominada codificação. Desta forma é necessário varrer os dados de entrada a fim de processar as frequências dos símbolos e realizar uma segunda varredura para codificá-los. Exemplos: codificação Huffman e codificação aritmética.

Os algoritmos que utilizam dicionário substituem uma sequência de símbolos por um ponteiro para uma ocorrência prévia desta mesma sequência. Estes algoritmos são adaptativos, ou seja, a codificação é realizada apenas nos dados processados até o momento atual. Desta forma é possível realizar a codificação em apenas uma varredura dos dados a serem comprimidos. Exemplos: ZivLempel e suas variações (zip, gzip, compress, etc.)

Além dos algoritmos de compressão, existem modelos que podem ser combinados a eles de forma a melhorar a taxa de compressão, em especial no caso de textos. Seguem abaixo alguns dos principais modelos utilizados:

- predição por casamento parcial (prediction by partial matching - PPM) criada por John Cleary e Ian Witten em (CW84), realiza predições baseadas nos caracteres já processados;

- ordenação por blocos (block sorting ou Burrows-Wheeler transform - BWT) criada por Michael Burrows e David Wheeler em (BW94), transforma o texto agrupando símbolos similares através da ordenação dos caracteres segundo o contexto do bloco em que estão. Este texto permutado têm o mesmo tamanho do texto original, porém como agrupa as repetições possibilita melhor compressão; 
- compressão dinâmica Markov (dynamic Markov compression - DMC) criada por Cormack e Horspool em (CH87), utiliza uma máquina de estados finita cujas probabilidades das transições e também os estados se modificam conforme a codificação é processada;

Os modelos acima descritos também podem ser vistos de forma didática no livro Managing Gigabytes (WMB99), onde são realizados experimentos comparativos que apontam como melhores métodos de compressão em termos práticos a compressão Huffman e a compressão Ziv-Lempel, as quais serão analisadas com mais detalhes a seguir. Para isto, define-se que o texto original $T$ com tamanho $n$ é comprimido, originando o texto comprimido $Z$ que possui tamanho $z$. 


\section{Capítulo 4}

\section{Compressão Ziv-Lempel}

Jacob Ziv e Abraham Lempel em 77 (ZL77) e 78 (ZL78), propuseram diferentes variantes de um algoritmo de compressão essencialmente idêntico, onde repetidas sequências de tamanho arbitrário são identificadas no texto, e as repetições são substituídas por ponteiros para as ocorrências anteriores. Nesta família, segundo o livro Text Compression (BCW90) é possível que $z=o(n)$ obtendo $z=O(\sqrt{n})$ ou até mesmo $z=O(\log n)$ nos melhores casos. A idéia geral da compressão Ziv-Lempel é substituir substrings do texto por um ponteiro para uma ocorrência prévia das mesmas. Se o ponteiro utilizar menos espaço que a substring que está substituindo, a compressão é obtida. Uma breve descrição das principais variantes da compressão Ziv-Lempel é feita a seguir:

- LZ77: algoritmo capaz de referenciar qualquer substring do texto já processada;

- LZ78: algoritmo que referencia somente uma referência prévia do texto já processado e mais uma letra que é adicionada;

- LZW: algoritmo similar ao LZ78, porém a letra adicionada faz parte da referência seguinte.

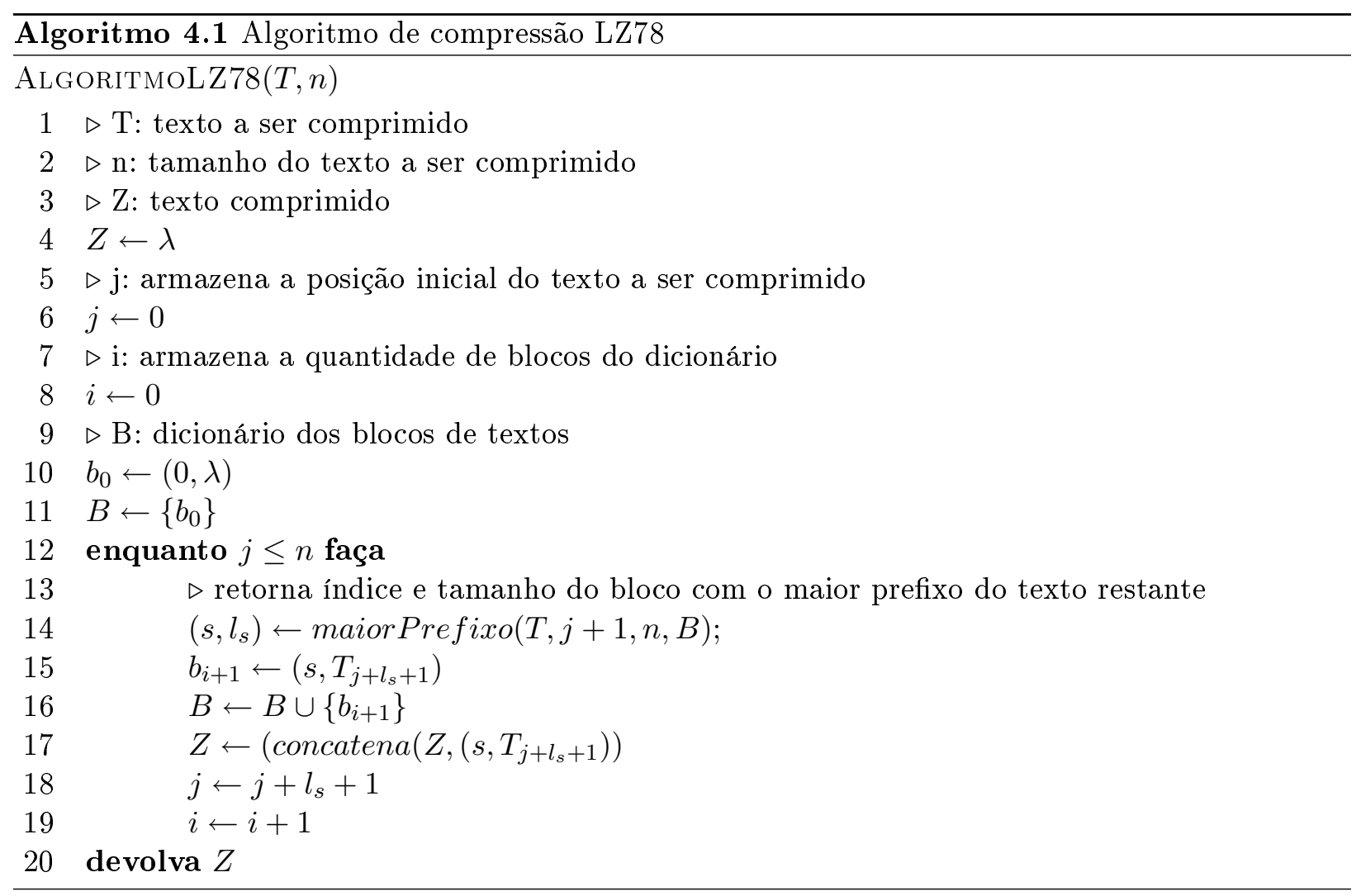


O algoritmo LZ78 é descrito em 4.1 devido ao fato deste algoritmo ter sido frequentemente utilizado em trabalhos envolvendo busca em arquivos comprimidos. O algoritmo LZ78 é baseado em um dicionário de blocos, no qual é adicionado cada novo bloco computado. No início da compressão, o dicionário contém um único bloco $b_{0}$ de tamanho 0 (zero).

Os passos são repetidos até que não haja mais caracteres restantes em $T$. Tal dicionário é fechado por prefixos, ou seja, qualquer prefixo de um elemento é também um elemento do dicionário. Por exemplo, o algoritmo LZ78 ao comprimir a palavra banana terá inicialmente apenas o bloco $b_{0}$ e o primeiro caractere, no caso "b", será inserido na árvore de prefixos, gerando o bloco $b_{1}$, e o texto comprimido "(0,b)", conforme se pode ver na figura 4.1.

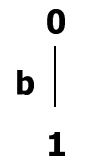

Figura 4.1: Exemplo após primeira iteração do algoritmo de compressão LZ78.

Durante a segunda iteração o caractere "a" será inserido na árvore de prefixos, gerando o bloco $b_{2}$, e o texto comprimido " $(0, \mathrm{~b})(0, \mathrm{a})$ ", conforme se pode ver na figura 4.2 .

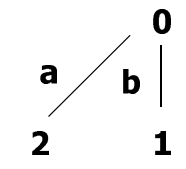

Figura 4.2: Exemplo após segunda iteração do algoritmo de compressão LZ78.

Durante a terceira iteração o caractere " $n$ " será inserido na árvore de prefixos, gerando o bloco $b_{3}$, e o texto comprimido " $(0, \mathrm{~b})(0, \mathrm{a})(0, \mathrm{n})$ ", conforme se pode ver na figura 4.3 .

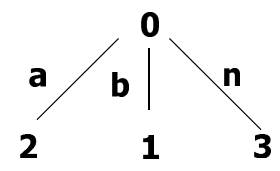

Figura 4.3: Exemplo após terceira iteração do algoritmo de compressão LZ78.

Durante a quarta iteração o caractere "a" será encontrado na árvore de prefixos e o caracter "n" será inserido na árvore abaixo deste nó, formando o novo prefixo "an" e gerando o bloco $b_{4}$, e o texto comprimido " $(0, \mathrm{~b})(0, \mathrm{a})(0, \mathrm{n})(2, \mathrm{n})$ ", conforme se pode ver na figura 4.4 .

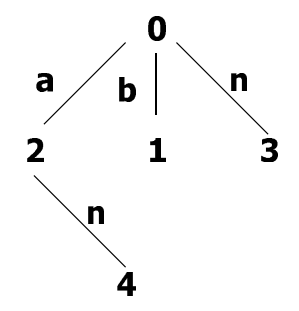

Figura 4.4: Exemplo após quarta iteração do algoritmo de compressão LZ78.

Durante a quinta iteração o caractere "a" será encontrado na árvore de prefixos e o caracter "s" será inserido na árvore abaixo deste nó, formando o novo prefixo "as" e gerando o bloco $b_{5}$, o texto comprimido " $(0, \mathrm{~b})(0, \mathrm{a})(0, \mathrm{n})(2, \mathrm{n})(2, \mathrm{~s})$ " e finalizando o algoritmo, conforme se pode ver na figura 4.5. 


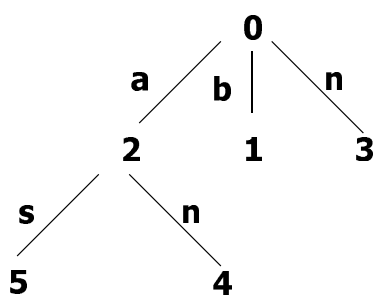

Figura 4.5: Exemplo após quarta iteração do algoritmo de compressão LZ78.

Como visto, o texto "bananas" se transforma em " $(0, \mathrm{~b}),(0, \mathrm{a}),(0, \mathrm{n}),(2, \mathrm{n})(2, \mathrm{~s})$ ", ou seja, 7 caracteres se transformam em 5 ponteiros, portanto quanto mais caracteres forem representados em um ponteiro, melhor a compressão.

O algoritmo de compressão é linear, e é muito eficiente na prática se o dicionário for armazenado em uma árvore digital. A descompressão precisa construir o mesmo dicionário (o par que define o bloco $r$ é lido no $r$-ésimo passo do algoritmo), porém desta vez é preferível uma implementação com vetor indexado pelo índice do bloco. Comparado ao LZ77 a compressão é mais rápida, porém a descompressão é lenta.

Existem diversas variantes do LZ78, que basicamente tratam da melhor forma de codificar os pares no arquivo comprimido. Uma variante interessante é a de Welch (Wel84), chamada LZW. Neste caso a letra extra (segundo elemento do par) não é codificada, mas é tomada como sendo a primeira letra do próximo bloco, assim sendo, o dicionário é iniciado com um bloco por letra. LZW é utilizado no programa Compress do UNIX.

\subsection{Busca em Textos Comprimidos}

Diversos artigos que tentam realizar buscas em arquivos comprimidos têm sido propostos. Nas seções subsequentes, descreve-se alguns trabalhos que fazem esta tarefa em arquivos comprimidos com algumas das variantes de algoritmos Ziv-Lempel. Primeiramente, analisa-se com mais detalhes um trabalho de Navarro et al. (NT00) com busca exata tipo Boyer-Moore. Logo após, observa-se a busca aproximada $\left(\mathrm{NKT}^{+} 01\right)$.

\subsection{Busca Exata}

Navarro e Tarhio (NT00) desenvolvem um algoritmo a fim de possibilitar a utilização da estratégia de busca de Boyer-Moore (BM77) em arquivos comprimidos com compressão Ziv-Lempel. O trabalho foca apenas nas variantes LZ78 e LZW que são mais adaptáveis para a utilização do algoritmo de Boyer-Moore devido à obrigatoriedade do caractere explícito em cada bloco da compressão, porém possuem taxa de compressão maior (comprimem menos) que a variante LZ77. Ademais, os autores adotam um formato de compressão já utilizado no trabalho de Navarro e Raffinot (NR99) onde a taxa de compressão é sacrificada em benefício do tempo de descrompressão e busca.

Antes de entrar em detalhes sobre as implementações e os resultados apresentados, convém comparar os tempos necessários às operações de compressão e descompressão bem como à taxa de compressão. A Tabela 4.1 compila resultados apresentados em Navarro e Tarhio (NT00) e os tempos são medidos em um Pentium III rodando Linux. Dois tipos de dados são avaliados: WSJ designa 10MB de artigos do Wall Street Journal de 1987 (texto em linguagem natural); enquanto DNA designa 10MB de um arquivo codificando DNA em formato FASTA, com 60 nucleotídeos por linha. Observa-se que os tempos de descompressão são melhores segundo este formato modificado 


\begin{tabular}{|c|c|c|c|}
\hline Método & $\begin{array}{c}\text { Taxa de } \\
\text { Compressão }\end{array}$ & $\begin{array}{c}\text { Tempo de } \\
\text { Compressão }\end{array}$ & $\begin{array}{c}\text { Tempo de } \\
\text { Descompressão }\end{array}$ \\
\hline (NT00) & WSJ: 45,02\% & WSJ: $5,09 \mathrm{~s}$ & WSJ: 0,79s \\
(LZ78) & DNA: $39,69 \%$ & DNA: 4,31s & DNA: 0,72s \\
\hline $\begin{array}{c}\text { Unix compress } \\
\text { (LZW) }\end{array}$ & WSJ: $38,75 \%$ & WSJ: 2,52s & WSJ: 0,92s \\
\hline Gnu gzip & WSJ: $\mathbf{3 3 , 9 1 \%}$ & DNA: 2,43s & DNA: $0,75 \mathrm{~s}$ \\
(LZ77) & DNA: $30,43 \%$ & DNA: $10,63 \mathrm{~s}$ & WSJ: $0,81 \mathrm{~s}$ \\
\end{tabular}

Tabela 4.1: Tempos de Compressão/Descompressão e Taxa de Compressão com diferentes variantes ZL. Dados extraídos de (NT00).

do que os tempos dos dois utilitários UNIX (WSJ: $0,79 s$ contra $0,92 s$ e $0,81 s$ ). A contrapartida é que as taxas de compressão de fato são piores ( $45 \%$ contra $39 \%$ e $33 \%$ ).

Já em (NR99) foi testado um algoritmo de busca exata em textos comprimidos por LZ78 com estratégia bastante eficiente de Bit-paralelismo. No trabalho de (NT00) foram avaliadas novas estratégias semelhantes ao algoritmo de Boyer-Moore. Em todas estas estratégias, o caractere explícito de cada bloco é inspecionado, a estratégia que se utiliza apenas deste caractere é denominada Boyer-Moore Simples. Além disto, algumas das principais idéias avaliadas incluem: o Boyer-Moore Multicaractere, o qual inspeciona $q$-gramas ( $q$ caracteres ao mesmo tempo); e o Boyer-Moore por Blocos, o qual inspeciona blocos LZ78 completos. As tabelas de deslocamentos das variantes com estas estratégias podem ser muito grandes.

Os algoritmos foram avaliados com padrões extraídos do texto de forma aleatória, todos com comprimentos de 10 a 100. A estratégia Boyer-Moore Simples foi a mais rápida para textos em linguagem natural, enquanto que a Boyer-Moore por Blocos foi a mais rápida para DNA. Estas duas estratégias vencedoras foram comparadas com duas estratégias ingênuas de descompressão simples seguida de busca, sendo que a melhor delas utiliza a ferramenta agrep criada por Sun Wu e Udi Manber (WM92) para a busca, bem como a estratégia de bit-paralelismo apresentada em (NR99). O Boyer-Moore por Blocos é consistentemente mais rápido que as estratégias ingênuas e a de bit-paralelismo quando o padrão tem comprimento pelo menos 15, sendo que a Boyer-Moore Simples é ainda melhor em textos de linguagem natural. Contudo, para padrões de tamanho 10 a estratégia de bit-paralelismo se mostrou sempre melhor, sendo que padrões com tamanho menor do que 10 não foram avaliados.

Outro fator importante a ser analisado é a taxa de varredura dos métodos. No caso das estratégias Boyer-Moore Simples e Boyer-Moore por Blocos a taxa de varredura está entre $12 \mathrm{MB} / \mathrm{s}$ e $17 \mathrm{MB} / \mathrm{s}$, enquanto que o agrep rodando no texto descomprimido varre a $300 \mathrm{MB} / \mathrm{s}$. Ou seja, estes métodos são interessantes para realizar buscas em um arquivo já comprimido, mas não dão razões em si para comprimir o texto a fim de gastar menos tempo buscando no arquivo comprimido do que buscando no arquivo não-comprimido, pois o tempo de busca do agrep em um arquivo não-comprimido é menor.

\subsection{Busca Aproximada}

Navarro et al. $\left(\mathrm{NKT}^{+} 01\right)$ desenvolvem algoritmos a fim de realizar buscas aproximadas em arquivos comprimidos com compressão Ziv-Lempel. Novamente o trabalho foca apenas nas variantes LZ78 e LZW devido à obrigatoriedade do caracter explícito em cada bloco da compressão, inclusive utilizando o mesmo formato analisado na seção 4.2 e comparado na tabela 4.1. Os algoritmos se 
apoiam em uma conhecida estratégia de filtragem para buscas aproximadas permitindo até $k$ erros. A idéia é dividir o padrão a ser buscado em $k+1$ sub-padrões não-sobrepostos. Então, ao menos um destes sub-padrões deve ocorrer de forma inalterada dentro de cada ocorrência do padrão no texto com até $k$ erros. A razão é que $k$ erros podem alterar, no máximo, apenas $k$ sub-padrões. Para maximizar o tamanho do menor elemento, o padrão é dividido em $k+1$ sub-padrões de igual tamanho, portanto seu tamanho é $\lfloor m /(k+1)\rfloor$, onde $m$ é o tamanho do padrão. Desta forma, executa-se uma busca multi-padrões para os $k+1$ sub-padrões e verifica-se o texto ao redor de cada ocorrência de qualquer sub-padrão encontrado (de tamanho $m+2 k$ ) para validar a ocorrência do padrão. Para maior eficiência, um lookahead de $m+k$ blocos é mantido. Deve-se notar que os algoritmos apresentados são mais rápidos que a solução ingênua de descompressão seguida de busca somente se o nível de erro for relativamente baixo:

$$
\frac{k}{m} \leq \frac{1}{\left(3 \log _{\sigma} m\right)}
$$

As estratégias de busca multi-padrão utilizadas são:

-Aho-Corasick (AC75), a máquina de estados de AC é modificada para processar os blocos do arquivo comprimido de forma que para cada bloco $b_{i}$ a máquina de estados realiza apenas uma transição que corresponde à sequência de caracteres representada por $b_{i}$, porém isto pode fazer com que ocorrências do padrão deixem de ser exibidas, com isto é necessário computar outra máquina de estados a fim de exibir corretamente todas as ocorrências do padrão para cada transição da máquina de estados de AC modificada;

-Bit-Paralelismo (NR99), o algoritmo de bit-paralelismo é modificado para processar blocos do arquivo comprimido, mantendo para cada bloco $b_{i}$ o conjunto de prefixos dos padrões que casam com o sufixo do bloco e o conjunto de sufixos dos padrões que casam com o prefixo do bloco. Além disso é mantida uma lista das posições dentro do bloco onde o padrão ocorre por completo a fim de exibir corretamente todas as ocorrências do padrão;

-Boyer-Moore, no mesmo estilo de (NT00) analisado na seção 4.2, porém com a utilização de uma única tabela com deslocamento pessimista, dado pelo mínimo deslocamento para o mesmo símbolo e posição entre todos os padrões. O revés de tal estratégia é que numa janela de texto em que cada símbolo casa com o símbolo correspondente em algum padrão, ou seja, nenhum dos símbolos na janela de texto processado leva a um deslocamento positivo, isso não necessariamente significa a ocorrência de um dos padrões. Por exemplo, ao se buscar pelos padrões "abc" e "def" na janela de texto "aec" não é possível nenhum deslocamento positivo pois "a" e "c" casam com o primeiro padrão enquanto que "e" casa com o segundo. Para cerificar se um dos padrões buscados realmente ocorreu, é necessária mais uma verificação que pode ser feita eficientemente com uma árvore digital.

Os resultados apresentados por Navarro et al. $\left(\mathrm{NKT}^{+} 01\right)$ foram medidos em um Pentium III rodando Linux. Novamente dois tipos de dados são avaliados: WSJ designa 10MB de artigos do Wall Street Journal de 1987 (texto em linguagem natural); enquanto DNA designa 10MB de um arquivo codificando DNA em formato FASTA, com 60 nucleotídeos por linha. Foram fixados dois comprimentos de padrão, 10 e 30 e $k$ é variado de 1 até $50 \%$ do comprimento do padrão. Para cada um destes comprimentos foram extraídos, de forma aleatória, 100 padrões de cada texto. As três estratégias de $\left(\mathrm{NKT}^{+} 01\right)$, prefixadas por "PP/", foram comparadas com duas estratégias ingênuas 
de descompressão ("U+") seguida de busca, a de Bit-Paralelismo de Myers (Mye99) ("BP") e a partição em $k+1$ partes de Navarro e Baeza-Yates (NBY99) ("PP"). Portanto, as séries exibidas na figura 4.6 são:

-PP $/ \mathrm{AC}=$ Partição em $k+1$ partes com Aho-Corasick;

-PP $/ \mathrm{BP}=$ Partição em $k+1$ partes com Bit-Paralelismo;

-PP $/ \mathrm{BM}=$ Partição em $k+1$ partes com Boyer-Moore;

$-\mathrm{U}+\mathrm{BP}=$ Descompressão seguida por Bit-Paralelismo de Myers;

$-\mathrm{U}+\mathrm{PP}=$ Descompressão seguida por partição em $k+1$ partes;

-Uncompress $=$ Tempo gasto apenas para a descompressão.
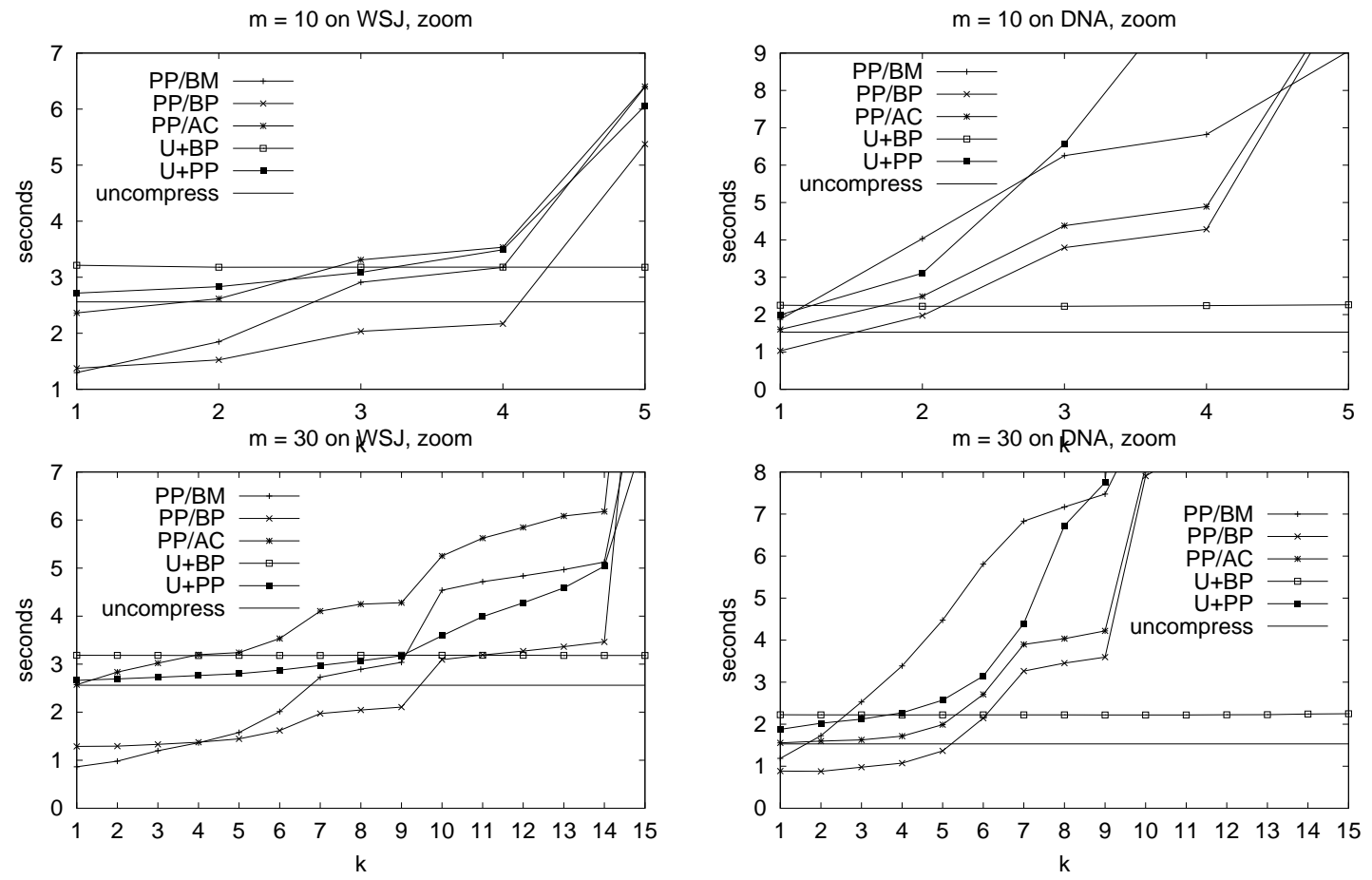

Figura 4.6: Busca aproximada em arquivo comprimido com Ziv-Lempel. Figura com resultados experimentais extraída de $\left(N K T^{+} 01\right)$.

A análise da figura 4.6 mostra que o Bit-Paralelismo ("PP/BP") é sempre a melhor dentre as três estratégias propostas em $\left(\mathrm{NKT}^{+} 01\right)$, tanto em linguagem natural com em DNA, porém em todos os casos há uma forte dependência do tempo de execução com o aumento do nível de erro $(k / m)$ e do tamanho do alfabeto, exceto para o Bit-Paralelismo de Myers, cujo tempo de execução é constante e independente do nível de erro e do tamanho do alfabeto. A estratégia de Boyer-Moore ("PP/BM") é melhor que a de Aho-Corasick ("PP/AC") para linguagem natural, mas para DNA a situação se inverte. Apesar das três estratégias propostas serem mais rápidas que a solução ingênua para níveis de erro pequenos, se o texto já estivesse em formato descomprimido, os tempos do Bit-Paralelismo de Myers e a partição em $k+1$ partes de (NBY99) seriam mais rápidas, a primeira para níveis de erro grandes e a segunda para níveis de erro pequenos.

O maior gargalo das estratégias de buscas em textos comprimidos por Ziv-Lempel é a necessidade de varrer todos os blocos da compressão. Com isto, se toda a coleção de documentos é comprimida não é possível o acesso aleatório. Se os documentos são comprimidos um a um, a taxa de compressão não é boa e o aumento de processamento para descomprimir os documentos ao exibir os resultados faz com que os ganhos não sejam tão compensadores. Finalmente, se os documentos são agrupados 
em blocos a serem comprimidos e indexados em uma estrutura de arquivo invertido por blocos, então as buscas nestes blocos passam a ser o ponto crítico do sistema, pois, como visto, o bloco terá de ser varrido por completo. Desta forma, busca-se outro modelo de compressão que possa ser melhor adaptado a um sistema de recuperação de informação, que é a compressão Huffman analisada a seguir. 


\section{Capítulo 5}

\section{Compressão Huffman}

A compressão Huffman, proposta por David Huffman em 1952 (Huf52) em resposta a um desafio de seu professor do $\mathrm{MIT}^{1}$, associa um código de bits de tamanho variável a cada símbolo, por exemplo, palavras ou separadores de um texto. A compressão é devida ao fato de se atribuir códigos mais curtos aos símbolos mais frequentes.

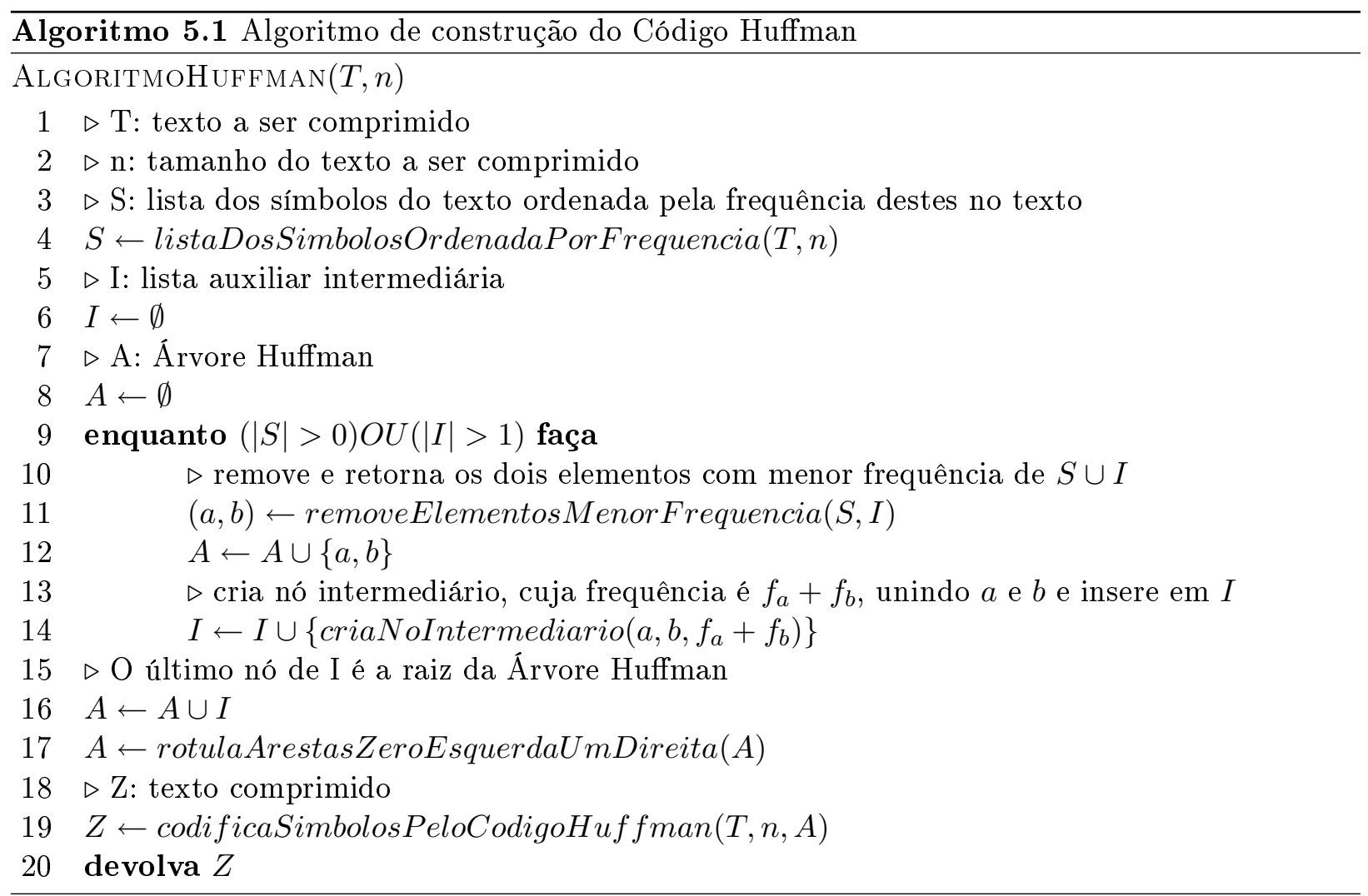

A figura 5.1 é um exemplo² já utilizado no capítulo 7, figura 7.3, do livro Modern Information Retrieval (BYRN99). O mesmo exemplo é analisado também em outros trabalhos de Moura et al. (MNZ97; dMNZBY00).

Para maior eficiência na compactação, os espaços não são codificados. O modelo assume que após uma palavra sempre há um espaço, exceto se esta palavra for seguida por um separador. Note que o separador, quando codificado, inclui os espaços subsequentes.

\footnotetext{
${ }^{1}$ Com isto Huffman se livrou do exame final do curso.

${ }^{2}$ No exemplo, ao invés de se trabalhar com as frequências, como visto no algoritmo 5.1, trabalha-se com as probabilidade dos símbolos, o que não altera nada pois que a probabilidade de um símbolo é a frequência dividida pelo número total de palavras no texto.
} 


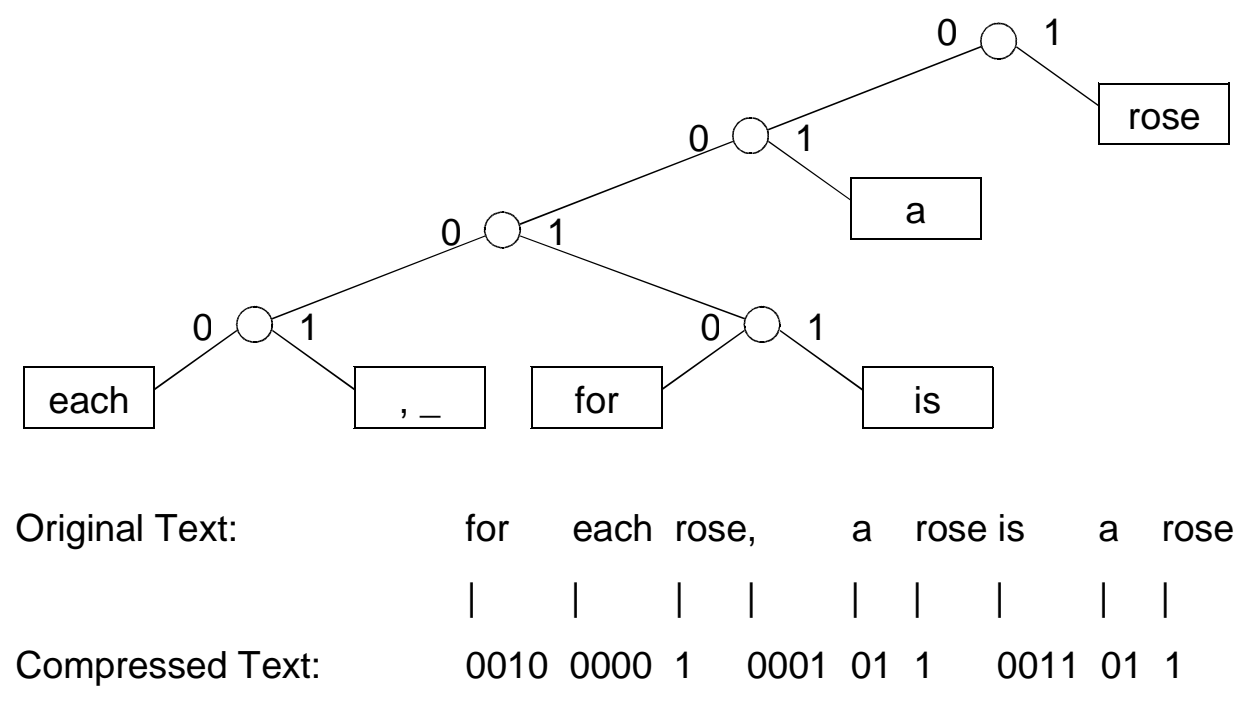

Figura 5.1: Código Huffman de compressão para exemplo de texto analisado em (BYRN99) e (dMNZBY00). O texto é comprimido com 23 bits.

O vocabulário do texto, já ordenado por probabilidade, é composto por:

$$
V=S=\{\text { "each", ", ", "for", "is", "a", "rose" }\},
$$

sendo que as probabilidades são, respectivamente:

$$
F=\{1 / 9,1 / 9,1 / 9,1 / 9,2 / 9,3 / 9\}
$$

e a lista $I$ é inicialmente vazia.

O laço principal (linha 9) do algoritmo 5.1 é então iterado diversas vezes. Durante a primeira iteração, são tomados os símbolos "each" e ", ", gerando um nó intermediário com probabilidade 2/9 que é inserido na lista $I$, conforme se pode ver na figura 5.2.

$$
\begin{aligned}
& S=\{\text { "for", "is", "a", "rose" }\} \\
& F=\{1 / 9,1 / 9,2 / 9,3 / 9\} \\
& I=\{2 / 9\}
\end{aligned}
$$

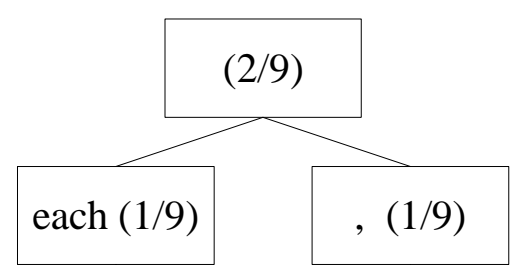

Figura 5.2: Exemplo após primeira iteração do Algoritmo de Huffman

Durante a segunda iteração, toma-se inicialmente o símbolo "for" com probabilidade $1 / 9$, as listas $S$ e $F$ são atualizadas, e posteriormente toma-se o símbolo "is" com probabilidade 1/9, gerando mais 
um nó intermediário com probabilidade $2 / 9$ que é inserido no final da lista $I$, conforme se pode ver na figura 5.3.

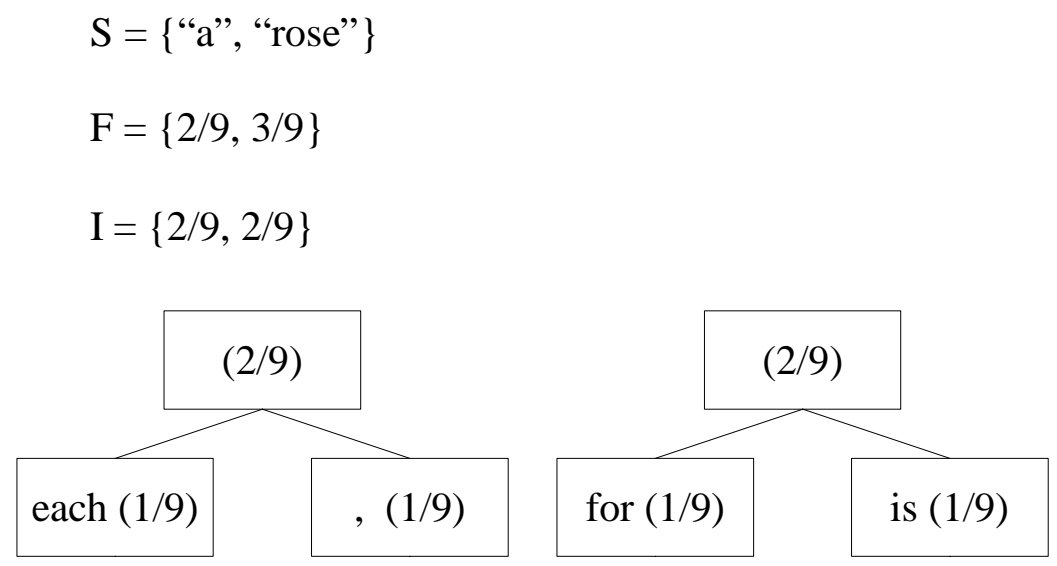

Figura 5.3: Exemplo após segunda iteração do Algoritmo de Huffman

Durante a terceira iteração, pode-se tomar indiferentemente qualquer um dos elementos com probabilidade $2 / 9$, pois o algoritmo de Huffman não prioriza nenhuma das listas. Neste exemplo, será dada prioridade à lista intermediária $I$. Portanto, toma-se os dois elementos da lista $I$, gerando mais um nó intermediário com probabilidade 4/9. Este novo nó intermediário é inserido na lista $I$, conforme se pode ver na figura 5.4.

$$
\begin{aligned}
& S=\{\text { "a", "rose" }\} \\
& F=\{2 / 9,3 / 9\} \\
& I=\{4 / 9\}
\end{aligned}
$$

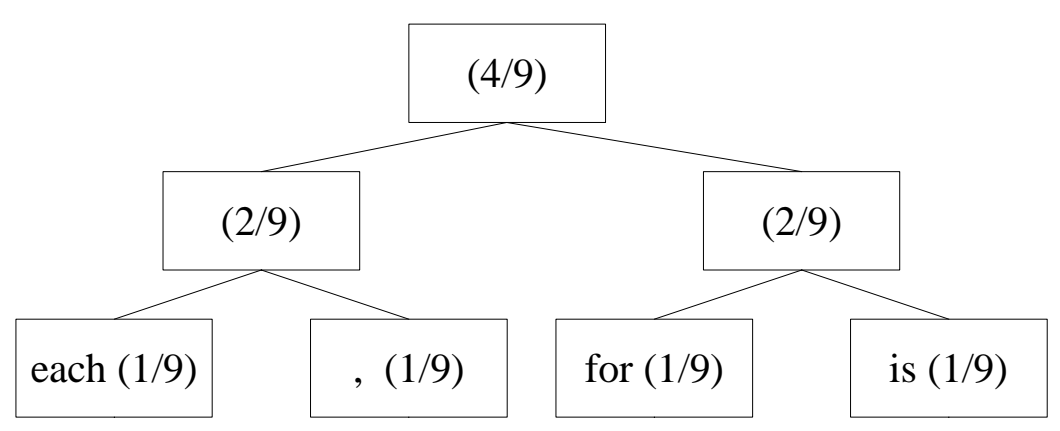

Figura 5.4: Exemplo após terceira iteração do Algoritmo de Huffman

Durante a quarta iteração, toma-se os símbolos "a", com probabilidade $2 / 9$, e posteriormente, "rose", com probabilidade $3 / 9$, já que ambos possuem probabilidades inferiores ao primeiro elemento da lista $I$ (4/9), gerando um nó intermediário com probabilidade 5/9. Este nó intermediário é então inserido no final da lista $I$. Note que desta forma a lista $I$ sempre se mantém ordenada em ordem não decrescente de probabilidade. Desta forma as listas $S$ e $F$ ficam vazias, conforme se pode ver na figura 5.5.

Durante a quinta iteração, toma-se os dois últimos elementos da lista $I$, gerando o nó raiz com probabilidade 9/9 e encerrando a geração da árvore Huffman, conforme se pode ver na figura 5.6.

Finalmente, o código é obtido ao se rotular as arestas esquerdas com zero e as direitas com 
$\mathrm{S}=\{\}$

$\mathrm{F}=\{\}$

$I=\{4 / 9,5 / 9\}$

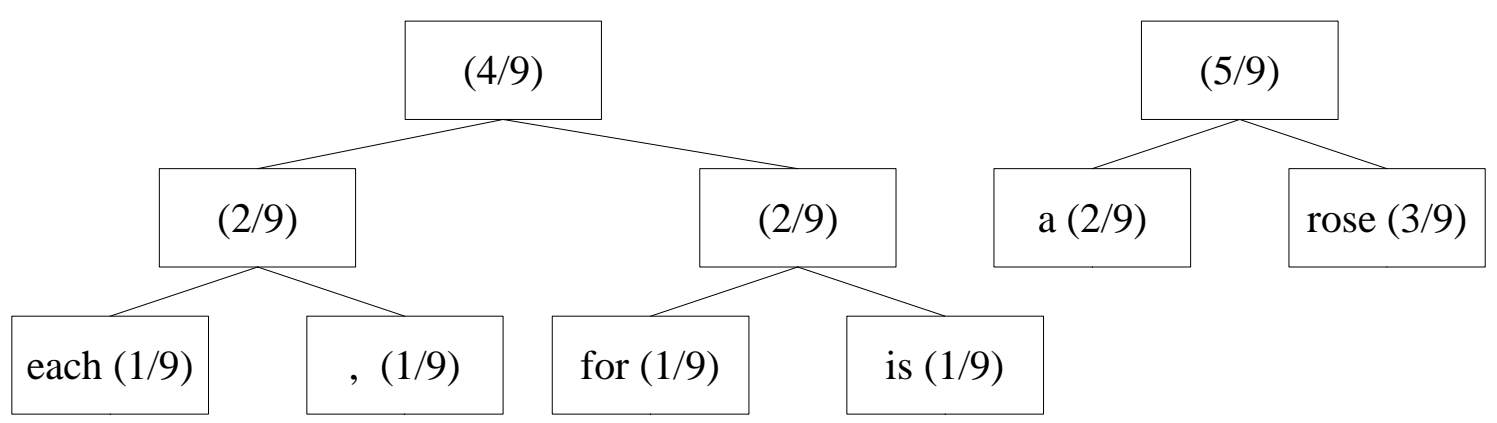

Figura 5.5: Exemplo após quarta iteração do Algoritmo de Huffman

$$
\begin{aligned}
& S=\{\} \\
& F=\{\} \\
& I=\{\}
\end{aligned}
$$

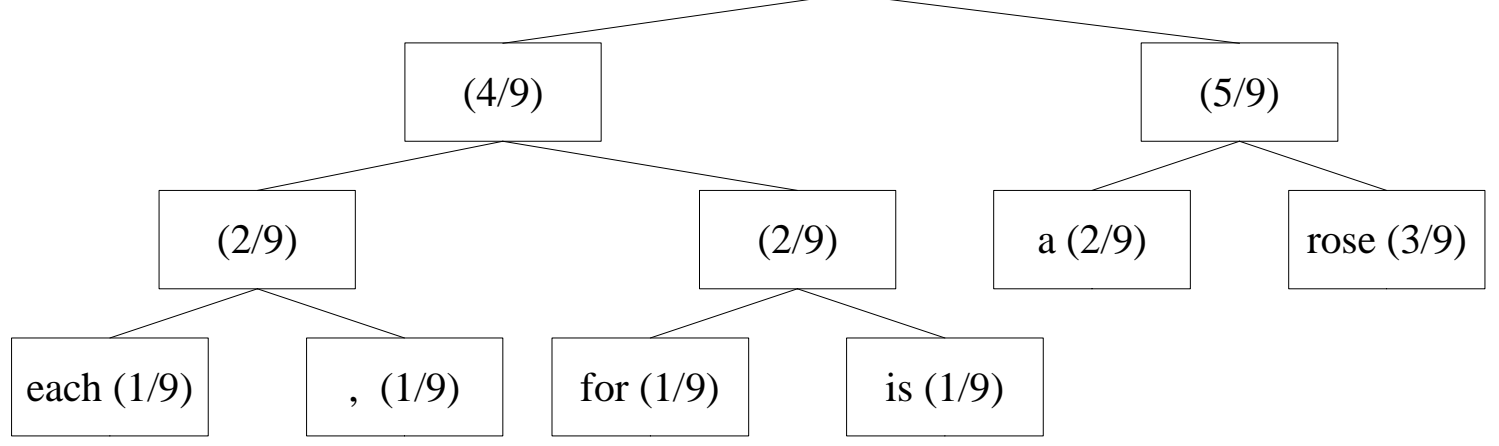

Figura 5.6: Exemplo após quinta iteração do Algoritmo de Huffman

um. Note que a árvore gerada na figura 5.7 é diferente da árvore apresentada nos trabalhos citados previamente (BYRN99; dMNZBY00) e reproduzida na figura 5.1. Da mesma forma, também o tamanho do texto final comprimido é diferente. Note que o tamanho do texto final (em bits) pode ser calculado somando-se os produtos das frequências de cada um dos símbolos pelos tamanhos dos respectivos códigos (o tamanho de um código é correpondente à altura do nó na árvore de Huffman, considerando-se que a altura da raiz é 0). Por exemplo, o texto usado na figura 5.7 é comprimido com 22 bits.

A codificação gerada pelo algoritmo de Huffman descrito em 5.1 é uma codificação livre de prefixos, ou seja, nenhum código gerado é prefixo de outro código, caso contrário existiriam códigos terminando em nós internos da árvore e isto ocasionaria ambiguidade na descompressão, já que o descompressor, ao encontrar um código que terminasse em um nó intermediário, não saberia se deveria emitir o símbolo correspondente ou continuar lendo mais dados da entrada. 


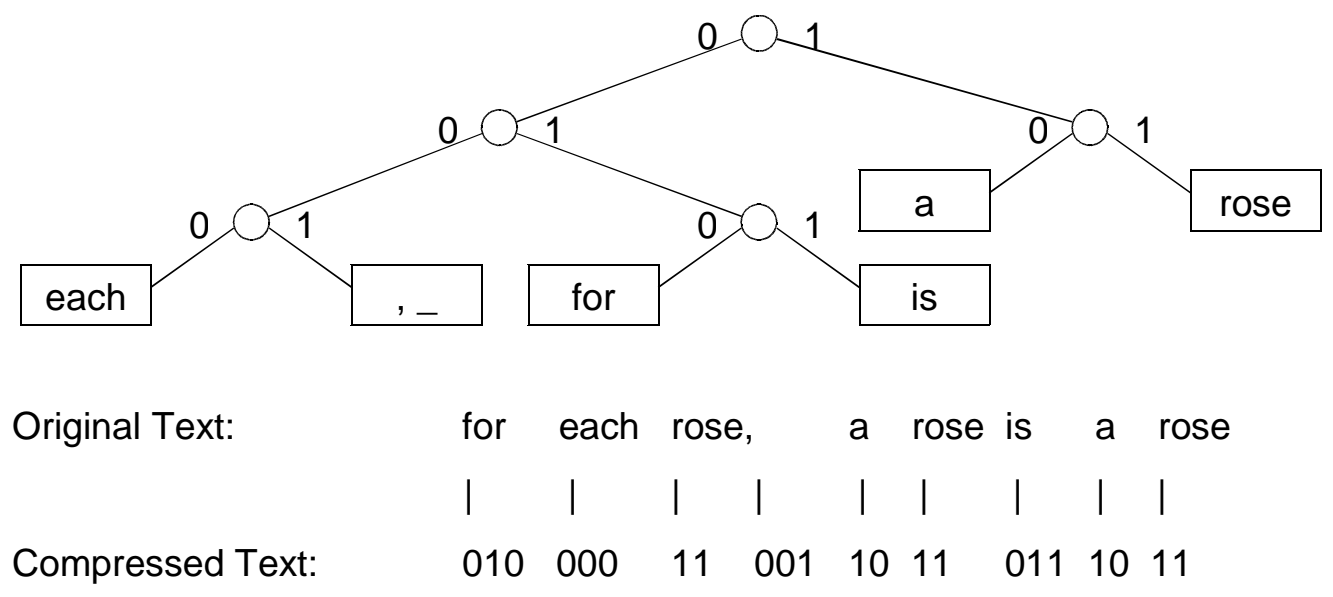

Figura 5.7: Exemplo de texto analisado em (BYRN99) e (dMNZBY00) comprimido segundo código Huffman descrito na figura 5.6. O texto aqui é comprimido com 22 bits

\subsection{Utilizando Bytes como Unidade de Informação}

No algoritmo original de Huffman, os símbolos, normalmente caracteres, eram codificados através de bits. Os primeiros a proporem a utilização de palavras como símbolos foram: Bentley em 1986 (BSTW86) e Moffat em 1989 (Mof89). Posteriormente Witten et al. implementaram um sistema de recuperação de informação descrito em (WMB99). Já Moura et al. (dMNZBY00) além codificarem palavras, ao invés de símbolos, propuseram também utilizar sequências de bytes, ao invés de sequências bits, como unidade de informação. A motivação para tais escolhas é o aumento da eficiência, pois os computadores trabalham com bytes como unidade de informação, além disso o vocabulário de um sistema de recuperação de informação é composto pelas palavras dos documentos da coleção, portanto pode-se compartilhar esta estrutura com a compressão.

O algoritmo descrito em 5.1 pode ser facilmente estendido para gerar árvores com grau $g>2$, basta agrupar $g$ elementos ao invés de 2 . Antes, porém é necessário verificar a necessidade de se adicionar nós vazios (com probabilidade igual a zero) para garantir que a árvore gerada seja ótima. Isso se deve ao fato de que a árvore deve formar um contrator de $g$ para 1 . Um contrator agrupa um número arbitrário e constante de nós, no caso $g$, em um novo nó e os nós já agrupados não participam mais do processo de contração. No caso do código binário, qualquer conjunto não vazio é um contrator de 2 para 1 . Note que a contração mantém como invariante a congruência módulo $g-1$ de $v$. Portanto, para que o vocabulário forme um contrator de $g$ para 1 é necessário que:

$$
v \equiv 1 \quad(\bmod (g-1))
$$

e a quantidade de nós vazios $d$ a ser inserida é:

$$
d=(g-(v \bmod (g-1))) \bmod (g-1)
$$

a qual é diferente da proposta em (BYRN99), segundo este texto, que trabalha com $g=256$, deve-se separar $o=1+((v-256) \bmod 255)$ nós de $V$ para serem juntados com $d=g-o$ nós vazios. Um exemplo da diferença pode ser notado $\operatorname{com} v=256$, na equação aqui descrita não são adicionados nós vazios $(d=0)$, já na equação de (BYRN99) adiciona-se 255 nós vazios; em ambos os casos o 
total de nós é congruente a $1 \bmod 255$, porém é totalmente desnecessário inserir 255 nós, já que $v+255 \equiv v(\bmod 255)$. Este mesmo fato ocorre para qualquer outro valor que já seja congruente a $1 \bmod 255$ (256, 511, etc. - é uma PA infinita com valor inicial 256 e razão 255).

Em (dMNZBY00) são apresentadas duas formas de compactação Huffman com bytes, uma simples (plain) onde o grau da árvore Huffman é 256, aqui denominada Huffman-256 e etiquetado (tagged) onde o grau da árvore Huffman é 128, aqui denominada Huffman-128. A compressão Huffman binária orientada a palavras será denominada Huffman-2. No Huffman-256 todos os bits do byte são utilizados, já no Huffman-128 o primeiro bit é reservado para marcar o fim do código. Em termos práticos no Huffman-256 é necessário verificar o sincronismo dos códigos em uma descompressão partindo de um ponto qualquer do arquivo; no Huffman-128 esta operação é simplificada, pois cada código possui seu marcador, basta avançar ou retroceder no arquivo, na pior das hipóteses, uma quantidade de bytes correspondente ao tamanho do maior código; em contrapartida, a compressão do Huffman-128 é levemente menor do que a simples.

As taxas de compressão e os tempos de compressão e descompressão obtidos em (dMNZBY00) foram competitivos com programas conhecidos do UNIX, como o compress e gzip, para textos maiores que $10 \mathrm{MB}$ se o vocabulário não for comprimido e para textos maiores que $1 \mathrm{MB}$ se o vocabulário for comprimido utilizando o Huffman binário codificando caracteres. A tabela 5.1 compila os resultados obtidos para os métodos de compressão utilizando a coleção do Wall Street Journal (WSJ) de 1987 a 1989 .

\begin{tabular}{|c|c|c|c|}
\hline Método & $\begin{array}{c}\text { Taxa de } \\
\text { Compressão }\end{array}$ & $\begin{array}{c}\text { Tempo de } \\
\text { Compressão }\end{array}$ & $\begin{array}{c}\text { Tempo de } \\
\text { Descompressão }\end{array}$ \\
\hline Huffman-2 & $\mathbf{2 7 , 1 3 \%}$ & $526 \mathrm{~s}$ & $185 \mathrm{~s}$ \\
\hline Huffman-256 & $30,60 \%$ & $520 \mathrm{~s}$ & $\mathbf{1 1 7} \mathbf{s}$ \\
\hline Huffman-128 & $33,70 \%$ & $534 \mathrm{~s}$ & $121 \mathrm{~s}$ \\
\hline compress & $42,94 \%$ & $\mathbf{4 5 6 s}$ & $273 \mathrm{~s}$ \\
\hline gzip & $37,53 \%$ & $1526 \mathrm{~s}$ & $161 \mathrm{~s}$ \\
\hline
\end{tabular}

Tabela 5.1: Tabela comparativa entre métodos de compressão. Dados obtidos de (dMNZBY00) para o arquivo WSJ.

A tabela 5.1 mostra que o método com melhor taxa de compressão é o Huffman-2. O melhor tempo de compressão é obtido pelo compress, porém com a pior taxa de compressão. Todos os métodos Huffman possuem tempos de compressão similares, isso se deve à dupla varredura do arquivo que domina o tempo de compressão. Os melhores tempos de descompressão são obtidos nos métodos Huffman que utilizam bytes como unidade de informação devido a simplicidade da descompressão.

\subsection{Descompressão e Acesso Aleatório}

Uma característica desejável na indexação por blocos é que seja possível descomprimir o texto a partir de um ponto qualquer. Como visto, a codificação Huffman descrita no algoritmo 5.1 é uma codificação livre de prefixos (nenhum código é prefixo de outro). Porém isso não elimina a possibilidade de haver ambiguidade na descompressão a partir de um ponto qualquer. Esta ambiguidade ocorre tanto no caso de bits como no de bytes. Na figura 5.8 há um exemplo para código binário, utilizando o texto e árvore analisados em 5.7 na página 21, pulando os primeiros bits, os colchetes se mostram a separação dos bits em códigos. 


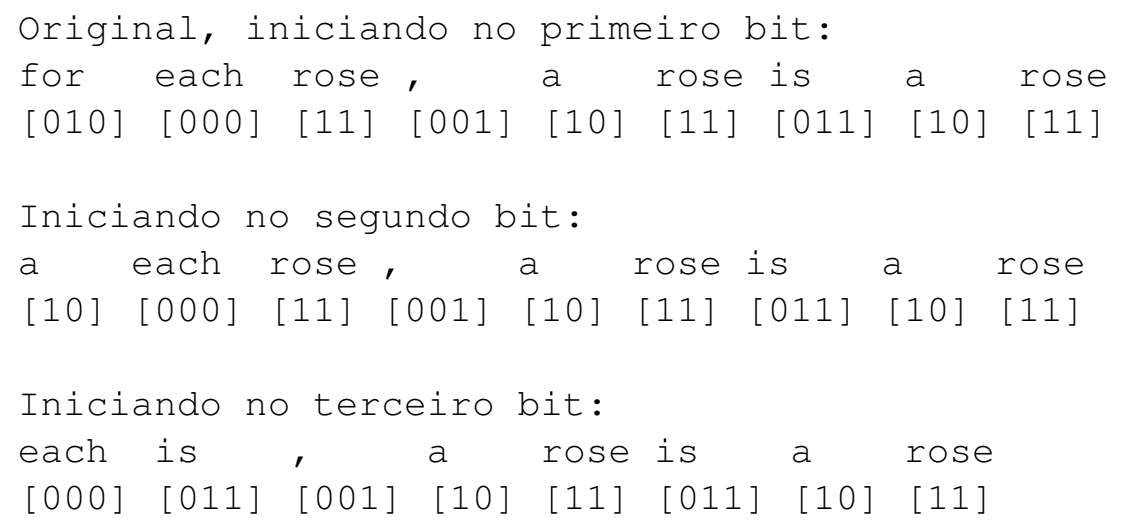

Figura 5.8: Exemplos de descompressão Huffman binária a partir de pontos arbitrários do texto comprimido

Na figura 5.9 há um exemplo de ambiguidade para bytes.

\begin{tabular}{|c|c|c|c|}
\hline Palavra & Código & Texto Original: & ... palavra real ... \\
\hline fantasma & 13421576 & Texto Comprimido: & 9313421576102 \\
\hline palavra & 93134 & & fantasma? \\
\hline real & 21576102 & & \\
\hline
\end{tabular}

Figura 5.9: Durante a busca em textos comprimidos podem-se encontrar ocorrências fantasmas de palavras. Dependendo do ponto inicial da descompressão, pode-se obter "palavra real" ou "fantasma".

Em ambos os casos, representados nas figuras 5.8 e 5.9, para ter certeza do código real é necessário retroceder até o início do bloco, ou até que não seja encontrado um código na árvore Huffman para cada uma das posições alternativas.

Com isto define-se uma codificação livre de prefixos auto-sincronizada como sendo uma codificação livre de prefixos que possibilita o acesso aleatório em qualquer posição do arquivo comprimido, sincronizando os códigos de forma determinística. Desta forma, motiva-se a utilização de um marcador de sincronismo dos códigos. No caso da codificação Huffman-128 apresentada por de Moura et al. (dMNZBY00), utiliza-se o bit mais significativo de cada byte como marcador de fim de código: o valor 1 indica o último byte do código. Com isto é garantido que, ao avançar ou retroceder um número de bytes igual ao tamanho do maior código permitido, o sincronismo dos códigos é encontrado.

\subsection{Huffman Dinâmico}

A fim de utilizar a compressão Huffman para transmissão de dados, o fato de ser necessário varrer o texto em dois passos torna-se uma grande penalidade. Para resolver esta questão foram propostos algoritmos que efetuam a compressão Huffman em uma única varredura. Dentre eles destacam-se o algoritmo de Faller, Gallager e Knuth (FGK) de (Knu85) e o algoritmo de Vitter (Vit85). Nestes algoritmos, a cada símbolo do texto a árvore Huffman do passo anterior é atualizada para uma nova árvore Huffman. A garantia destes algoritmos é usar menos de $n$ bits a mais que codificação Huffman estática, onde $n$ é o número de símbolos no texto. Com as análises de Gagie (Gag07) e de Ye e Yeung (YY02) verifica-se que o algoritmo de Vitter utiliza o mínimo de bits extras.

No escopo do presente trabalho, a varredura dupla não é considerada uma penalidade, pois uma segunda leitura já é necessária na criação do vocabulário e do índice invertido. Neste ponto de vista, não há compensação no uso dos bits extras necessários na compressão dinâmica. 


\subsection{Compressão Utilizando Super-Alfabetos}

Uma idéia proposta por Udi Manber em (Man97) é uma variação simplificada do código de Huffman, onde pares de símbolos são codificados em um byte. Esta junção de símbolos origina o Super-Alfabeto. O estudo é restrito ao alfabeto ASCII (128 símbolos) e a textos em inglês (para português o alfabeto mínimo seria o ISO-8859-1 com 256 símbolos).

Para que seja possível realizar a busca diretamente no texto comprimido, mais uma restrição é feita, os pares de símbolos não podem se sobrepor, ou seja, o primeiro símbolo de um par não pode ocorrer como segundo símbolo de outro par e vice-versa. Desta forma não é possível codificar qualquer par de símbolos e uma escolha deve ser feita de forma a maximizar a compressão. Após verificar que a solução ótima é um problema NP-completo, o autor sugere algumas heurísticas a fim de possibilitar tal computação. A melhor foi a mais simples, onde $f(a b)$ é a frequência do par composto pelos símbolos a e b e $\mathrm{G}=(\mathrm{V}, \mathrm{E})$, onde $\mathrm{V}$ é composto pelo conjunto dos símbolos presentes no texto e $\mathrm{E}$ corresponde aos pares de símbolos presentes no texto e $\mathrm{f}(\mathrm{ab})$ é o peso da aresta. A idéia é particionar os vértices em dois conjuntos, $V_{1}$ e $V_{2}$ de tal forma que a soma dos pesos das arestas que ligam estes conjuntos seja máxima. A heurística é, para uma dada partição inicial de $V_{1}$ e $V_{2}$, para cada vértice é examinado se a troca de partição do mesmo aumenta o peso das arestas que ligam o novo conjunto $V_{1}^{\prime}$ e $V_{2}^{\prime}$.

Apesar de todas as restrições e heurísticas, se fosse possível comprimir todos os pares que ocorrem no texto, a taxa de compressão máxima seria 1/2 (meio). E nos resultados práticos é algo em torno de $2 / 3$ (dois terços), aproximadamente $70 \%$, mesmo realizando a dupla varredura para levantar a frequência dos pares de símbolos.

Já no trabalho de Fredriksson e Tarhio (FT03) é apresentada uma forma genérica para processar blocos de bits na compressão Huffman usual. Neste caso o super-alfabeto é utilizado apenas para a busca e não para a compressão. Para a busca de padrões são comparados os métodos de AhoCorasick (AC75) e Shift-Or (BYG92), onde ambos são extrapolados de forma a considerar o superalfabeto. O método de Aho-Corasick é superior ao Shift-Or no comparativo obtido. O principal ponto a se destacar de (FT03) são as idéias para agilizar as transições de busca dos métodos comparados, pois em termos práticos os resultados são pequenos. A taxa de compressão para linguagem natural variou entre 54,8\% e 63\%, melhor que (Man97), porém ainda aquém das necessidades práticas. 


\section{Capítulo 6}

\section{Comparativo das Estratégias de Compressão}

\subsection{Comparação entre Huffman e Ziv-Lempel}

Em grande parte dos trabalhos analisados, nota-se que a taxa de compressão é melhor (possui valores menores) na compressão Ziv-Lempel, exceto em (dMNZBY00) onde a estratégia Huffman foi superior para textos grandes (acima de 10MB).

Com relação ao consumo de memória, por um lado, a compressão Ziv-Lempel leva vantagem, pois na compressão Huffman é necessário armazenar o vocabulário de símbolos e suas frequências, por outro lado, isso não representa impacto em sistemas de recuperação de informação, pois estes sistemas também necessitam tanto do vocabulário como da frequência das palavras.

Com relação à velocidade de compressão, novamente a compressão Ziv-Lempel leva vantagem, pois ao contrário da compressão Huffman, não requer duas varreduras no arquivo original, porém com o Huffman Dinâmico o tempo é muito próximo à compressão Ziv-Lempel (à custa de perda de compressão).

Com relação à velocidade de descompressão ambas as estratégias possuem tempos muito próximos, pois em ambos os casos as substituições necessárias para a descompressão são realizadas através de algoritmos simples e rápidos, na compressão Huffman basta percorrer a árvore e na compressão Ziv-Lempel basta recuperar o bloco apontado.

A grande vantagem da compressão Huffman é tanto permitir a descompressão a partir de um ponto qualquer do arquivo, assim como a busca direta no arquivo comprimido pelo código equivalente da palavra buscada, o que não ocorre na compressão Ziv-Lempel, pois a palavra buscada pode ocorrer de diversas formas dentro do texto comprimido.

Além disso, outro grande mérito da compressão Huffman é um casamento entre as estruturas por ela utilizadas e as estruturas utilizadas nos sistemas de recuperação de informação, como visto, em um arquivo invertido é composto pelo vocabulário e a lista com todas as ocorrências das palavras, sendo que o tamanho desta lista é a frequência da palavra no texto.

\subsection{Comparativo entre Variantes da Compressão Huffman}

As variantes comparadas são "Bits" (Huffman de bits codificando caracteres), "Huffman-2" (Huffman de bits codificando palavras), "Huffman-256" (Huffman de bytes codificando palavras), "Huffman-128" (Huffman de bytes codificando palavras com bit sinalizador de fim de código), "Dinâmico" (Huffman de bits em uma única varredura) e "Super-Alfabeto" (Huffman de bytes capturando mais de um caracter ao mesmo tempo). Pode-se observar na tabela 6.1 uma comparação das diversas variantes da compressão Huffman.

Desta comparação da tabela 6.1 observam-se as seguintes características: 


\begin{tabular}{|c|c|c|c|c|c|c|}
\hline Critérios & Bits & $\begin{array}{c}\text { Huffman } \\
2\end{array}$ & $\begin{array}{c}\text { Huffman } \\
256\end{array}$ & $\begin{array}{c}\text { Huffman } \\
128\end{array}$ & $\begin{array}{c}\text { Huffman } \\
\text { Dinâmico }\end{array}$ & $\begin{array}{c}\text { Super- } \\
\text { Alfabeto }\end{array}$ \\
\hline Varredura & Dupla & Dupla & Dupla & Dupla & Simples & Dupla \\
\hline $\begin{array}{c}\text { Consumo de } \\
\text { Memória }\end{array}$ & Baixo & Alto & Alto & Alto & Médio & Alto \\
\hline $\begin{array}{c}\text { Velocidade de } \\
\text { Compressão }\end{array}$ & Média & Média & Média & Média & Alta & Média \\
\hline $\begin{array}{c}\text { Velocidade de } \\
\text { Descompressão }\end{array}$ & Alta & Alta & Alta & Alta & Média & Alta \\
\hline $\begin{array}{c}\text { Taxa de } \\
\text { Compressão }\end{array}$ & Ruim & Boa & Média & Média & Média & Ruim \\
\hline $\begin{array}{c}\text { Acesso } \\
\text { Aleatório }\end{array}$ & Não & Não & Não & Sim & Não & Não \\
\hline Busca Direta & Não & Não & Não & Sim & Não & Restrita \\
\hline
\end{tabular}

Tabela 6.1: Comparação entre diversos tipos de codificação Huffman.

- Huffman Dinâmico é o único método que realiza apenas uma varredura;

- As estratégias que procuram utilizar bytes para codificar palavras consomem mais memória;

- A velocidade de compressão tende a ser semelhante, a vantagem da compressão Huffman Dinâmico é por realizar uma varredura apenas;

- A velocidade de descompressão é alta pois basta varrer os códigos em sincronismo com a árvore de Huffman, exceção feita para o Huffman Dinâmico que precisa atualizar a árvore a cada código recebido;

- A taxa de compressão por bits é melhor que a de bytes comprimindo palavras, a qual é melhor que nos experimentos utilizando super-alfabetos;

- O acesso aleatório é importante para sistemas de informação que utilizam a estrutura de arquivos invertidos por blocos. Para este caso a única solução realmente viável é o Huffman128. Nos demais casos se não houver a divisão por blocos do arquivo pode ser necessário retroceder até o início do mesmo para sincronizar os códigos;

- A busca direta também é importante para sistemas de informação que utilizam a estrutura de arquivos invertidos por blocos. Para este caso as únicas soluções são o Huffman de bytes simples ou etiquetado. O super-alfabeto possui restrições em sua utilização e possui uma taxa de compressão baixa, por isso não é recomendado. 


\section{Capítulo 7}

\section{Proposta de Novas Codificações Livres de Prefixo}

Como visto no capítulo 2, o índice mais adequado a sistemas de recuperação de informação com maiores restrições ao consumo de memória é o arquivo invertido por blocos, ademais, a pesquisa de estratégias de compressão indica que a compressão Huffman orientada a palavras é a que melhor se adequa à estrutura de arquivo invertido por blocos, pois compartilha mesmo vocabulário e proporciona acesso aleatório. Neste capítulo estudam-se estratégias que possibilitam maiores ganhos especialmente na compressão. Para isto define-se a árvore de codificação $A(M)$ para um mapeamento $M$ de uma codificação qualquer.

Sendo $v$ o tamanho do vocabulário e $M$ um mapeamento associado a uma codificação qualquer, associa-se ao mapeamento em questão sua árvore de codificação $A(M)$ definida da seguinte forma:

- As folhas de $A(M)$ são o conjunto de códigos $\{M(i) \mid 1 \leq i \leq v\}$;

- Os vértices internos de $A(M)$ são os prefixos próprios dos códigos $\{M(i) \mid 1 \leq i \leq v\}$;

- A raiz é o vértice interno formado pela sequência vazia de bytes $\lambda$;

- As únicas arestas de $A(M)$ são aquelas que ligam um prefixo de $M(i)$ de comprimento $j$ ao prefixo de comprimento $j+1$ para $1 \leq i \leq v, 0 \leq j \leq|M(i)|$ e $|M(i)|$ é o tamanho do código $M(i)$.

\subsection{Codificação X-Huffman-128}

O primeiro resultado obtido do estudo das estratégias anteriormente citadas é o código aqui batizado de X-Huffman-128 por se tratar de uma extensão da codificação Huffman em bytes e do Huffman-128 descrito em (dMNZBY00). A intenção deste novo codigo é reduzir o consumo de memória e os tempos de compressão e descompressão. O código X-Huffman-128 é um mapeamento $M$ da árvore com grau 256 obtida na utilização da compressão Huffman a uma enumeração $e$.

A idéia chave é verificar que a utilização do oitavo bit, o mais significativo, do byte faz com que se tenha dois universos separados de sete bits (128 combinações). O primeiro universo é dos valores terminadores, ou seja, ao encontrar um destes valores sabe-se que o final do código foi encontrado. O segundo universo é dos valores de continuação, ou seja, ao encontrar um destes valores sabe-se que o código continua no próximo byte. Desta forma, pode-se pensar que os códigos são números de base 128 codificados em bytes (base 256), sendo que o bit mais significativo é reservado para indicar o término.

A fim de expôr o mapeamento, a seguinte terminologia será utilizada:

- $e=\{1, \ldots v\}$ é a enumeração dos símbolos a serem codificados pelo novo mapeamento; 
- $C=\left(c_{1}, c_{2}, \ldots, c_{j}\right), j \geq 1,1 \leq i \leq j$ e $0 \leq c_{i}<256$ é um código formado por uma sequência de bytes de tamanho variável;

- $M$ mapeia um valor e em um código $C$, determinando a quantidade $j$ de bytes e o valor de cada um dos mesmos;

- $M^{-1}$ é o inverso de $M$ e mapeia uma sequência $C$ de bytes em um valor $e$.

Com isto, propõe-se o seguinte mapeamento $M$ na codificação X-Huffman-128 onde:

$$
\begin{aligned}
& M(e)=C=\left(c_{1}, c_{2}, \ldots, c_{j}\right) \\
& j=\left\lfloor\log _{128}(e)\right\rfloor+1, \\
& r_{i}=\left\lfloor\frac{e}{128^{j-i}}\right\rfloor \bmod 128, \\
& c_{i}= \begin{cases}r_{i}, & \text { para } 1 \leq i<j ; \\
r_{i}+128, & \text { para } i=j .\end{cases}
\end{aligned}
$$

equivalentemente, o mapeamento $M$ transforma o inteiro $e$ em uma representação numérica na base 128 com a diferença de que o último "dígito" é acrescido de 128 para indicar que é o terminador da sequência $C$. O mapeamento inverso $M^{-1}$ é:

$$
\begin{aligned}
& M^{-1}(C)=e \\
& e=\left(c_{j}-128\right)+\sum_{i=1}^{j-1} c_{i} \cdot 128^{j-i}
\end{aligned}
$$

o mapeamento $M^{-1}$ transforma a sequência $C$ de bytes (semelhante a representação numérica na base 128) na enumeração $e$, tratando o caso especial do byte terminador $c_{j}$. Este mapeamento requer que mais uma restrição seja respeitada: não pode haver códigos que sejam iniciados com o byte zero, por exemplo, tanto o código "0x81" (129 decimal) de tamanho um, como o código "0x00 0x81" de tamanho dois resultariam no mesmo mapeamento $e=1$.

Outra forma de tratar o mapeamento $M$ é verificando a sequência de códigos gerada para cada valor $e$ de 1 a $v$ :

- para $1 \leq e \leq 127$, os códigos variam de (128) a (255), respectivamente;

- para $128 \leq e \leq 255$, os códigos variam de $(1,128)$ a $(1,255)$, respectivamente;

- para $256 \leq e \leq 511$, os códigos variam de $(2,128)$ a $(2,255)$, respectivamente; $\ldots$

- para $16.256=128^{2}-128 \leq e \leq 16.384=128^{2}-1$, os códigos variam de $(127,128)$ a $(127,255)$, respectivamente;

- para $16.384=128^{2} \leq e \leq 16.511=128^{2}+127$, os códigos variam de $(1,0,128)$ a $(1,0,255)$, respectivamente;

- para $16.512=128^{2}+128 \leq e \leq 16.639=128^{2}+255$, os códigos variam de $(1,1,128)$ a $(1,1,255)$, respectivamente. 
Com este exemplo pode-se verificar que cada nível da árvore de códigos gerada é semelhante ao uso de um novo "dígito". Na figura 7.1 é representado um esquema da árvore de códigos gerados pelo mapeamento $M$. Neste esquema todos os grupos de 256 nós filhos de um mesmo nó pai foram agrupados, em cada nível $i$, em um único retângulo, representando o "dígito" correspondente. Cada retângulo armazena um byte, podendo assumir valores de 0 a 255. Este intervalo de valores está dividido na metade: os códigos terminadores (128 a 255) e os códigos de continuação (0, exceto no primeiro nível, a 127). As linhas diagonais ligando o nível $i$ ao nível $i+1$ formando um trapézio indicam que um byte $c_{i}$ presente no intervalo descrito no nível $i$ (base menor) continua no próximo nível (base maior).

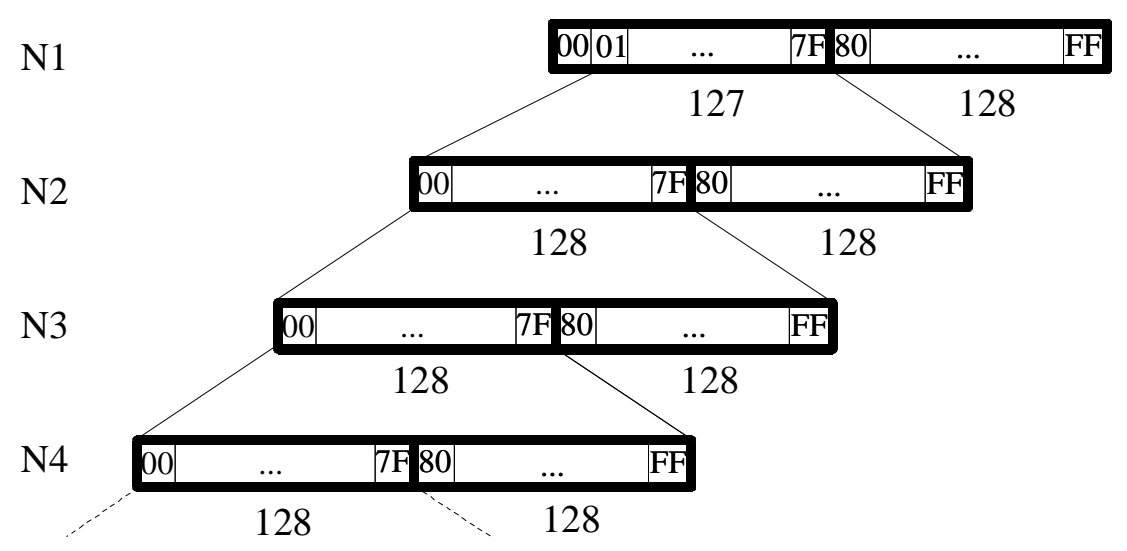

Figura 7.1: Esquema da árvore gerada com a divisão de códigos terminadores e de continuação em 128 segundo o mapeamento $M$. Todos os grupos de 256 nós filhos de um mesmo nó pai foram agrupados, por nivel, em um único retângulo para melhor visualização.

Note que o nó interno de uma árvore de codificação X-Huffman-128 possui 256 filhos, tipicamente, e é completamente diferente da árvore obtida pela codificação Huffman-128 descrita na seção 5.1, página 21, que possui em geral 128 filhos. Porém ambas possuem a característica de ter um conjunto de 128 códigos terminadores e 128 códigos de continuação.

Ambos os mapeamentos podem ser implementados eficientemente através dos códigos em $\mathrm{C}$ com até $j \leq 4$ bytes. Observe-se que:

- multiplicação por $2^{i}$ equivale a um deslocamento (shift) de $i$ bits à esquerda;

- chão da divisão por $2^{i}$ equivale a um deslocamento de $i$ bits à direita;

- resto da divisão por $2^{i}$ equivale a um "E" lógico com $2^{i}-1$;

- soma de valores que possuam bits zero em uma das parcelas equivale a um "OU" lógico.

- outra forma de representar o código $C$ é através do valor $c$ que interpreta cada um de seus bytes como dígitos da base 256

$$
\begin{aligned}
c & =\sum_{i=1}^{j} 256^{j-i} c_{i} \\
& =\left(r_{j}+128\right)+\sum_{i=1}^{j-1} 256^{j-i} r_{i}
\end{aligned}
$$




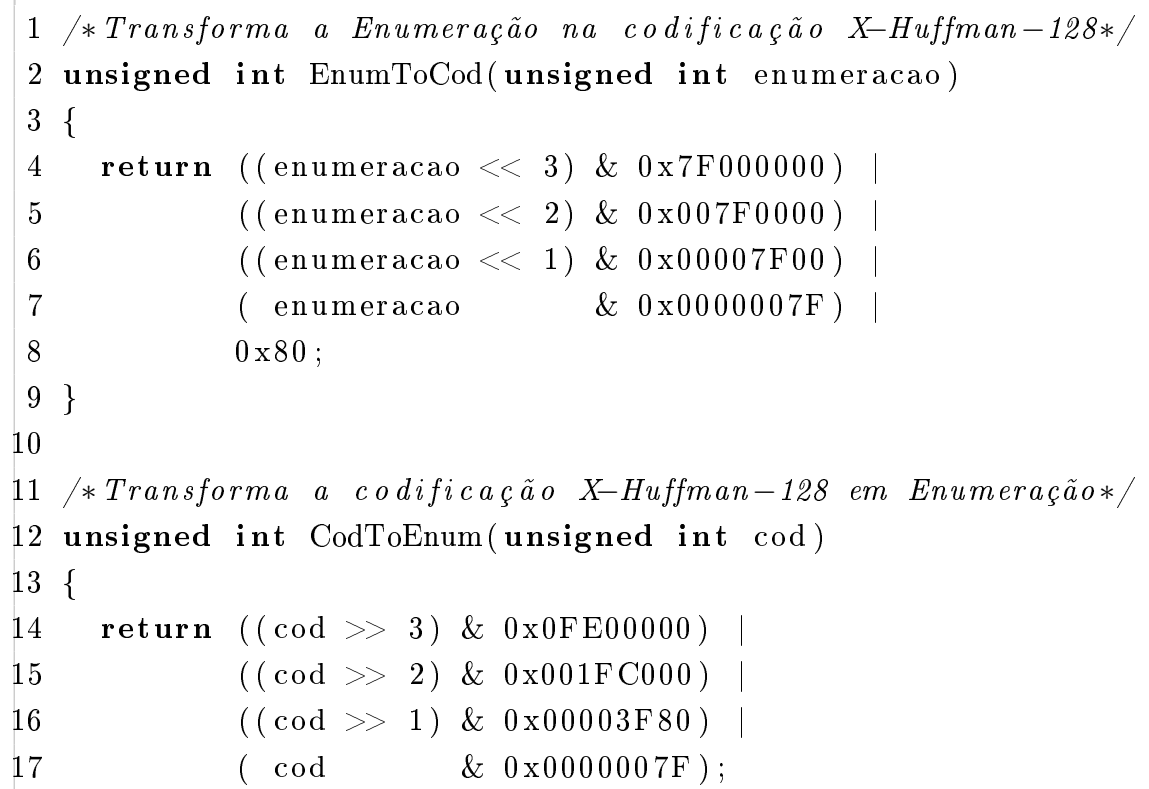

\subsection{Atribuição dos Códigos às Palavras do Vocabulário}

Em um texto comprimido com um código como o de Huffman, é necessário codificar não somente o texto, mas também armazenar o vocabulário, descrevendo o código utilizado. Assim o texto comprimido é composto do vocabulário e dos códigos que representam os símbolos do texto original. Como o vocabulário é o mesmo nos métodos aqui tratados, seu tamanho nos textos comprimidos também será o mesmo em todas as variantes comparadas. Assim este fator constante não será considerado no cálculo do tamanho do texto comprimido, na análise que se segue. Então o tamanho $z$ do texto comprimido é dado pela soma do tamanho dos códigos $C_{i}$ de cada um dos símbolos $s_{i}$ do vocabulário $v,(1 \leq i \leq v)$ multiplicado pela frequência $f_{i}$ com que cada símbolo ocorre no texto:

$$
z=\sum_{i=1}^{v}\left|C_{i}\right| \cdot f_{i}
$$

Resta, desta forma, verificar a forma de atribuição dos códigos $C_{i}$ para cada símbolo $s_{i}$ do vocabulário. A forma de realizar estas atribuições de forma a minimizar o tamanho do texto comprimido será demonstrada a seguir: suponha que o vocabulário do texto seja composto apenas por dois símbolos $s_{a}$ e $s_{b}$ e que se dispõe de dois códigos $C_{1}$ e $C_{2}$, cujos tamanhos são, respectivamente, $c_{1}$ e $c_{2}$ sendo que $c_{2}>c_{1}$, ou seja, $c_{2}=c_{1}+x(x>0)$. Os símbolos $s_{a}$ e $s_{b}$ ocorrem no texto com frequências $f_{a}$ e $f_{b}$ respectivamente, sendo que $f_{b}<f_{a}$, ou seja, $f_{b}=f_{a}-y(y>0)$. Como uma codificação como a de Huffman atribui "códigos de menor tamanho aos símbolos mais frequentes", o símbolo $s_{a}$ será mapeado no código $C_{1}$ e $s_{b}$ em $C_{2}$ e o tamanho $z_{H}$ do arquivo comprimido segundo o algoritmo de Huffman é:

$$
\begin{aligned}
z_{H} & =c_{1} \cdot f_{a}+c_{2} \cdot f_{b} \\
& =c_{1} \cdot f_{a}+\left(c_{1}+x\right) \cdot\left(f_{a}-y\right) \\
& =2 \cdot c_{1} \cdot f_{a}-c_{1} \cdot y+x \cdot f_{a}-x \cdot y
\end{aligned}
$$


Já se a atribuição dos códigos aos símbolos for alterada, atribuindo códigos maiores aos símbolos mais frequentes, $s_{a}$ será mapeado em $C_{2}$ e $s_{b}$ em $C_{1}$. O tamanho $z_{G}$ do arquivo comprimido é:

$$
\begin{aligned}
z_{G} & =c_{2} \cdot f_{a}+c_{1} \cdot f_{b} \\
& =\left(c_{1}+x\right) \cdot f_{a}+c_{1} \cdot\left(f_{a}-y\right) \\
& =2 \cdot c_{1} \cdot f_{a}-c_{1} \cdot y+x \cdot f_{a}
\end{aligned}
$$

e a diferença entre tamanho dos arquivos $z_{H}$ e $z_{G}$ é:

$$
\begin{aligned}
z_{G}-z_{H} & =\left(2 \cdot c_{1} \cdot f_{a}-c_{1} \cdot y+x \cdot f_{a}\right) \\
& -\left(2 \cdot c_{1} \cdot f_{a}-c_{1} \cdot y+x \cdot f_{a}-x \cdot y\right) \\
& =x \cdot y \\
& >0
\end{aligned}
$$

Como $x>0$ e $y>0$, então $z_{G}>z_{H}$. Este é um fato importante da compressão Huffman pois, ao se dividir os dados nos símbolos a serem codificados, no caso de texto em palavras e separadores, os quais formam o vocabulário, importa unicamente frequência, e não o tamanho do símbolo, na atribuição dos códigos. Portanto, para atribuir os códigos nas codificações vistas, basta ordenar os símbolos do vocabulário em ordem decrescente de frequência e esta ordem é a enumeração $e$.

Com o mapeamento $M$ definido em 7.1 e a atribuição de códigos aqui definida é possível reduzir o tempo e o consumo de memória na compressão, pois não é preciso gerar uma árvore canônica de codificação Huffman. Basta realizar a varredura do texto para levantar os símbolos e suas respectivas frequências e ordenar decrescentemente os símbolos por sua frequência. Neste ponto, os códigos Huffman são atribuídos aos símbolos simplesmente utilizando o índice do símbolo na ordenação.

Na descompressão é importante que o vocabulário seja representado como um vetor contendo os símbolos ordenados tal como na compressão, pois o mapeamento $M^{-1}$ transforma os códigos $C$ no índice deste vetor, proporcionando uma diminuição no tempo de descompressão, já que nas árvores canônicas são necessários dois passos, um para determinar o comprimento do código e outro para determinar qual a posição do símbolo dentro daquele comprimento; este vetor de vetores faz com que a utilização da memória cache do processador seja otimizado nas codificações aqui propostas.

Em termos práticos, utilizando o código definido em 7.1, na compressão, a cada símbolo encontrado, basta transformar seu valor na enumeração utilizando a função EnumToCod e enviar para a saída o código retornado desprezando os bytes "0x00" mais significativos. Já na descompressão, a cada código encontrado, basta transformar o código na posição equivalente da enumeração com a função CodToEnum e enviar para a saída o símbolo correspondente daquela posição.

Una das vantagens dos mapeamentos propostos, é que não é necessário construir a árvore de codificação Huffman nem na compressão nem na descompressão, o que reduz o consumo de memória e de tempo de ambas as fases. Comparando com o algoritmo de Moffat (MK95), que requer três varreduras completas do vetor com as frequências para fazer o cálculo sem espaço adicional, este é um ganho bastante grade. Note que o algoritmo apenas calcula o tamanho, e não os códigos. 


\subsection{Codificação X-Huffman-F}

Apesar dos ganhos apresentados, há uma perda de compressão intrínseca na codificação XHuffman-128, pois utiliza-se um bit para marcar o byte terminador do código. Para cada byte utilizado, o espaço de codificação cai pela metade. Em termos práticos, considerando arquitetura de 32 bits, o espaço de $2^{32}=4.294 .967 .296(4 \mathrm{G})$ é reduzido para $2^{28}=268.435 .456(256 \mathrm{M})$. Por isso, procurou-se encontrar alternativas de forma a possibilitar o controle do espaço de codificação. A forma sugerida para realizar este controle é dividir os 256 valores do byte não necessariamente em dois grupos de mesmo tamanho, mas de forma que qualquer valor entre 1 e 255 possa ser escolhido, já que o 0 não pode ser utilizado. Esta idéia transforma a figura 7.1 da página 29 na figura 7.2 , onde há $X$ códigos terminadores e $Y=256-X$ códigos de continuação.

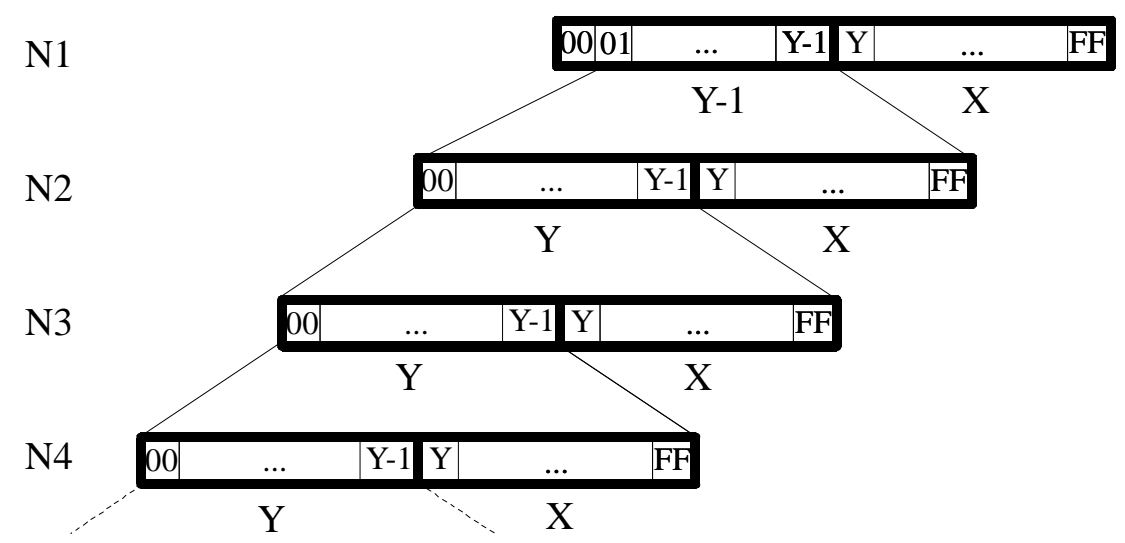

Figura 7.2: Primeiro esquema com a divisão de $X$ códigos terminadores e de $Y$ códigos de continuação. Todos os grupos de 256 nós filhos de um mesmo nó pai foram agrupados, por nível, em um único retângulo para melhor visualização.

No caso visto em 7.1, $X=128$, é o único valor que possibilita uma tranformação entre bases. Note que a restrição do byte "0x00" no primeiro nível continua. A idéia chave é ver que qualquer ponto pode ser utilizado como separação entre o universo dos valores terminadores e o universo dos valores de continuação. Esta árvore não será analisada em detalhes, pois ao espelhá-la, obtemos outra árvore esquematizada na figura 7.3 que elimina a restrição do valor 0 no primeiro nível.

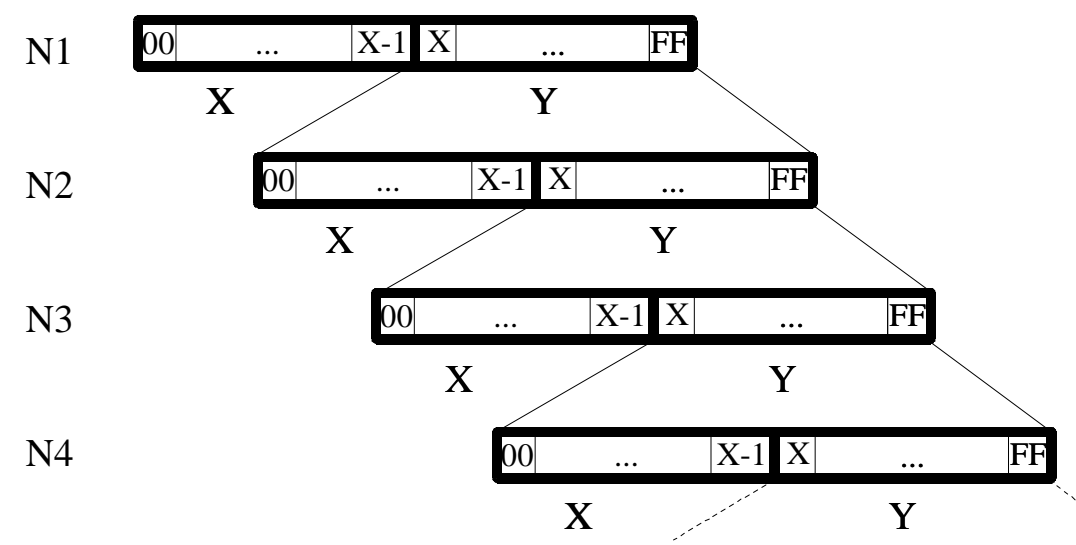

Figura 7.3: Esquema de codificação X-Huffman-F com a divisão de $X$ códigos terminadores e $Y$ códigos de continuação, sem o problema do prefixo "0x00". Todos os grupos de 256 nós filhos de um mesmo nó pai foram agrupados, por nível, em um único retângulo para melhor visualização. 
Da forma proposta na figura 7.3, o byte "0x00" é um terminador e, portanto, não prefixa nenhum código com mais que um byte. Com isto há um aumento de $X \cdot Y^{i-2}$ códigos para cada nível $i \geq 2$. Porém, na compressão e descompressão a quantidade de adições e subtrações aumenta, pois anteriormente estas operações eram realizadas apenas para o valor terminador $c_{j}$ e nesta situação as operações são feitas em todos os códigos de continuação $c_{i}, 1 \leq i<j$. Com a flexibilidade de se escolher o ponto de delimitação dos códigos terminadores e de continuação, define-se:

$-\ell_{i}$ é a quantidade de códigos com tamanho $i$, ou seja, que terminam no nível $i$ :

$$
\begin{aligned}
\ell_{i} & =X \cdot Y^{i-1} \\
& =X \cdot(256-X)^{i-1}
\end{aligned}
$$

$-k_{i}$ é a quantidade total de códigos com tamanho no máximo $i$ :

$$
\begin{aligned}
k_{i} & =\sum_{u=1}^{i} X \cdot Y^{u-1} \\
& =X \cdot \sum_{u=1}^{i} Y^{u-1} \\
& =X \cdot\left(\frac{Y^{i}-1}{Y-1}\right) \\
& =X \cdot\left(\frac{(256-X)^{i}-1}{255-X}\right)
\end{aligned}
$$

Com isto, o código $C$ é determinado por:

$$
\begin{aligned}
M(e)=C & =\left(c 1, c 2, \ldots, c_{j}\right), \\
j & =\min \left(u \mid e<k_{u}\right), \\
r_{j} & =e \bmod X, \\
q_{j} & =\left\lfloor\frac{e}{X}\right\rfloor, \\
r_{i} & =\left(q_{i+1}-1\right) \bmod Y, \\
q_{i} & =\left\lfloor\frac{q_{i+1}-1}{Y}\right\rfloor, \\
c_{i} & = \begin{cases}r_{i}+X, & \text { para } 1 \leq i<j ; \\
r_{i}, & \text { para } i=j .\end{cases}
\end{aligned}
$$

portanto, o valor $c$, que interpreta cada um dos bytes do código $C$ como dígitos da base 256 é:

$$
\begin{aligned}
c & =\sum_{i=1}^{j} 256^{j-i} c_{i} \\
& =r_{j}+\sum_{i=1}^{j-1} 256^{j-i} \cdot\left(r_{i}+X\right)
\end{aligned}
$$


A enumeração $e$ associada ao código $C$ é determinada por:

$$
\begin{aligned}
M^{-1}(C) & =e \\
e & =c_{j}+\sum_{i=1}^{j-1}\left(c_{i}-X+1\right) \cdot X \cdot Y^{j-i-1} \\
& =c_{j}+X \cdot\left(\sum_{i=1}^{j-1}\left(c_{i}-X+1\right) \cdot Y^{j-i-1}\right)
\end{aligned}
$$

Note que foi adicionada uma subtração nos cálculos de $q_{i}$ e $r_{i}$ e a correspondente adição no cálculo de $e$. Isso se deve ao fato dos códigos extras gerados com o espelhamento da árvore, pois ao realizar o mapeamento de um nível é necessário os códigos gerados mantenham a sequência com relação aos níveis anteriores. Para isto, basta subtrair a quantidade de códigos dos níveis anteriores, $k_{j-1}$ na codificação e posteriormente adicionar esta quantidade ao se calcular a enumeração $e$. Por exemplo, a sequência de códigos gerada para $X=175$ é:

- para $0 \leq e \leq 174$, os códigos variam de (0) a (174), respectivamente;

- para $175 \leq e \leq 349$, os códigos variam de $(175,0)$ a $(175,174)$, respectivamente;

- para $350 \leq e \leq 524$, os códigos variam de $(176,0)$ a $(176,174)$, respectivamente; $\ldots ;$

- para $14.175=X \cdot Y=175 \cdot(256-175) \leq e \leq 14.349=X \cdot Y+174=175 \cdot(256-175)+174$, os códigos variam de $(255,0)$ a $(255,174)$, respectivamente;

- para $16.350=X \cdot(Y+1)=175 \cdot(256-175+1) \leq e \leq 14.525=X \cdot(Y+1)+174=$ $175 \cdot(256-175)+174$, os códigos variam de $(175,175,0)$ a $(175,175,174)$, respectivamente.

Desta forma é possível escolher o valor de $X$ a fim controlar o espaço de códigos. De forma geral, quanto maior for o $X$, maior a quantidade de códigos nos níveis iniciais e menor nos níveis finais. A Tabela 7.1 compara a quantidade de códigos totais em cada nível $i\left(k_{i}\right)$ em função de $X$. Os valores em negrito destacam os valores máximos em cada nível.

\begin{tabular}{|l|r|r|r|r|r|}
\hline $\mathrm{X} / \mathrm{i}$ & 1 & 2 & 3 & 4 & 5 \\
\hline 32 & 32 & 7.200 & 1.612 .832 & 361.274 .400 & 80.925 .465 .632 \\
\hline 64 & 64 & 12.352 & 2.371 .648 & $\mathbf{4 5 5 . 3 5 6 . 4 8 0}$ & $\mathbf{8 7 . 4 2 8 . 4 4 4 . 2 2 4}$ \\
\hline 96 & 96 & 15.456 & $\mathbf{2 . 4 7 3 . 0 5 6}$ & 395.689 .056 & 63.310 .249 .056 \\
\hline 128 & 128 & $\mathbf{1 6 . 5 1 2}$ & 2.113 .664 & 270.549 .120 & 34.630 .287 .488 \\
\hline 160 & 160 & 15.520 & 1.490 .080 & 143.047 .840 & 13.732 .592 .800 \\
\hline 192 & 192 & 12.480 & 798.912 & 51.130 .560 & 3.272 .356 .032 \\
\hline 224 & 224 & 7.392 & 236.768 & 7.576 .800 & 242.457 .824 \\
\hline 256 & $\mathbf{2 5 6}$ & 256 & 256 & 256 & 256 \\
\hline
\end{tabular}

Tabela 7.1: Quantidade total de códigos até o nível $i\left(k_{i}\right)$ em função de $X$.

Nota-se que o último nível praticamente domina a quantidade total de códigos. Porém, com respeito à compressão, é tanto melhor quanto mais códigos houver nos menores níveis, pois quanto mais símbolos com grande frequência forem codificados com menos bytes, menor será o tamanho do arquivo codificado. 
Com relação a implementação, o parâmetro $X$, que divide o universo dos valores terminadores e de continuação, é adicionado às funções EnumToCod e CodToEnum apresentadas no apêndice A.1.

\subsection{Codificação X-Huffman-V}

A fim de ampliar ainda mais o controle do espaço de codificação apresentado na seção 7.3, podese variar o ponto de separação entre o universo dos valores terminadores e o universo dos valores de continuação a cada nível. Assim, ao invés de um único $X$ e $Y$ haverá diferentes $X_{i}$ e $Y_{i}$ para cada nível $i$, com a restrição de que $X_{i}+Y_{i}=256$. No entanto, com esta opção, a codificação gerada deixa de ser sempre auto-sincronizada. No pior caso, pode ser necessário retroceder até o início dos dados comprimidos a fim de descomprimir corretamente os dados, tal como no Huffman-256. Com isto a figura 7.2 se transforma na figura 7.4, representado o esquema da árvore de códigos gerados por esta generalização da extensão do mapeamento $M$.

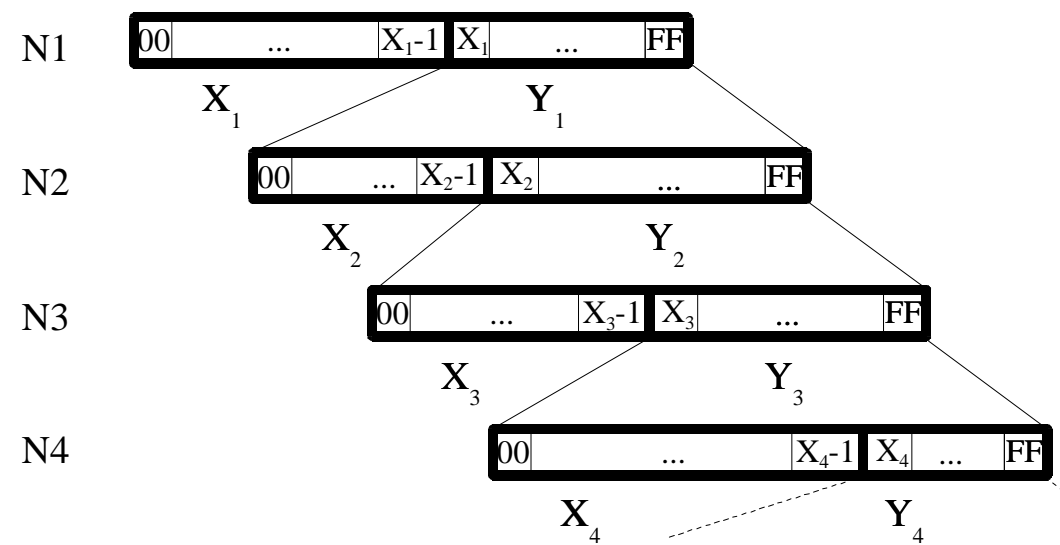

Figura 7.4: Esquema da árvore gerada com a divisão de códigos terminadores e de continuação em valores arbitrários para cada nivel, sem o problema do prefixo "0x00". Todos os grupos de 256 nós filhos de um mesmo nó pai foram agrupados, por nivel, em um único retângulo para melhor visualização.

Desta forma, os cálculos das variáveis são modificados conforme segue abaixo:

$-\ell_{i}$ é a quantidade de códigos com tamanho $i$, ou seja, que terminam no nível $i$ :

$$
\begin{aligned}
\ell_{i} & =X_{i} \cdot \prod_{u=1}^{i-1} Y_{u} \\
& =X_{i} \cdot \prod_{u=1}^{i-1}\left(256-X_{u}\right)
\end{aligned}
$$

$-k_{i}$ é a quantidade total de códigos com tamanho entre 1 e $i$ :

$$
\begin{aligned}
k_{i} & =\sum_{s=1}^{i} \ell_{i} \\
& =\sum_{s=1}^{i} X_{i} \cdot \prod_{u=1}^{s-1} Y_{u} \\
& =\sum_{s=1}^{i} X_{i} \cdot \prod_{u=1}^{s-1}\left(256-X_{u}\right)
\end{aligned}
$$


Com isto, o código $C$ é determinado por:

$$
\begin{aligned}
M(e)=C & =\left(c 1, c 2, \ldots, c_{j}\right), \\
j & =\min \left(u \mid e<k_{u}\right), \text { assumindo } k_{0}=0, \\
r_{j} & =\left(e-k_{j-1}\right) \bmod X_{j}, \\
q_{j} & =\left\lfloor\frac{\left(e-k_{j-1}\right)}{X_{j}}\right\rfloor, \\
r_{i} & =q_{i+1} \bmod Y_{i}, \\
q_{i} & =\left\lfloor\frac{q_{i+1}}{Y_{i}}\right\rfloor, \\
c_{i} & = \begin{cases}r_{i}+X_{i}, & \text { para } 1 \leq i<j ; \\
r_{i}, & \text { para } i=j .\end{cases}
\end{aligned}
$$

portanto, o valor $c$, que interpreta cada um dos bytes do código $C$ como dígitos da base 256 é:

$$
\begin{aligned}
c & =\sum_{i=1}^{j} 256^{j-i} c_{i} \\
& =r_{j}+\sum_{i=1}^{j-1} 256^{j-i} \cdot\left(r_{i}+X_{i}\right)
\end{aligned}
$$

A enumeração $e$ associada ao código $C$ é determinada por:

$$
\begin{aligned}
M^{-1}(C) & =e \\
e & =\left(k_{j-1}+c_{j}\right)+\sum_{i=1}^{j-1}\left(c_{i}-X_{i}\right) \cdot X_{j} \cdot \prod_{u=i+1}^{j-1} Y_{i}
\end{aligned}
$$

Nesta equação a somatória é 0 se o índice inferior for maior que o índice superior e a produtória é 1 em situação análoga.

Note que nesta codificação é possível que $X_{1}=0$, o que significa que não há códigos de tamanho 1 , já que não haveria bytes terminadores no primeiro nível. Fato este que pode se repetir em qualquer outro nível $i$, indicando que não há códigos de tamanho $i$. Em contrapartida, se $X_{i}=256$, isso indica todos os bytes do nível $i$ são terminadores e, portanto, o tamanho máximo de um código é $i$.

É justamente este "controle fino" que faz com que a compressão obtida pela codificação XHuffman-V seja extremamente próxima do ótimo, que é obtido pelo algoritmo original de Huffman na codificação Huffman-256, como poderá ser visto no capítulo 8 nos resultados experimentais, onde a maior diferença percentual entre as duas codificações é de $0,024 \%$.

Com relação a implementação, os valores $X_{i}$ são armazenandos em um vetor, os valores $k_{i}$ são armazenados em outro vetor e o parâmetro $l$ indica o quantidade máxima de níveis, ou seja, o comprimento máximo que um código pode ter. Como usualmente $l \leq 5$ estes vetores são muito propícios de serem mantidos na memória cache do processador, o que mantém o bom desempenho da compressão e descompressão mesmo com estes parâmetros extras. Segue o código C correspondente no apêndice A.2. 


\subsection{Otimização da Compressão Huffman}

Nesta seção descreve-se algumas idéias que permitiram otimizar as escolhas arbitrárias de $X$ na codificação X-Huffman-F ou $X_{i}$ na codificação X-Huffman-V de forma a minimizar o tamanho do arquivo comprimido. Como já visto na seção 7.2, o tamanho $z$ do arquivo comprimido é dado por:

$$
z=\sum_{i=1}^{v}\left|C_{i}\right| \cdot f_{i}
$$

Lembrando que $v$ é o número de palavras no vocabulário, $\left|C_{i}\right|$ é o tamanho do código da $i$-ésima palavra e $f_{i}$ é a frequência da $i$-ésima palavra, sendo que $f_{1} \geq f_{2} \geq \ldots \geq f_{v}$. Em conjunto com o que foi visto em na seção 7.4, pode-se controlar $X$ e $Y$ a fim de obter mais ou menos códigos em cada nível $i$. Então segue que:

$$
z=\sum_{i=1}^{k_{1}} f_{i}+2 \cdot \sum_{i=k_{1}+1}^{k_{2}} f_{i}+3 \cdot \sum_{i=k_{2}+1}^{k_{3}} f_{i}+\ldots+j \cdot \sum_{i=k_{j-1}+1}^{\min \left(v, k_{j}\right)} f_{i}
$$

onde $j$ é o tamanho do código mais comprido. Note que a relação acima vale tanto para X-Huffman$\mathrm{F}$ como para X-Huffman-V, a alteração entre um modelo e outro modifica a quantidade dos $k_{i}$. Note que $\ell_{1}=k_{1}$ e para $2 \leq i \leq n, \ell_{i}=k_{i}-k_{i-1}$.

Portanto, para minimizar o tamanho do arquivo comprimido deve-se escolher o $X$ de X-Huffman$\mathrm{F}$ ou os $X_{i}, 1 \leq i \leq j$ de X-Huffman-V que minimizam a somatória. Uma forma eficiente de se calcular cada parcela desta somatória é através de um vetor $G$ que armazena a soma acumulada das frequências do símbolos de 1 a $i$, portanto:

$$
\begin{aligned}
G & =\left(g_{0}, g_{1}, \ldots, g_{v}\right) \\
g_{i} & =\sum_{u=1}^{i} f_{i} \text { para } 0 \leq i \leq v .
\end{aligned}
$$

a soma acumulada $s_{(a, b)}$ entre dois índices quaisquer $a$ e $b$, com $0 \leq a \leq b \leq v$, de $G$ é:

$$
s_{(a, b)}=g_{b}-g_{a}
$$

desta forma, ao se escolher um $X$ para X-Huffman-F ou os $X_{i}$ de X-Huffman-V, pode-se calcular o tamanho do arquivo comprimido.

Note que o vetor $G$ não necessariamente precisa existir, pois todas as codificações requerem um vocabulário com as respectivas frequências das palavras. Conforme visto na seção 7.2, para se atribuir aos símbolos as respectivas enumerações, basta ordenar as palavras por frequência em ordem não crescente, que é a como é a ordem dos $f_{i}$ decrescentes. Pode-se utilizar o mesmo vetor que contém as frequências $f_{i}$ para guardar estas somas acumuladas $g_{i}$. Neste caso, tanto os valores de $f_{i}$ quanto os valores de $s_{(a, b)}$ podem ser computados em tempo constante.

O algoritmo 7.1 tranforma as frequências $f_{i}$ em $g_{i}$ e o algoritmo 7.2 realiza a tranformação inversa. Esta transformação inversa é opcional, pois:

$$
f_{i}=s_{(i, i-1)}=g_{i}-g_{i-1}, 1 \leq i \leq v
$$



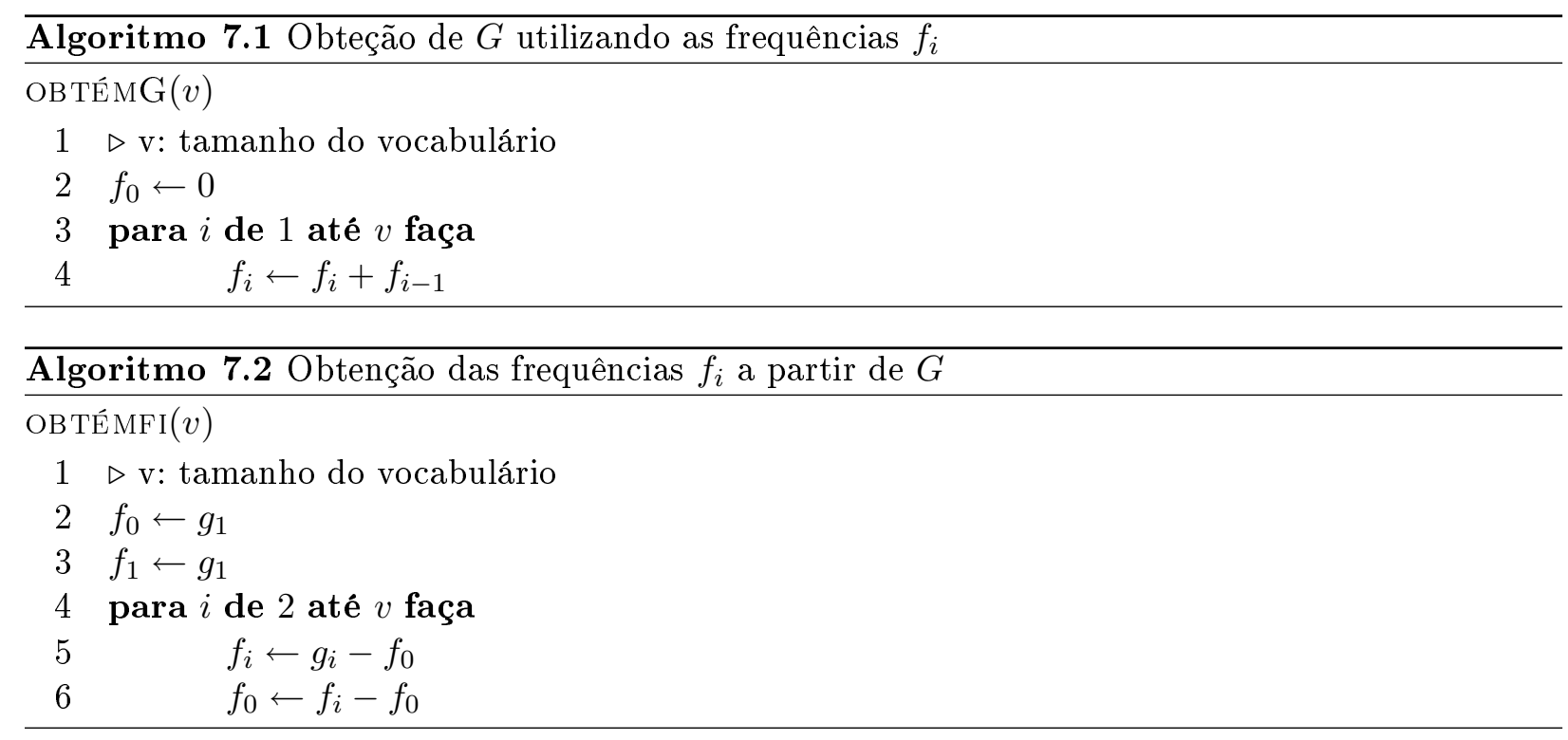

Desta forma o cálculo do tamanho do arquivo comprimido pode ser feito sem necessidade de se alocar um espaço extra $\theta(v)$ e de forma incremental, já que basta iterar em cada nível $i$ até que $k_{i} \geq v$, como pode ser visto no algoritmo 7.3.

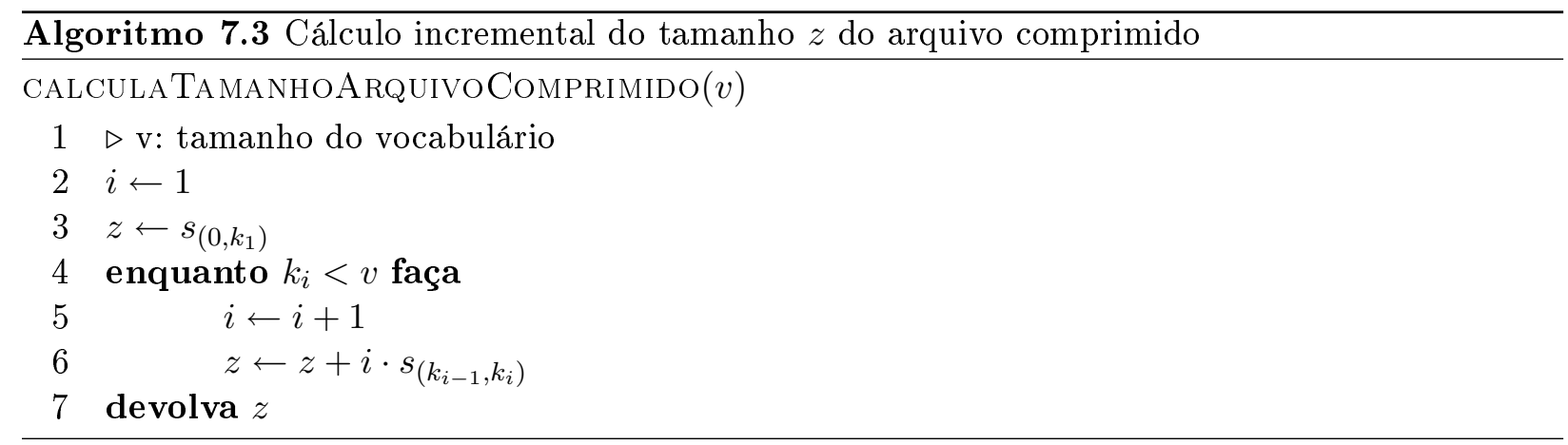

Para otimizar a codificação X-Huffman-F bastar iterar pelos 255 valores possíveis (já que $X \neq 0$, senão não haveria universo de bytes terminadores), calculando para cada um deles o tamanho $z$ do arquivo comprimido. Porém, para a otimização da codificação X-Huffman-V a busca exaustiva tem que gerar $256^{j}$ combinações. Mesmo que seja fixado em 256 o valor do último nível, isto "reduz" para $256^{j-1}$ combinações. Considerando o tamanho do espaço de busca, algumas heurísticas poderão ser adotadas. Por exemplo, supondo que a codificação X-Huffman-F representa a busca na diagonal do hipercubo de dimensão $j$ e aresta 256 , pode-se utilizar o melhor $X$ fixo para ser o ponto inicial da busca ao ponto ótimo da codificação X-Huffman-V, pois conforme será visto nos resultados experimentais do capítulo 8 o comportamento de $X$ e $X_{1}$ são relativamente próximos dependendo da distribuição. Deste ponto inicial pode-se utilizar o método de busca por gradiente verificando a direção onde o tamanho do arquivo comprimido diminui. No apêndice C é apresentado um exemplo desta diagonal e do espaço de busca. 


\section{Capítulo 8}

\section{Resultados Experimentais - Codificações}

Neste capítulo, os algoritmos de compressão baseados nas codificações anteriormente vistas foram aplicados de forma a poder avaliar o desempenho dos diferentes tipos de codificação. A fim de verificar a eficiência das novas codificações propostas foram executados três experimentos. Em cada um deles foram gerados dados simulados seguindo uma distribuição conforme a lei de Zipf (Zip49). Esta lei diz que em um texto com $t$ palavras, ao se ordenar as $v$ palavras distintas deste texto em ordem decrescente de probabilidade, então a probabilidade da primeira palavra é $i^{\theta}$ vezes a probabilidade da $i$-ésima palavra, para todo $i$. Assim:

$$
\begin{gathered}
p_{i}=\frac{1}{i^{\theta} \cdot \sum_{j=1}^{v} \frac{1}{j^{\theta}}} \\
t=\sum_{i=1}^{v} f_{i} \text { e } p_{i}=\frac{f_{i}}{t}
\end{gathered}
$$

em todos os experimentos a distribuição de probabilidade das palavras foi calculada para os seguintes valores de $\theta$ :

$$
\{1 ; 1,01 ; 1,1 ; 1,14 ; 1,2 ; 1,3 ; 1,4 ; 1,5 ; 1,6 ; 1,7 ; 1,8 ; 1,9 ; 2\}
$$

Define-se a constante harmônica $H(\theta)$ :

$$
H(\theta)=\sum_{j=1}^{v} \frac{1}{j^{\theta}}
$$

tem-se:

$$
p_{i}=\frac{1}{i^{\theta} \cdot H(\theta)}
$$

e a frequência (número de ocorrências) da $i$-ésima palavra $f_{i}$ é:

$$
\begin{aligned}
f_{i} & =t \cdot p_{i} \\
& =\frac{t}{i^{\theta} \cdot H(\theta)}
\end{aligned}
$$

Para valores grandes de $\theta$ a frequência rapidamente é arredondada para 0 e pode ser mais difícil obter uma distribuição com o tamanho $v$ desejado. Por isso deve ser tomado cuidado com o arredondamento na distribuição de Zipf gerada. Se toda vez em que $f_{i}<1, f_{i}$ for arredondado para 0 , a distribuição terá um vocabulário com menos que $v$ palavras distintas. Para solucionar tal problema, é calculado o ponto crítico $\alpha$ em que $f_{\alpha}=a$, e $a$ é o menor valor que é arredondado para 
1. Após várias simulações com diferentes regras de arredondamento, foi verificado que $a=0,45$ é o valor que leva a uma melhor aproximação da distribuição de Zipf. Observe que $\alpha$ é o inverso de $a$ por $f$ :

$$
\alpha=\sqrt[\theta]{\frac{t}{a \cdot H(\theta)}}
$$

Por este motivo as modificações a seguir descritas são feitas de forma a uma distribuição de Zipf que melhor se adeque aos parâmetros $t, v$ e $\theta$ desejados. O valor $\alpha$ é utilizado para calcular uma nova constante multiplicativa $t^{\prime}$ para que seja mantida as proporções da distribuição de Zipf. De forma empírica foi determinado que:

$$
\begin{gathered}
t^{\prime}=t-v+\alpha, \text { então } \\
f_{i}=\frac{t^{\prime}}{i^{\theta} \cdot H(\theta)}
\end{gathered}
$$

A figura 8.1 mostra um exemplo entre a distribuição de Zipf gerada sem a correção e com a correção proposta para $v=5.000, t=25.000$ e $\theta=1,5$. No caso sem correção $v=1.289$ e $t=25.000$, um erro de $74,22 \%$ em $v$. No caso com correção $v=5.000$ e $t=25.019$, um erro de $0,076 \%$ para $t$. A figura 8.2 mostra com detalhe os valores iniciais.

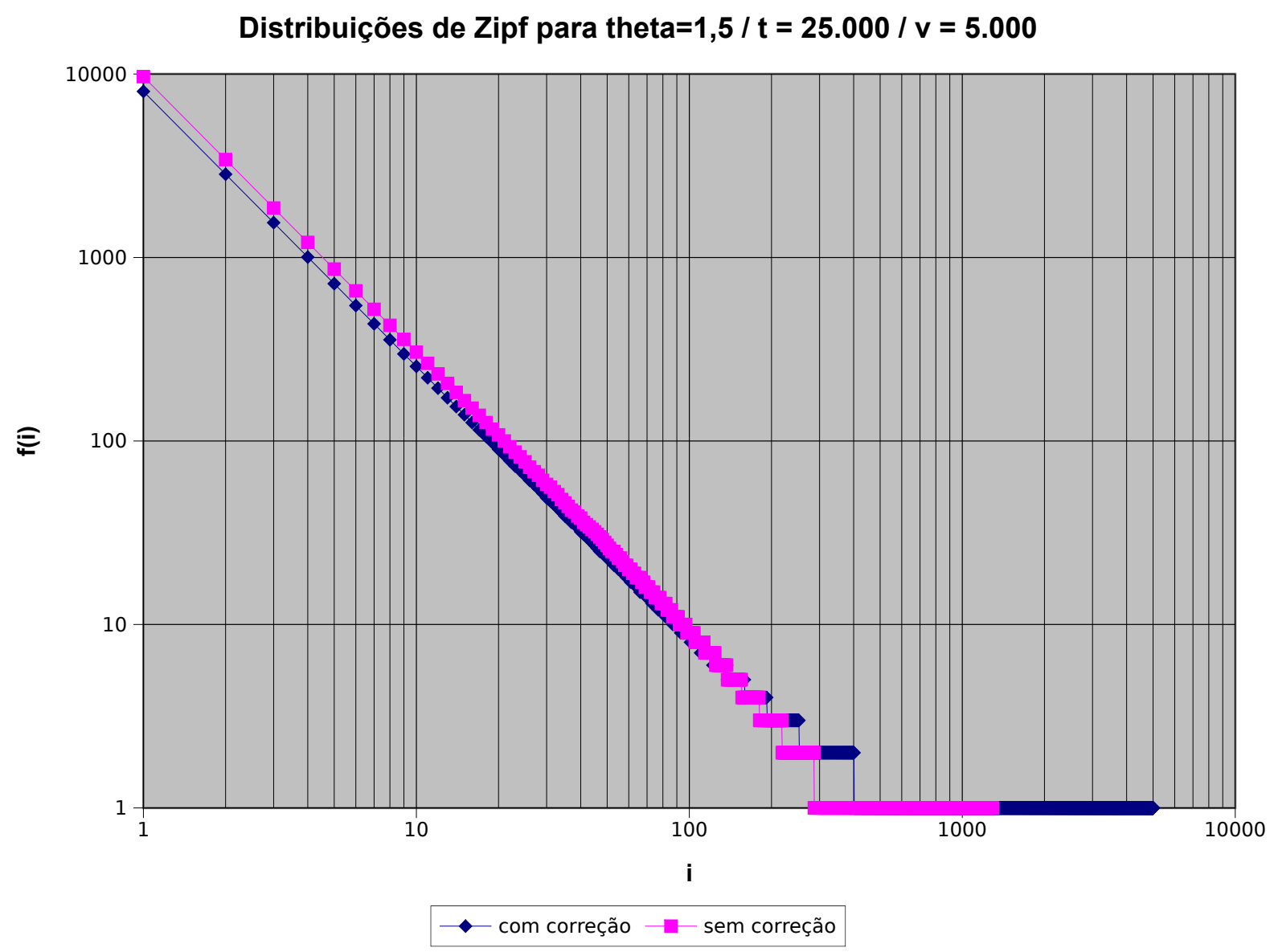

Figura 8.1: Comparação das distribuições de Zipf geradas sem e com a correção proposta para $v=5.000$, $t=25.000$ e $\theta=1,5$.

A análise das figuras mostra que a correção sugerida não distorce a distribuição de Zipf, gerando 


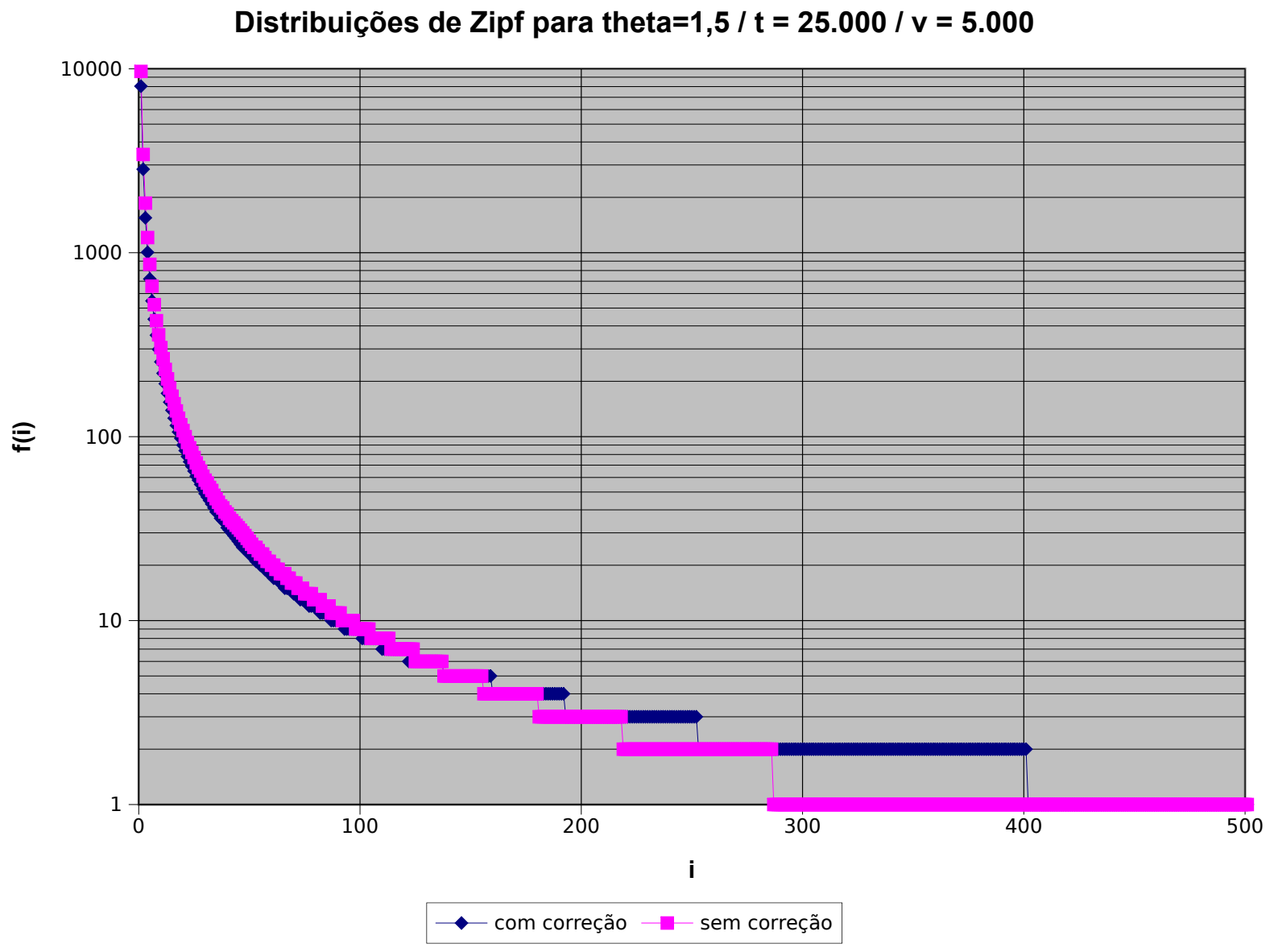

Figura 8.2: Detalhe da comparação das distribuições de Zipf geradas sem e com a correção proposta, para os 500 primeiros valores, para $v=5.000, t=25.000$ e $\theta=1,5$.

dados muito próximos aos parâmetros $t, v$ e $\theta$ requeridos.

\subsection{Descrição dos Experimentos}

Foram realizados três experimentos, descritos nas seções subsequentes, o primeiro analisa uma situação hipotética com $t=500.000$ palavras e um vocabulário $v=100.000$ palavras, denominado "100k/500k". Após verificar a eficácia das compressões propostas foram analisadas duas situações reais do BuscaPé, uma envolvendo as descrições das ofertas do site com $t=240.000 .000$ de palavras e um vocabulário $v=3.000 .000$ de palavras, denominado "3M/240M" e a outra envolvendo as URLs das ofertas do site com $t=120.000 .000$ de palavras e vocabulário $v=10.000 .000$ de palavras, denominado "10M/120M".

A análise dos dados para diversos valores de $\theta$ é útil não só para verificar a distribuição dos dados reais nos experimentos " $3 \mathrm{M} / 240 \mathrm{M}$ " e " $10 \mathrm{M} / 120 \mathrm{M}$ ", como para analisar a robustez das codificações em situações que fujam ao caso de textos de linguagem natural.

Para cada experimento foram gerados os arquivos comprimidos, para cada $\theta$, utilizando cada uma das codificações: Huffman-256 (H-256), Huffman-128 (H-128), X-Huffman-128 (XH-128), XHuffman-F (XH-F) e X-Huffman-V (XH-V). Com os dados obtidos foram gerados os seguintes gráficos:

-gráficos com título "Experimento $<$ nome $>$ - Variação do tamanho dos arquivos comprimidos, $\mathrm{X}$ e X1 ótimos por theta", onde " $<$ nome $>$ " é o nome do experimento, tem-se as seguintes séries de 
dados:

- tamanho comprimido - indica o tamanho de todos os códigos que compõem o arquivo comprimido. Não inclui o tamanho do vocabulário do texto que é idêntico em todas as variantes analisadas. Estes tamanhos foram gerados usando as seguintes codificações:

- XH-F - codificação da seção 7.3 que escolhe o $X$ ótimo dentre as 255 possibilidades para delimitar o universo de valores dos bytes terminadores e de continuação;

- XH-128 - codificação da seção 7.1 que delimita o universo de valores dos bytes terminadores e de continuação em 128;

- XH-V - codificação da seção 7.4 que escolhe um conjunto $X_{i}, 1 \leq i \leq j$ arbitrário para delimitar o universo de valores dos bytes terminadores e de continuação em cada nível $i$. Foram geradas todas as combinações possíveis $\left(256^{3}=16.777 .216\right.$, pois para $j \geq 4$ o último nível foi fixado em 256) de forma a encontrar os $X_{i}$ ótimos, pois o algoritmo de busca por gradiente convergia tão lentamente quanto a geração de todas as combinações já que a superfície a ser buscada próxima ao ponto ótimo é praticamente plana;

- H-128 - codificação que gera a árvore canônica de grau 128 para o algoritmo Huffman-128 da seção 5.1;

- H-256 - codificação que gera a árvore canônica de grau 256 para o algoritmo Huffman-256 da seção 5.1 .

- X ótimo para XH-F - indica o $X$ que minimiza o tamanho do arquivo comprimido utilizando a codificação descrita em 7.3;

- X1 ótimo para XH-V - indica o valor de $X_{1}$ para os valores $X_{i}, 1 \leq i \leq j$ que minimizam o tamanho do arquivo comprimido utilizando a codificação descrita em 7.4.

-gráficos com título "Experimento $<$ nome $>$ - Razões entre tipos de codificação por theta", onde " $<$ nome $>$ " é o nome do experimento, são calculadas as razões dos tamanhos dos arquivos comprimidos gerados em cada uma das codificações comparadas. A codificação em negrito indica a que possui melhor compressão entre as duas codificações comparadas:

- H-128/H-256 - Huffman-128 que obtém a pior compressão contra Huffman-256 que obtém a melhor compressão;

- XH-F/XH-V - X-Huffman-F que obtém boa compressão, levemente melhor que X-Huffman128 , proporcionando acesso aleatório contra X-Huffman-V que obtém a segunda melhor compressão, praticamente idêntica a Huffman-256, portanto é muito próximo de "XH-F/H-256" e de "XH-128/H-256";

- XH-128/H-128 - ambas codificações possuem 128 códigos terminadores e 128 códigos de continuação, porém X-Huffman-128 tem grau máximo 256 contra 128 de Huffman-128;

- XH-V/H-256 - comparação das codificações com melhor compressão;

- XH-F/H-128 - comparação indireta de X-Huffman-F com X-Huffman-128 ao se comparar com "XH-128/H-128", a distância entre estas duas razões é proporcional a "XH-F/XH-128", foi necessário fazer desta maneira, pois caso contrário esta última razão seria sobreposta à razão "XH-V/H-256"; 
- XH-V/H-128 - comparação indireta de X-Huffman-V com Huffman-256, praticamente é muito próximo ao inverso de "H-128/H-256";

Os experimentos foram executados no ambiente Linux do BuscaPé e os dados reais foram extraídos da base de dados disponibilizada aos usuários através do site http://www.buscape.com.br/.

A análise de todos os experimentos encontra-se na seção 8.5, página 55, comparando também as características de cada uma das codificações.

\subsection{Experimento $100 \mathrm{k} / 500 \mathrm{k}$}

Primeiramente foi realizado um experimento denominado " $100 \mathrm{k} / 500 \mathrm{k}$ ", pois foi simulado um texto com $v=100.000$ e $t=500.000$ e os resultados encontram-se nas tabelas $8.1,8.2$ e 8.3 e nas figuras 8.3 e 8.4. A análise destes dados mostra as seguintes características:

- o tamanho dos arquivos comprimidos descresce monotonicamente com $\theta$ independentemente da codificação utilizada;

- a codificação Huffman-128 sempre gera o maior arquivo comprimido, portanto possui a pior taxa de compressão;

- as codificações Huffman-256 e X-Huffman-V geram os menores arquivos comprimidos, com tamanhos praticamente idênticos;

- a razão do tamanho do arquivo comprimido por Huffman-128 com relação à Huffman-256 e X-Huffman-V fica próxima a $90 \%$, ou seja, o arquivo comprimido gerado por estas duas codificações é $10 \%$ menor; isso é compatível com o que foi relatado em (dMNZBY00), pois no referido trabalho a taxa de compressão média de Huffman-256 foi de $30 \%$ contra $33 \%$ de Huffman-128, esta diferença de 3 pontos percentuais representa exatamente os $10 \%$ de diferença no tamanho dos arquivos;

- as codificações X-Huffman-128 e X-Huffman-F geram arquivos comprimidos com tamanhos próximos, com vantagem para X-Huffman-F se $\theta \leq 1,4$. Além disso X-Huffman-F é próximo de Huffman-256 e de X-Huffman-V se $1,1 \leq \theta \leq 1,3$;

- o valor ótimo de $X$ na codificação X-Huffman-F cresce em $1 \leq \theta \leq 1,2$ chegando próximo a 200 e depois decresce em $1,2<\theta \leq 2$, isso se deve ao fato da distribuição ficar cada vez mais desbalanceada conforme $\theta$ aumenta, no início, com $\theta$ próximo de 1 , muitas palavras possuem frequências grandes, o que obriga a reservar um número intermediário bytes terminadores, que vai aumentando $\operatorname{com} \theta$, porém há um limiar entre compressão e quantidade de códigos gerados que limita este crescimento, e no final, com $\theta$ próximo de 2 , poucas palavras são muito frequentes, então a quantidade de bytes terminadores pode diminuir, de forma a gerar a quantidade necessária de códigos mantendo o tamanho máximo do código;

- o valor ótimo de $X_{1}$ na codificação X-Huffman-V cresce rapidamente em $1 \leq \theta \leq 1,1$ chegando próximo a 150 e depois decresce em $1,1<\theta \leq 2$, ficando abaixo de 30, este comportamento tem os mesmos motivos do item anterior, porém $X_{1}$ cai antes do $X$ da codificação X-Huffman$\mathrm{F}$, pois como se pode ver na tabela 8.2 o $X_{2}$ diminui o suficiente aumentar a quantidade de bytes de continuação para gerar a quantidade de bytes suficiente no terceiro nível. Note que 
$X_{3}$ poderia ser 256, já que, para a maioria das combinações, não são necessários mais do que três níveis para gerar os 100.000 códigos distintos;

- as codificações X-Huffman-128 e X-Huffman-F convergiram para tamanhos de arquivos comprimidos bem próximos para $\theta=2$, porém ficaram distantes de Huffman-256 e X-Huffman-V, mas menores que Huffman-128.

\begin{tabular}{|l|c|c|c|c|c|}
\hline$\theta$ & H-128 & H-256 & XH-128 & XH-F & XH-V \\
\hline 1,00 & 1.030 .365 & 925.902 & 966.599 & 960.233 & 926.036 \\
\hline 1,01 & 1.012 .034 & 910.975 & 949.563 & 943.271 & 911.058 \\
\hline 1,10 & 889.266 & 817.990 & 840.176 & 832.971 & 818.042 \\
\hline 1,14 & 852.421 & 790.503 & 807.930 & 801.443 & 790.585 \\
\hline 1,20 & 810.063 & 758.534 & 774.667 & 766.366 & 758.535 \\
\hline 1,30 & 763.853 & 721.923 & 738.771 & 733.113 & 721.983 \\
\hline 1,40 & 736.658 & 698.138 & 716.818 & 713.371 & 698.253 \\
\hline 1,50 & 720.566 & 682.043 & 703.375 & 701.423 & 682.204 \\
\hline 1,60 & 711.318 & 670.887 & 695.245 & 694.204 & 670.889 \\
\hline 1,70 & 704.964 & 662.912 & 690.336 & 689.806 & 662.934 \\
\hline 1,80 & 700.448 & 657.125 & 687.419 & 687.158 & 657.161 \\
\hline 1,90 & 697.174 & 652.855 & 685.707 & 685.582 & 652.905 \\
\hline 2,00 & 694.737 & 649.630 & 684.697 & 684.638 & 649.690 \\
\hline
\end{tabular}

Tabela 8.1: Tamanho do arquivo comprimido para texto com 500.000 palavras e vocabulário de 100.000 palavras.

\begin{tabular}{|l|c|c|c|}
\hline$\theta$ & $\begin{array}{c}X \text { ótimo } \\
(\mathrm{XH}-\mathrm{F})\end{array}$ & $\begin{array}{c}X_{1} \text { ótimo } \\
(\mathrm{XH}-\mathrm{V})\end{array}$ & $\begin{array}{c}\left(X_{1}, X_{2}, X_{3}\right) \\
(\mathrm{XH}-\mathrm{V})\end{array}$ \\
\hline 1,00 & 169 & 96 & $(96,254,186)$ \\
\hline 1,01 & 168 & 106 & $(106,254,206)$ \\
\hline 1,10 & 179 & 146 & $(146,253,219)$ \\
\hline 1,14 & 176 & 138 & $(138,253,198)$ \\
\hline 1,20 & 190 & 125 & $(125,254,255)$ \\
\hline 1,30 & 188 & 106 & $(106,254,206)$ \\
\hline 1,40 & 176 & 87 & $(87,254,169)$ \\
\hline 1,50 & 165 & 72 & $(72,254,145)$ \\
\hline 1,60 & 156 & 59 & $(59,255,253)$ \\
\hline 1,70 & 148 & 49 & $(49,255,228)$ \\
\hline 1,80 & 143 & 42 & $(42,255,213)$ \\
\hline 1,90 & 138 & 35 & $(35,255,198)$ \\
\hline 2,00 & 135 & 30 & $(30,255,188)$ \\
\hline
\end{tabular}

Tabela 8.2: Valores ótimos para texto com 500.000 palavras e vocabulário de 100.000 palavras.

\subsection{Experimento $3 \mathrm{M} / 240 \mathrm{M}$}

O segundo experimento realizado foi denominado " $3 \mathrm{M} / 240 \mathrm{M}$ " simulando um texto com $v=$ 3.000 .000 e $t=240.000 .000$ que são valores próximos aos encontrados nas descrições de ofertas do site BuscaPé.

Além dos valores simulados de $\theta$ também há um ponto extra com dados reais onde $\theta \approx 1,11$. Este valor foi obtido interpolando este ponto com os valores simulados de forma a causar a menor 


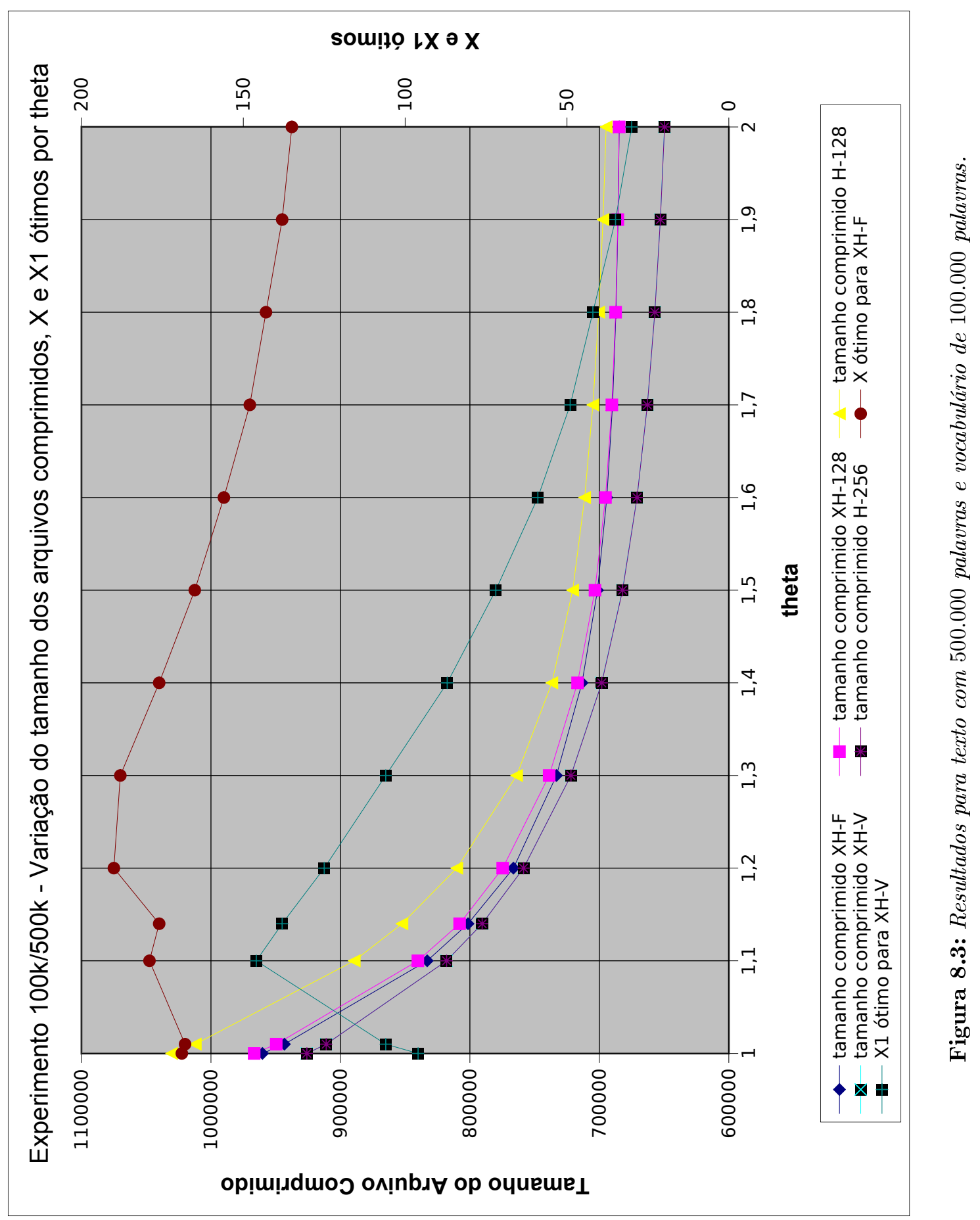




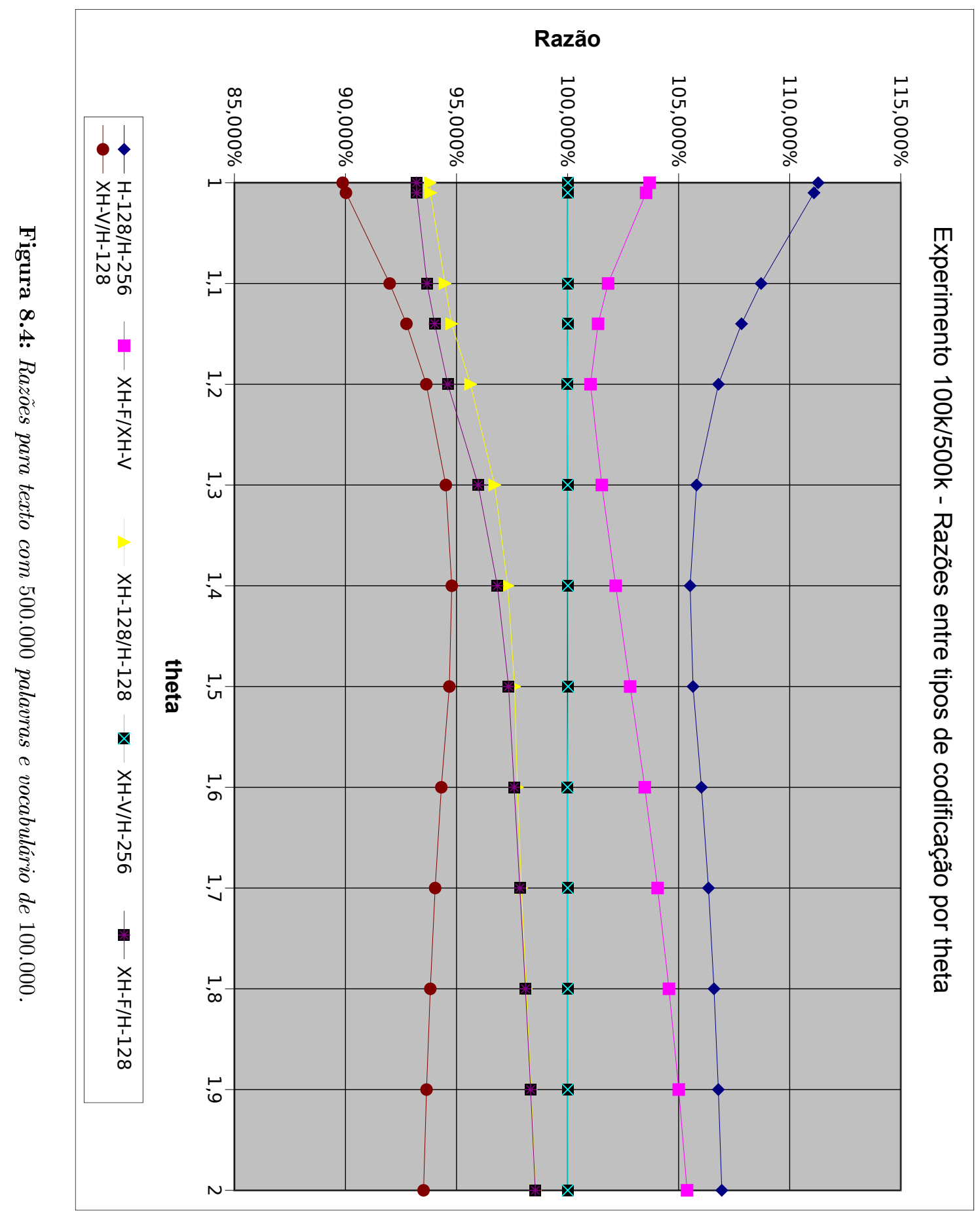




\begin{tabular}{|l|c|c|c|c|c|c|}
\hline$\theta$ & $\frac{H-128}{\mathbf{H - 2 5 6}}$ & $\frac{X H-F}{\mathbf{X H - V}}$ & $\frac{\mathbf{X H - 1 2 8}}{H-128}$ & $\frac{X H-V}{\mathbf{H - 2 5 6}}$ & $\frac{\mathbf{X H - F}}{H-128}$ & $\frac{\mathbf{X H - V}}{H-128}$ \\
\hline 1,00 & $111,282 \%$ & $103,693 \%$ & $93,811 \%$ & $100,014 \%$ & $93,193 \%$ & $89,875 \%$ \\
\hline 1,01 & $111,093 \%$ & $103,536 \%$ & $93,827 \%$ & $100,009 \%$ & $93,205 \%$ & $90,022 \%$ \\
\hline 1,10 & $108,714 \%$ & $101,825 \%$ & $94,480 \%$ & $100,006 \%$ & $93,669 \%$ & $91,991 \%$ \\
\hline 1,14 & $107,833 \%$ & $101,373 \%$ & $94,781 \%$ & $100,010 \%$ & $94,020 \%$ & $92,746 \%$ \\
\hline 1,20 & $106,793 \%$ & $101,032 \%$ & $95,630 \%$ & $100,000 \%$ & $94,606 \%$ & $93,639 \%$ \\
\hline 1,30 & $105,808 \%$ & $101,542 \%$ & $96,716 \%$ & $100,008 \%$ & $95,976 \%$ & $94,519 \%$ \\
\hline 1,40 & $105,518 \%$ & $102,165 \%$ & $97,307 \%$ & $100,016 \%$ & $96,839 \%$ & $94,787 \%$ \\
\hline 1,50 & $105,648 \%$ & $102,817 \%$ & $97,614 \%$ & $100,024 \%$ & $97,343 \%$ & $94,676 \%$ \\
\hline 1,60 & $106,026 \%$ & $103,475 \%$ & $97,740 \%$ & $100,000 \%$ & $97,594 \%$ & $94,316 \%$ \\
\hline 1,70 & $106,344 \%$ & $104,053 \%$ & $97,925 \%$ & $100,003 \%$ & $97,850 \%$ & $94,038 \%$ \\
\hline 1,80 & $106,593 \%$ & $104,565 \%$ & $98,140 \%$ & $100,005 \%$ & $98,103 \%$ & $93,820 \%$ \\
\hline 1,90 & $106,788 \%$ & $105,005 \%$ & $98,355 \%$ & $100,008 \%$ & $98,337 \%$ & $93,650 \%$ \\
\hline 2,00 & $106,943 \%$ & $105,379 \%$ & $98,555 \%$ & $100,009 \%$ & $98,546 \%$ & $93,516 \%$ \\
\hline
\end{tabular}

Tabela 8.3: Razões para texto com 500.000 palavras e vocabulário de 100.000 palavras.

variação possível nas séries analisadas, em especial no tamanho do arquivo comprimido.

Os resultados encontram-se nas tabelas $8.4,8.5$ e 8.6 e nas figuras 8.5 e 8.6. Analisando estes dados pode-se notar as seguintes características:

- o tamanho dos arquivos comprimidos descresce monotonicamente com $\theta$ independentemente da codificação utilizada;

- a codificação Huffman-128 sempre gera o maior arquivo comprimido, portanto possui a pior taxa de compressão;

- as codificações Huffman-256 e X-Huffman-V geram os menores arquivos comprimidos com tamanhos praticamente idênticos;

- as codificações X-Huffman-128 e X-Huffman-F geram arquivos comprimidos com tamanhos próximos, com vantagem para X-Huffman-F se $\theta \leq 1,6$. Além disso, X-Huffman-F é próximo de Huffman-256 e de X-Huffman-V se $1,2 \leq \theta \leq 1,5$;

- a diferença entre o tamanho dos arquivos comprimidos das diversas codificações sempre diminui com o aumento do $\theta$, ficando todos muito próximos para $\theta=2$;

- o valor ótimo de $X$ na codificação X-Huffman-F cresce em $1 \leq \theta \leq 1,4$ chegando próximo a 210 e depois decresce em $1,5 \leq \theta \leq 2$, isso se deve ao fato da distribuição ficar cada vez mais desbalanceada conforme $\theta$ aumenta, porém desta vez o limiar entre compressão e quantidade de códigos gerados se deu mais à frente, em $\theta=1,5$;

- o valor ótimo de $X_{1}$ na codificação X-Huffman-V cresce em quase todos os pontos, exceto nos dados reais $(\theta \approx 1,11)$ e para $1,3 \leq \theta \leq 1,4$, pela tabela 8.5 note como $X_{2}$ diminui com $\theta$ para que a quantidade de códigos gerada aumente, mantendo o tamanho máximo do código em 3, por isso $X_{1}$ praticamente só aumenta, enquanto o $X$ fixo de X-Huffman-F é obrigado a decrescer para continuar gerando a quantidade de códigos necessária mantendo o tamanho máximo do código para não degradar a compressão; 
- a diferença absoluta no tamanho dos arquivos comprimidos com a melhor e pior compressão cai de $70.618 .000(70 \mathrm{M})$ bytes para $\theta=1$ para $3.478 .442(3,4 \mathrm{M})$ bytes para $\theta=2$. No caso dos dados reais a diferença é de 46.163 .818 (46M) bytes, ou seja, mais de $11 \%$, o que é acima da média relatada em (dMNZBY00).

\begin{tabular}{|l|c|c|c|c|c|}
\hline$\theta$ & $\mathrm{H}-128$ & $\mathrm{H}-256$ & $\mathrm{XH}-128$ & $\mathrm{XH}-\mathrm{F}$ & $\mathrm{XH}-\mathrm{V}$ \\
\hline 1,00 & 608.679 .158 & 538.061 .158 & 549.913 .046 & 549.904 .088 & 538.070 .202 \\
\hline 1,01 & 590.243 .469 & 522.421 .680 & 533.361 .923 & 533.356 .849 & 522.428 .075 \\
\hline 1,10 & 460.576 .370 & 413.932 .659 & 419.631 .751 & 418.762 .964 & 413.941 .940 \\
\hline $\mathbf{1 , 1 1}$ & $\mathbf{4 5 1 . 6 6 0 . 6 8 6}$ & $\mathbf{4 0 5 . 4 9 6 . 8 6 8}$ & $\mathbf{4 1 3 . 5 7 0 . 3 6 6}$ & $\mathbf{4 1 2 . 1 4 2 . 8 8 0}$ & $\mathbf{4 0 5 . 4 9 7 . 4 6 4}$ \\
\hline 1,14 & 418.215 .935 & 379.168 .571 & 383.628 .666 & 382.179 .978 & 379.189 .755 \\
\hline 1,20 & 368.541 .391 & 338.450 .857 & 342.307 .976 & 340.059 .834 & 338.465 .122 \\
\hline 1,30 & 314.400 .594 & 295.252 .984 & 298.675 .341 & 295.645 .317 & 295.254 .272 \\
\hline 1,40 & 285.445 .464 & 272.713 .569 & 275.786 .646 & 273.404 .580 & 272.720 .618 \\
\hline 1,50 & 269.558 .092 & 260.528 .316 & 263.296 .866 & 261.859 .960 & 260.528 .600 \\
\hline 1,60 & 260.697 .982 & 253.943 .873 & 256.317 .896 & 255.701 .263 & 253.943 .926 \\
\hline 1,70 & 255.700 .446 & 250.361 .189 & 252.350 .910 & 252.185 .417 & 250.361 .246 \\
\hline 1,80 & 252.856 .205 & 248.401 .740 & 250.068 .886 & 250.055 .283 & 248.402 .272 \\
\hline 1,90 & 251.228 .859 & 247.325 .653 & 248.745 .492 & 248.735 .850 & 247.326 .533 \\
\hline 2,00 & 250.211 .135 & 246.732 .693 & 247.974 .047 & 247.908 .794 & 246.732 .823 \\
\hline
\end{tabular}

Tabela 8.4: Tamanho do arquivo comprimido para texto das descrições das ofertas do site BuscaPé com 240.000 .000 palavras e vocabulário de 3.000 .000 palavras. A linha em negrito representa os dados reais.

\begin{tabular}{|l|c|c|c|}
\hline$\theta$ & $\begin{array}{c}\text { X ótimo } \\
(\mathrm{XH}-\mathrm{F})\end{array}$ & $\begin{array}{c}X_{1} \text { ótimo } \\
(\mathrm{XH}-\mathrm{V})\end{array}$ & $\begin{array}{c}\left(X_{1}, X_{2}, X_{3}\right) \\
(\mathrm{XH}-\mathrm{V})\end{array}$ \\
\hline 1,00 & 126 & 105 & $(105,179,256)$ \\
\hline 1,01 & 129 & 107 & $(107,178,256)$ \\
\hline 1,10 & 147 & 132 & $(132,162,256)$ \\
\hline $\mathbf{1 , 1 1}$ & $\mathbf{1 5 2}$ & $\mathbf{1 2 0}$ & $\mathbf{( 1 2 0 , 2 2 4 , 2 5 4 )}$ \\
\hline 1,14 & 155 & 137 & $(137,158,256)$ \\
\hline 1,20 & 167 & 157 & $(157,162,255)$ \\
\hline 1,30 & 184 & 188 & $(188,198,254)$ \\
\hline 1,40 & 203 & 173 & $(173,115,256)$ \\
\hline 1,50 & 203 & 182 & $(182,98,256)$ \\
\hline 1,60 & 183 & 188 & $(188,84,256)$ \\
\hline 1,70 & 154 & 191 & $(191,76,256)$ \\
\hline 1,80 & 134 & 194 & $(194,67,256)$ \\
\hline 1,90 & 121 & 197 & $(197,57,256)$ \\
\hline 2,00 & 111 & 198 & $(198,54,256)$ \\
\hline
\end{tabular}

Tabela 8.5: Valores ótimos para texto das descrições das ofertas do site BuscaPé com 240.000 .000 palavras e vocabulário de 3.000 .000 palavras. A linha em negrito representa os dados reais.

\subsection{Experimento $10 \mathrm{M} / 120 \mathrm{M}$}

Finalmente, foi realizado o terceiro experimento denominado "10M/120M" simulando um texto $\operatorname{com} v=10.000 .000$ e $t=120.000 .000$ que são valores próximos aos encontrados nas URLs das ofertas do site BuscaPé. Assim sendo, além dos valores simulados de $\theta$ também há um ponto extra com dados reais onde $\theta \approx 1,22$. Este valor foi obtido interpolando este ponto com os valores simulados 


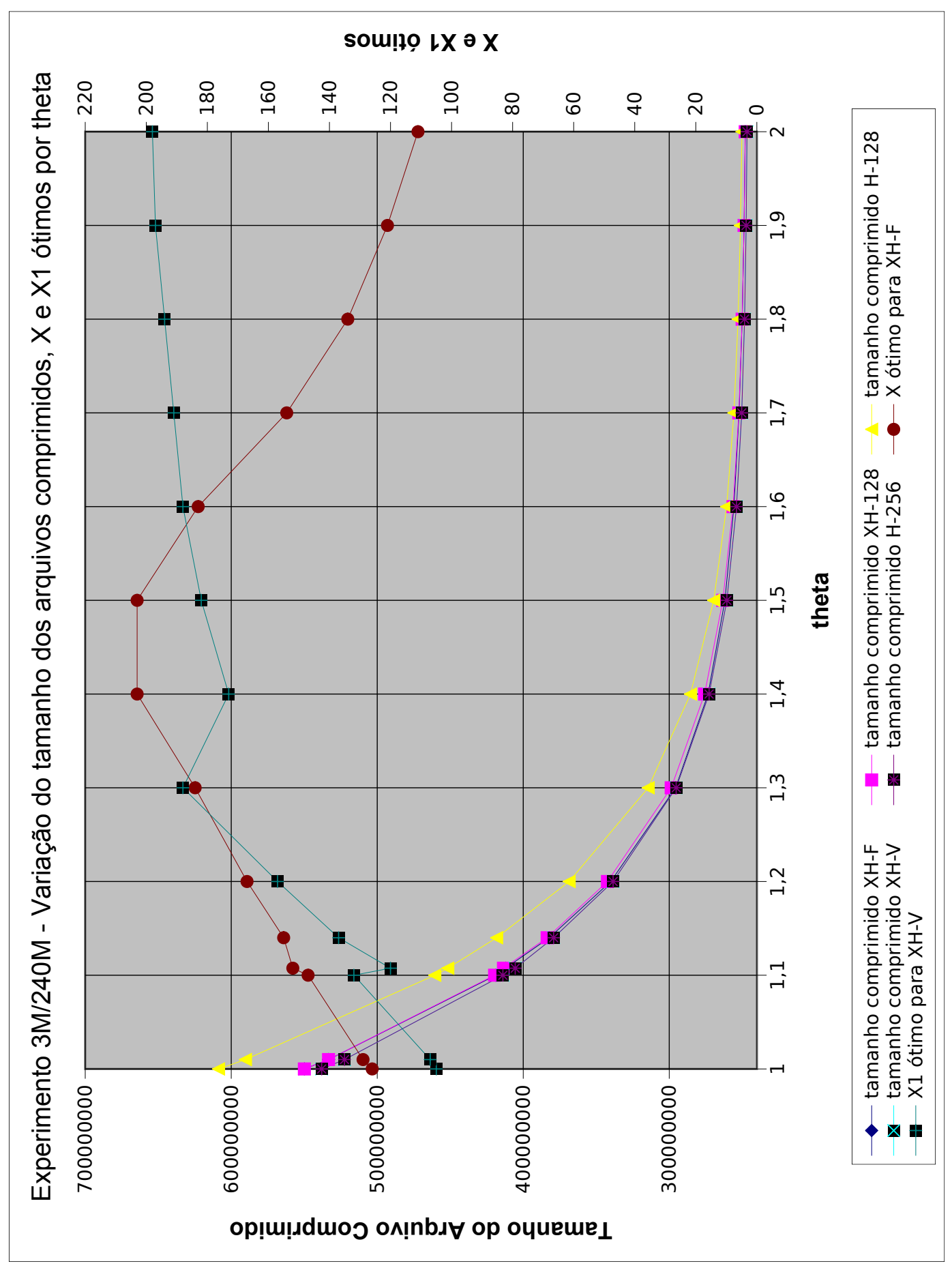

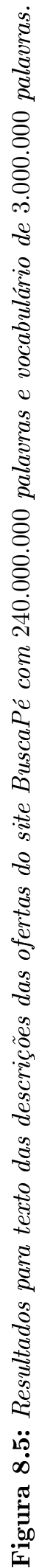




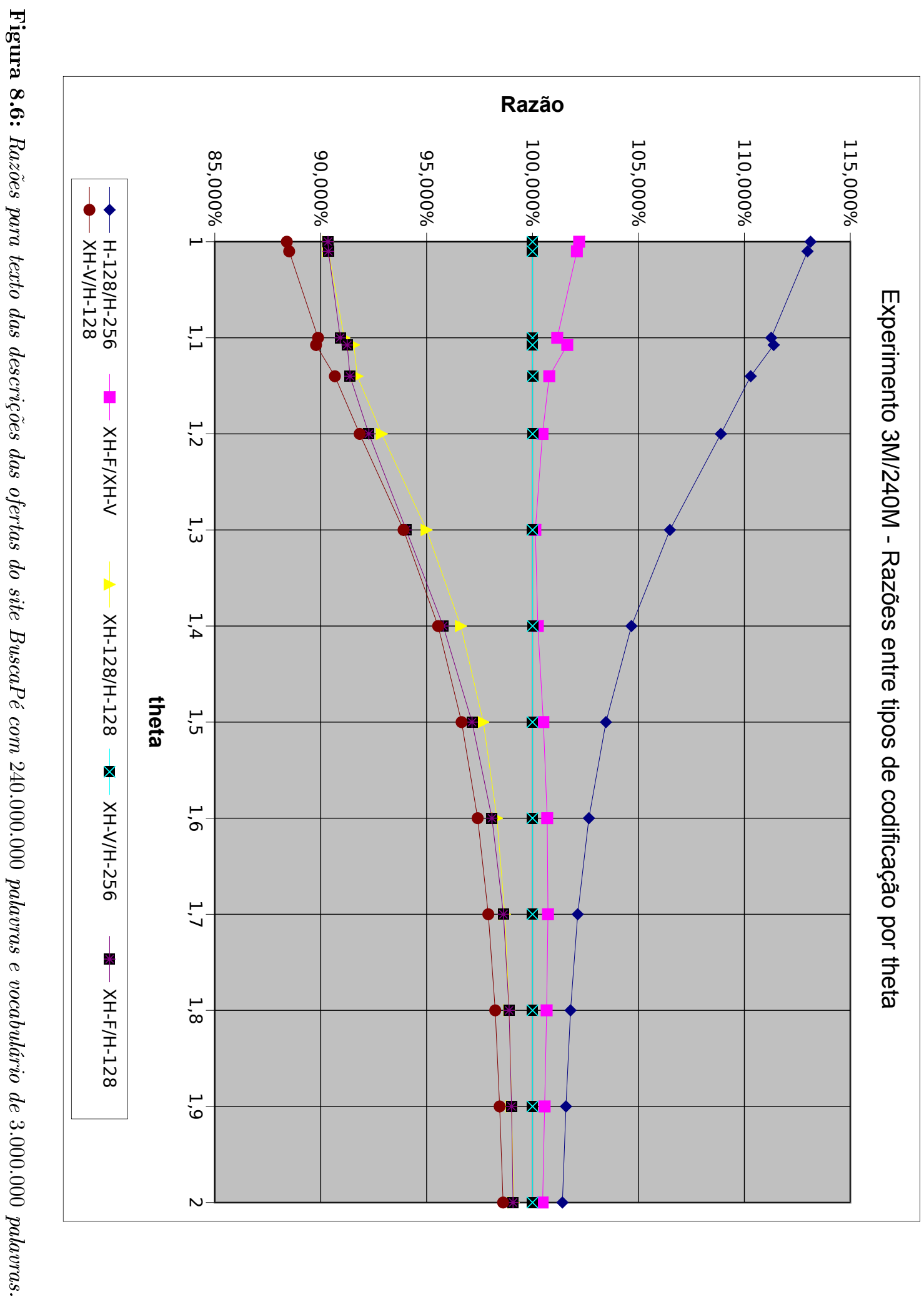




\begin{tabular}{|l|c|c|c|c|c|c|}
\hline$\theta$ & $\frac{H-128}{\mathbf{H - 2 5 6}}$ & $\frac{X H-F}{\mathbf{X H - V}}$ & $\frac{\mathbf{X H - 1 2 8}}{H-128}$ & $\frac{X H-V}{\mathbf{H - 2 5 6}}$ & $\frac{\mathbf{X H - F}}{H-128}$ & $\frac{\mathbf{X H - V}}{H-128}$ \\
\hline 1,00 & $113,125 \%$ & $102,199 \%$ & $90,345 \%$ & $100,002 \%$ & $90,344 \%$ & $88,400 \%$ \\
\hline 1,01 & $112,982 \%$ & $102,092 \%$ & $90,363 \%$ & $100,001 \%$ & $90,362 \%$ & $88,511 \%$ \\
\hline 1,10 & $111,268 \%$ & $101,165 \%$ & $91,110 \%$ & $100,002 \%$ & $90,922 \%$ & $89,875 \%$ \\
\hline $\mathbf{1 , 1 1}$ & $\mathbf{1 1 1 , 3 8 5 \%}$ & $\mathbf{1 0 1 , 6 3 9 \%}$ & $\mathbf{9 1 , 5 6 7 \%}$ & $\mathbf{1 0 0 , 0 0 0 \%}$ & $\mathbf{9 1 , 2 5 1 \%}$ & $\mathbf{8 9 , 7 7 9 \%}$ \\
\hline 1,14 & $110,298 \%$ & $100,789 \%$ & $91,730 \%$ & $100,006 \%$ & $91,383 \%$ & $90,668 \%$ \\
\hline 1,20 & $108,891 \%$ & $100,471 \%$ & $92,882 \%$ & $100,004 \%$ & $92,272 \%$ & $91,839 \%$ \\
\hline 1,30 & $106,485 \%$ & $100,132 \%$ & $94,998 \%$ & $100,000 \%$ & $94,035 \%$ & $93,910 \%$ \\
\hline 1,40 & $104,669 \%$ & $100,251 \%$ & $96,616 \%$ & $100,003 \%$ & $95,782 \%$ & $95,542 \%$ \\
\hline 1,50 & $103,466 \%$ & $100,511 \%$ & $97,677 \%$ & $100,000 \%$ & $97,144 \%$ & $96,650 \%$ \\
\hline 1,60 & $102,660 \%$ & $100,692 \%$ & $98,320 \%$ & $100,000 \%$ & $98,083 \%$ & $97,409 \%$ \\
\hline 1,70 & $102,133 \%$ & $100,729 \%$ & $98,690 \%$ & $100,000 \%$ & $98,625 \%$ & $97,912 \%$ \\
\hline 1,80 & $101,793 \%$ & $100,665 \%$ & $98,898 \%$ & $100,000 \%$ & $98,892 \%$ & $98,239 \%$ \\
\hline 1,90 & $101,578 \%$ & $100,570 \%$ & $99,012 \%$ & $100,000 \%$ & $99,008 \%$ & $98,447 \%$ \\
\hline 2,00 & $101,410 \%$ & $100,477 \%$ & $99,106 \%$ & $100,000 \%$ & $99,080 \%$ & $98,610 \%$ \\
\hline
\end{tabular}

Tabela 8.6: Razões para texto das descrições das ofertas do site BuscaPé com 240.000 .000 palavras e vocabulário de 3.000 .000 palavras. A linha em negrito representa os dados reais.

de forma a causar a menor variação possível nas séries dos tamanhos do arquivo comprimido. Os resultados encontram-se nas tabelas 8.7, 8.8 e 8.9 e nas figuras 8.7 e 8.8. Analisando estas figuras pode-se notar as seguintes características:

- o tamanho dos arquivos comprimidos descresce monotonicamente com $\theta$ independentemente da codificação utilizada;

- a codificação Huffman-128 sempre gera o maior arquivo comprimido, portanto possui a pior taxa de compressão;

- as codificações Huffman-256 e de X-Huffman-V geram os menores arquivos comprimidos com tamanhos praticamente idênticos;

- as codificações X-Huffman-128 e X-Huffman-F geram arquivos comprimidos com tamanhos próximos, com vantagem para X-Huffman-F se $1,1 \leq \theta \leq 1,3$. Neste mesmo intervalo o $\mathrm{X}$ Huffman-F é próximo do Huffman-256 e do X-Huffman-V;

- o valor ótimo de $X$ na codificação X-Huffman-F cresce em $1 \leq \theta \leq 1,3$ chegando próximo a 180 e depois decresce em $1,3<\theta \leq 2$, isso se deve ao fato da distribuição ficar cada vez mais desbalanceada conforme $\theta$ aumenta, porém desta vez o limiar entre compressão e quantidade de códigos gerados se deu em um valor intermediário, em $\theta=1,3$;

- o valor ótimo de $X_{1}$ na codificação $X$ variável cresce rapidamente em $1 \leq \theta \leq 1,1$, exceto pelo pico de 160 nos dados reais $(\theta \approx 1,22)$, e depois decresce em $1,14 \leq \theta \leq 1,4$, até 90 e depois praticamente se estabiliza entre 95 e 100 para $1,5 \leq \theta \leq 2,0$. Pela tabela 8.8 note que inicialmente $(\theta \leq 1,3)$ são utilizados códigos com tamanho máximo 4 , pois é importante que seja gerado o maior número possível de códigos curtos, já que boa parte das palavras possui frequência elevada, posteriormente $(\theta \geq 1,3)$, com poucas palavras de frequência elevada, a necessidade de códigos curtos é menor, inclusive possibilitando que o tamanho máximo diminua para 3 ; 
- as codificações Huffman-128, X-Huffman-128 e X-Huffman-F convergiram para tamanhos de arquivos comprimidos bem próximos, porém ficaram distantes de Huffman-256 e X-Huffman-V para $\theta=2$.

- a diferença absoluta no tamanho dos arquivos comprimidos com a melhor e pior compressão cai de 35.445.194 $(35 \mathrm{M})$ bytes para $\theta=1$ para $9.511 .979(9,5 \mathrm{M})$ bytes para $\theta=2$. No caso dos dados reais a diferença é de $16.955 .802(16,9 \mathrm{M})$ bytes, ou seja, $9,4 \%$, o que é pouco abaixo da média relatada em (dMNZBY00).

\begin{tabular}{|l|c|c|c|c|c|}
\hline$\theta$ & H-128 & H-256 & XH-128 & XH-F & XH-V \\
\hline 1,00 & 315.008 .645 & 279.563 .451 & 288.711 .914 & 288.703 .811 & 279.602 .386 \\
\hline 1,01 & 305.216 .842 & 271.282 .765 & 279.532 .138 & 279.526 .262 & 271.310 .990 \\
\hline 1,10 & 241.244 .946 & 218.692 .130 & 221.784 .117 & 221.446 .412 & 218.692 .600 \\
\hline 1,14 & 222.488 .433 & 203.510 .678 & 205.603 .656 & 205.248 .721 & 203.521 .195 \\
\hline 1,20 & 201.451 .157 & 186.333 .673 & 188.590 .050 & 187.592 .243 & 186.338 .636 \\
\hline $\mathbf{1 , 2 2}$ & $\mathbf{1 9 7 . 2 7 7 . 4 3 3}$ & $\mathbf{1 8 0 . 3 2 1 . 6 3 1}$ & $\mathbf{1 8 4 . 3 2 5 . 3 8 4}$ & $\mathbf{1 8 3 . 3 8 6 . 1 7 6}$ & $\mathbf{1 8 0 . 3 3 3 . 5 5 1}$ \\
\hline 1,30 & 179.128 .515 & 167.627 .705 & 170.792 .481 & 169.990 .549 & 167.650 .010 \\
\hline 1,40 & 166.539 .016 & 156.424 .558 & 160.890 .882 & 160.450 .066 & 156.444 .661 \\
\hline 1,50 & 159.428 .959 & 149.644 .491 & 155.335 .568 & 155.189 .433 & 149.650 .563 \\
\hline 1,60 & 155.399 .497 & 145.674 .730 & 152.185 .783 & 152.169 .985 & 145.684 .570 \\
\hline 1,70 & 153.105 .916 & 143.349 .160 & 150.381 .448 & 150.375 .023 & 143.357 .059 \\
\hline 1,80 & 151.754 .612 & 141.982 .823 & 149.339 .309 & 149.283 .247 & 141.987 .017 \\
\hline 1,90 & 150.846 .615 & 141.176 .728 & 148.733 .718 & 148.609 .488 & 141.179 .364 \\
\hline 2,00 & 150.212 .001 & 140.700 .022 & 148.379 .101 & 148.189 .296 & 140.701 .621 \\
\hline
\end{tabular}

Tabela 8.7: Tamanho do arquivo comprimido para texto das URLs das ofertas do site BuscaPé com 120.000.000 palavras e vocabulário de 10.000 .000 palavras. A linha em negrito representa os dados reais.

\begin{tabular}{|l|c|c|c|}
\hline$\theta$ & $\begin{array}{c}\text { X ótimo } \\
\text { (XH-F) }\end{array}$ & $\begin{array}{c}X_{1} \text { ótimo } \\
(\mathrm{XH}-\mathrm{V})\end{array}$ & $\begin{array}{c}\left(X_{1}, \ldots, X_{j}\right) \\
(\mathrm{XH}-\mathrm{V})\end{array}$ \\
\hline 1,00 & 125 & 68 & $(68,99,255,256)$ \\
\hline 1,01 & 125 & 75 & $(75,107,255,256)$ \\
\hline 1,10 & 149 & 126 & $(126,152,254,256)$ \\
\hline 1,14 & 151 & 126 & $(126,127,254,256)$ \\
\hline 1,20 & 170 & 120 & $(120,91,255,256)$ \\
\hline $\mathbf{1 , 2 2}$ & $\mathbf{1 6 9}$ & $\mathbf{1 5 6}$ & $\mathbf{( 1 5 6 , 8 7 , 2 5 4 , 2 5 6 )}$ \\
\hline 1,30 & 178 & 105 & $(105,50,255,256)$ \\
\hline 1,40 & 170 & 84 & $(84,29,256)$ \\
\hline 1,50 & 152 & 89 & $(89,22,256)$ \\
\hline 1,60 & 135 & 91 & $(91,19,256)$ \\
\hline 1,70 & 122 & 93 & $(93,16,256)$ \\
\hline 1,80 & 112 & 95 & $(95,13,256)$ \\
\hline 1,90 & 105 & 97 & $(97,10,256)$ \\
\hline 2,00 & 99 & 97 & $(97,10,256)$ \\
\hline
\end{tabular}

Tabela 8.8: Valores ótimos para texto das URLs das ofertas do site BuscaPé com 120.000 .000 palavras e vocabulário de 10.000 .000 palavras. A linha em negrito representa os dados reais. 


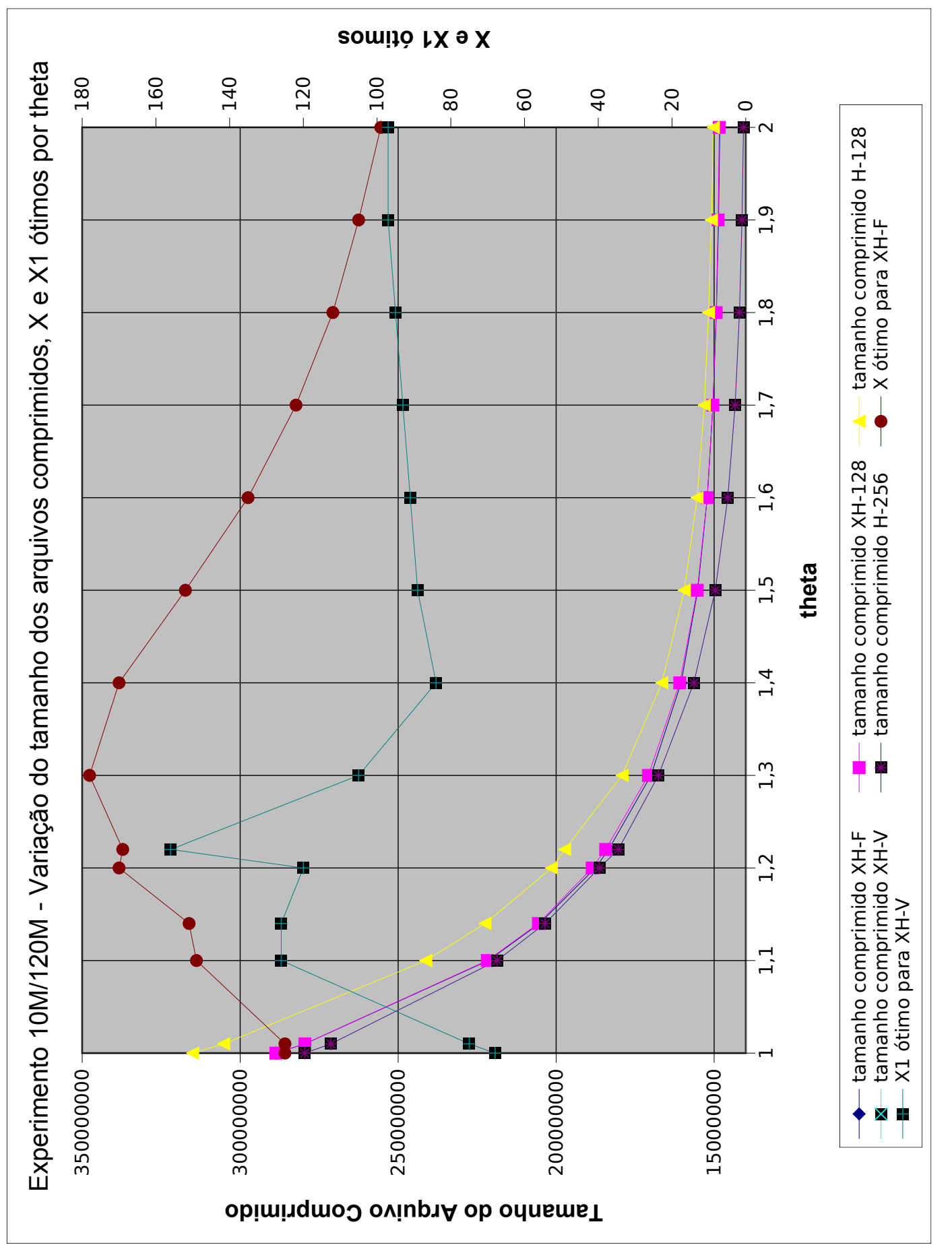

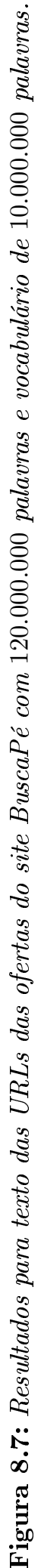




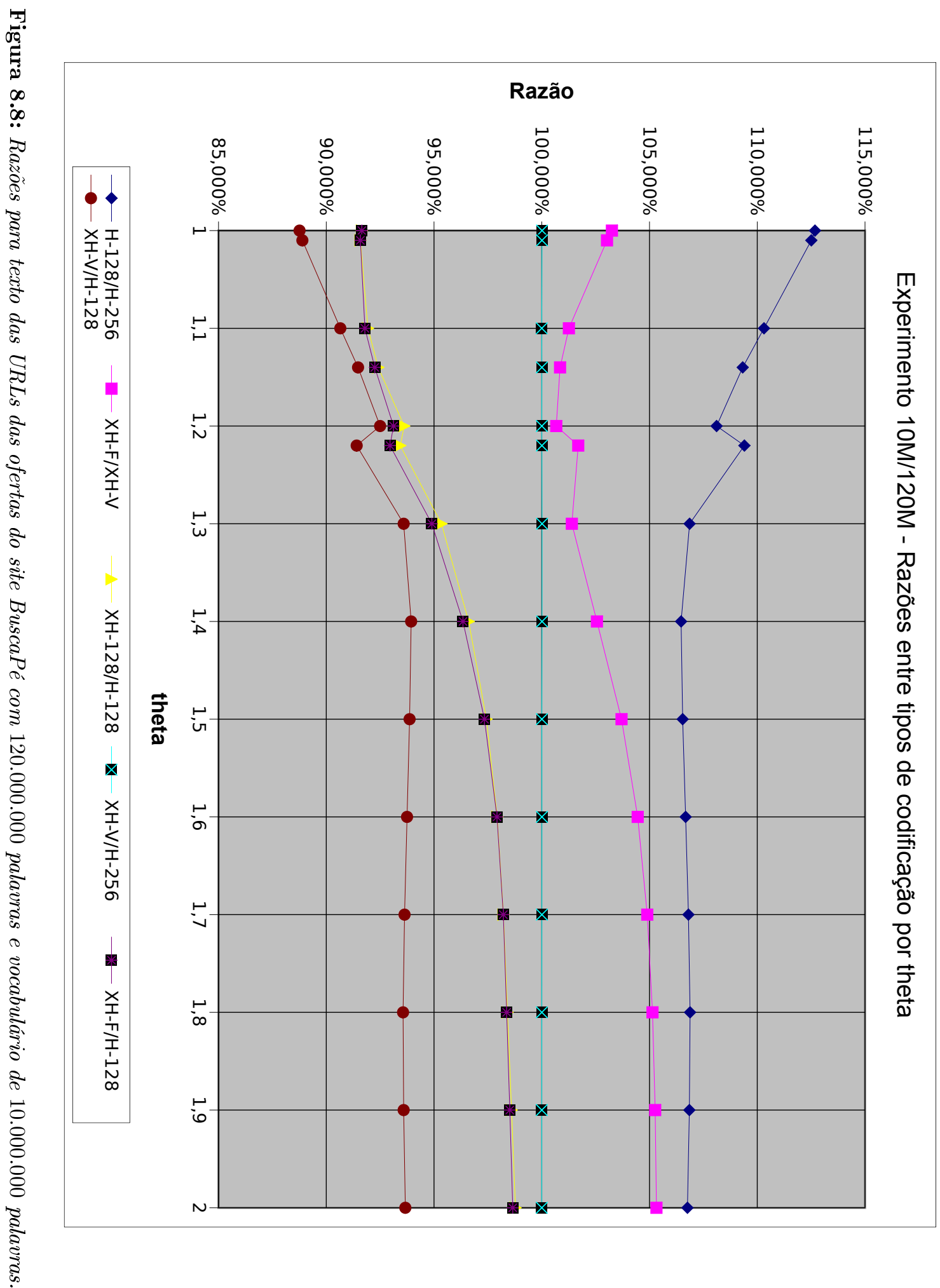




\begin{tabular}{|l|c|c|c|c|c|c|}
\hline$\theta$ & $\frac{H-128}{\mathbf{H - 2 5 6}}$ & $\frac{X H-F}{\mathbf{X H}-\mathbf{V}}$ & $\frac{\mathbf{X H}-\mathbf{1 2 8}}{H-128}$ & $\frac{X H-V}{\mathbf{H - 2 5 6}}$ & $\frac{\mathbf{X H - F}}{H-128}$ & $\frac{\mathbf{X H}-\mathbf{V}}{H-128}$ \\
\hline 1,00 & $112,679 \%$ & $103,255 \%$ & $91,652 \%$ & $100,014 \%$ & $91,649 \%$ & $88,760 \%$ \\
\hline 1,01 & $112,509 \%$ & $103,028 \%$ & $91,585 \%$ & $100,010 \%$ & $91,583 \%$ & $88,891 \%$ \\
\hline 1,10 & $110,313 \%$ & $101,259 \%$ & $91,933 \%$ & $100,000 \%$ & $91,793 \%$ & $90,652 \%$ \\
\hline 1,14 & $109,325 \%$ & $100,849 \%$ & $92,411 \%$ & $100,005 \%$ & $92,251 \%$ & $91,475 \%$ \\
\hline 1,20 & $108,113 \%$ & $100,673 \%$ & $93,616 \%$ & $100,003 \%$ & $93,120 \%$ & $92,498 \%$ \\
\hline $\mathbf{1 , 2 2}$ & $\mathbf{1 0 9 , 4 0 3 \%}$ & $\mathbf{1 0 1 , 6 9 3 \%}$ & $\mathbf{9 3 , 4 3 5 \%}$ & $\mathbf{1 0 0 , 0 0 7 \%}$ & $\mathbf{9 2 , 9 5 9 \%}$ & $\mathbf{9 1 , 4 1 1 \%}$ \\
\hline 1,30 & $106,861 \%$ & $101,396 \%$ & $95,346 \%$ & $100,013 \%$ & $94,899 \%$ & $93,592 \%$ \\
\hline 1,40 & $106,466 \%$ & $102,560 \%$ & $96,609 \%$ & $100,013 \%$ & $96,344 \%$ & $93,939 \%$ \\
\hline 1,50 & $106,538 \%$ & $103,701 \%$ & $97,432 \%$ & $100,004 \%$ & $97,341 \%$ & $93,867 \%$ \\
\hline 1,60 & $106,676 \%$ & $104,452 \%$ & $97,932 \%$ & $100,007 \%$ & $97,922 \%$ & $93,748 \%$ \\
\hline 1,70 & $106,806 \%$ & $104,895 \%$ & $98,221 \%$ & $100,006 \%$ & $98,216 \%$ & $93,633 \%$ \\
\hline 1,80 & $106,882 \%$ & $105,139 \%$ & $98,408 \%$ & $100,003 \%$ & $98,371 \%$ & $93,564 \%$ \\
\hline 1,90 & $106,849 \%$ & $105,263 \%$ & $98,599 \%$ & $100,002 \%$ & $98,517 \%$ & $93,591 \%$ \\
\hline 2,00 & $106,760 \%$ & $105,322 \%$ & $98,780 \%$ & $100,001 \%$ & $98,653 \%$ & $93,669 \%$ \\
\hline
\end{tabular}

Tabela 8.9: Razões para texto das URLs das ofertas do site BuscaPé com 120.000 .000 palavras e vocabulário de 10.000.000 palavras. A linha em negrito representa os dados reais.

\subsection{Análise dos Experimentos}

Conforme visto nas seções 8.2 a 8.4, todos os experimentos revelam que, consistentemente, as melhores codificações, com relação à taxa de compressão, são Huffman-256 e X-Huffman-V, com resultados praticamente idênticos, lembrando, no entanto que são métodos de codificação que não possuem auto-sincronismo, seguidas de X-Huffman-F e X-Huffman-128 relativamente próximas e, por fim e mais distante, Huffman-128. Porém, com relação ao acesso aleatório, as codificações auto-sincronizadas são: Huffman-128, X-Huffman-128 e X-Huffman-F; as demais, Huffman-256 e $\mathrm{X}-H u f f m a n-\mathrm{V}$ podem requerer que se volte ao início do arquivo ou do bloco para se sincronizarem.

Todas as codificações permitem a busca comprimida direta e fazem dupla varredura do texto. Quanto ao consumo de memória, tanto para compressão como para descompressão, as melhores codificações são X-Huffman-128, X-Huffman-F e X-Huffman-V, pois Huffman-256 e Huffman-128 precisam gerar a árvore de Huffman canônica com grau 256 ou 128, respectivamente.

A codificação mais simples é a X-Huffman-128, pois só precisa das frequências ordenadas, já que codifica apenas manipulando os bits da posição correspondente à ordem da palavra, depois é a $\mathrm{X}$-Huffman-F, que além disso precisa do cálculo do parâmetro $X$ que é feito comparando o tamanho calculado do arquivo comprimido para cada uma das 255 possibilidades, em seguida as codificações Huffman-256 e Huffman-128 precisam gerar a árvore canônica e, por fim, X-Huffman-V que requer uma busca em um espaço multidimensional ou a geração de todas as combinações $\operatorname{dos} X_{i}, 1 \leq i \leq j$.

A decodificação mais simples é a X-Huffman-128, que simplesmente rearranja os bits dos códigos para obter a posição do símbolo no vetor ordenado por frequências, depois a X-Huffman-F que só precisa do parâmetro $X$, seguida por X-Huffman-V que precisa dos parâmetros $X_{i}, 1 \leq i \leq j$ e, finalmente as codificações Huffman-256 e Huffman-128 que precisam da árvore canônica. Estes dados podem ser vistos na tabela 8.10.

Através dos dados da tabela 8.10, pode-se classificar as codificações quanto à utilidade:

- melhor compressão - Huffman-256 e X-Huffman-V quando tiver melhor resolvida sua otimização, pois terá menor consumo de memória; 


\begin{tabular}{|c|c|c|c|c|c|}
\hline Critérios & H-256 & XH-V & XH-F & XH-128 & H-128 \\
\hline $\begin{array}{c}\text { Taxa de } \\
\text { Compressão }\end{array}$ & Melhor & Melhor & Boa & Boa & Pior \\
\hline $\begin{array}{c}\text { Acesso } \\
\text { Aleatório }\end{array}$ & Restrito & Restrito & Sim & Sim & Sim \\
\hline $\begin{array}{c}\text { Auto- } \\
\text { Sincronizado }\end{array}$ & Não & Não & Sim & Sim & Sim \\
\hline $\begin{array}{c}\text { Consumo de } \\
\text { Memória }\end{array}$ & Alto & Baixo & Baixo & Baixo & Alto \\
\hline $\begin{array}{c}\text { Complexidade da } \\
\text { Codificação }\end{array}$ & Média & Alta & Baixa & $\begin{array}{c}\text { Muito } \\
\text { Baixa }\end{array}$ & Média \\
\hline $\begin{array}{c}\text { Complexidade da } \\
\text { Decodificação }\end{array}$ & Alta & Média & Baixa & $\begin{array}{c}\text { Muito } \\
\text { Baixa }\end{array}$ & Alta \\
\hline
\end{tabular}

Tabela 8.10: Comparação das codificações com relação aos resultados dos experimentos.

- busca comprimida, acesso aleatório e menor uso de memória para compressão e descompressão - X-Huffman-F e X-Huffman-128. Ambas codificações tiveram resultados muito bons, especialmente se comparados com Huffman-128, que é outra codificação auto-sincronizada, os ganhos chegam próximos a $10 \%$ dependendo do caso. Nos dados reais os ganhos foram de $7 \%$ para URLs e $9 \%$ para descrições de ofertas. No desempate o X-Huffman-F leva ligeira vantagem sobre X-Huffman-128 por comprimir um pouco melhor os arquivos. 


\section{Capítulo 9}

\section{Resultados Experimentais - Compressor Xhuff}

A fim de verificar na prática as codificações propostas foi implementado um compressor Huffman denominado xhuff. Este compressor está em sua fase $\beta$ otimizada para arquivos texto em linguagem natural, sem bytes "0x00". A intenção é que seja disponibilizada uma versão estável para quaisquer tipos de arquivos. O compressor atualmente comprime e descomprime corretamente e calcula o $X$ ótimo do algoritmo X-Huffman-F, porém não está totalmente otimizado para obter a melhor performance na compressão e descompressão e sua busca é realizada através do algoritmo BoyerMoore padrão. A busca poderia ser melhorada utilizando o algoritmo de Sunday para padrões e para multi-padrões utilizando o Shift-And.

\subsection{Experimento Comparativo de Xhuff, gzip e bzip2}

Os experimentos utilizaram três tipos de informações do BuscaPé: ("OFR") as descrições das ofertas incluindo caracteres acentuados e todos os separadores (colchetes, parênteses, chaves, asterisco, barra, etc.); ("DNR") as descrições das ofertas normalizadas, ou seja, apenas com caracteres de "a" a "z" (apenas letras minúsculas) e números de "0" a "9" e ("URL") as URLs das ofertas. Foram realizadas 10 buscas com padrões aleatórios de cada um dos arquivos, utilizando zgrep e bzgrep para, respectivamente, gzip e bzip2. Estes dados foram obtidos utilizando um computador Linux com AMD Athlon 2.0GHz e 8GB de memória. Os resultados podem ser vistos na tabela 9.1.

A análise da tabela 9.1 mostra que a melhor taxa de compressão é sempre obtida pelo bzip2, porém com tempos de compressão, descompressão e busca sempre piores. O gzip tem a melhor relação entre taxa de compressão e tempos de compressão e descompressão. Já o xhuff obtém os melhores tempos de busca, chegando a ser 2 vezes mais rápido que o gzip e até 20 vezes mais rápido que o bzip2. O xhuff apenas necessita encontrar a palavra buscada no vocabulário do arquivo

\begin{tabular}{|c|c|c|c|c|}
\hline $\begin{array}{c}\text { Tipo de } \\
\text { Compressão }\end{array}$ & $\begin{array}{c}\text { Taxa de } \\
\text { Compressão }\end{array}$ & $\begin{array}{c}\text { Tempo de } \\
\text { Compressão }\end{array}$ & $\begin{array}{c}\text { Tempo de } \\
\text { Descompressão }\end{array}$ & $\begin{array}{c}\text { Tempo de } \\
\text { Busca }\end{array}$ \\
\hline \multirow{3}{*}{ xhuff } & OFR: 42,1\% & OFR: 139,9s & OFR: $20,6 \mathrm{~s}$ & OFR: 3,4s \\
& DNR: $36,4 \%$ & DNR: $130,6 \mathrm{~s}$ & DNR: 15,8s & DNR: 2,6s \\
& URL: $45,6 \%$ & URL: $126,7 \mathrm{~s}$ & URL: 25,9s & URL: $\mathbf{6 , 5 s}$ \\
\hline \multirow{3}{*}{ gzip } & OFR: $30,4 \%$ & OFR: 51,9s & OFR: 10,4s & OFR: $7,7 \mathrm{~s}$ \\
& DNR: $27,7 \%$ & DNR: 48,1s & DNR: 8,6s & DNR: $6,9 \mathrm{~s}$ \\
& URL: $8,4 \%$ & URL: 23,9s & URL: 9,8s & URL: $6,7 \mathrm{~s}$ \\
\hline \multirow{3}{*}{ bzip2 } & OFR: 22,2\% & OFR: $284,7 \mathrm{~s}$ & OFR: $73,1 \mathrm{~s}$ & OFR: $60,3 \mathrm{~s}$ \\
& DNR: $\mathbf{2 1 , 2 \%}$ & DNR: $206,5 \mathrm{~s}$ & DNR: $62,0 \mathrm{~s}$ & DNR: $53,5 \mathrm{~s}$ \\
& URL: $\mathbf{5 , 9 \%}$ & URL: $946,1 \mathrm{~s}$ & URL: $73,7 \mathrm{~s}$ & URL: $53,9 \mathrm{~s}$ \\
\hline
\end{tabular}

Tabela 9.1: Comparação das compressões xhuff, gzip e bzip2 
comprimido e buscar pelo código em questão, verificando a cada ocorrência se o código está corretamente sincronizado, já os demais algoritmos são obrigados a descomprimir praticamente todo o arquivo que, conforme citado na seção 4.3, página 12, é o maior gargalo das técnicas de compressão Ziv-Lempel. O tempo de compressão do xhuff comparado ao gzip é praticamente o dobro por causa da dupla varredura do arquivo. O tempo de descompressão do xhuff pode ser melhorado, pois na implementação atual os dados descomprimidos são escritos diretamente no arquivo enquanto que o ideal seria escrevê-los em um buffer e utilizá-lo para escrever uma página completa de uma só vez. Os tempos de busca do xhuff também podem ser melhorados, pois a execução do grep para a busca dos padrões no arquivo descomprimido foi ainda mais rápido (OFR: 0,9s, DNR: 0,8s e URL: $1,9 \mathrm{~s})$. O arquivo de URLs, por se tratar de dados que não seguem o padrão de textos em linguagem natural, mostra vários pontos: a taxa de compressão do xhuff foi péssima comparada aos demais compressores, pois está otimizado para textos em linguagem natural; o bzip2 demorou um tempo absurdo para conseguir comprimir o arquivo, provavelmente porque diversas cadeias fossem muito similares, o que fez com que a comparação das strings ficasse muito lenta. Finalmente, o tempo de busca do xhuff, mesmo percorrendo um arquivo comprimido mais que 5 vezes maior, ainda assim, foi levemente mais rápido que o gzip. 


\section{Capítulo 10}

\section{Conclusão}

Foram estudados algoritmos que podem ser utilizados em um sistema de recuperação de informação que realize buscas eficientes em uma coleção de documentos comprimida, com limitações de memória.

Foi feita uma revisão de diversos sistemas de indexação que podem ser utilizados para este fim, sendo que o mais econômico no uso de memória é o arquivo invertido por blocos que, em uma coleção comprimida, necessita fazer buscas eficientes nos blocos comprimidos para completar a operação de busca.

Foram revistos diversos métodos de busca de padrão em textos comprimidos, com destaque para um casamento muito adequado, onde compressão Huffman se mostra mais eficiente para coleções grandes, além de integrar-se melhor com os vocabulários dos índices incompletos do arquivo invertido e arquivo invertido por blocos. Este casamento é analisado nos livros Modern Information Retrieval (BYRN99) e Managing Gigabytes (WMB99) e nos artigos de Moura et al., inicialmente em (MNZ97), e, na sua forma final, em (dMNZBY00). Apesar de ser um assunto bastante amadurecido, este trabalho apontou algumas correções e introduziu as seguintes melhorias através das novas codificações propostas:

- taxa de compressão - os ganhos das codificações auto-sincronizadas foram de $7 \%$ a $9 \%$ nos experimentos com dados reais, o que praticamente elimina as perdas do Huffman-128 com relação ao Huffman-256 relatadas em (dMNZBY00), porém mantendo a busca comprimida. Estes ganhos foram originados com a possibilidade de mais códigos de menor comprimento e com o estudo da otimização da compressão;

- consumo de memória e tempo de compressão - foram reduzidos através da substituição da geração da árvore canônica pela utilização das codificações propostas. O algoritmo de Moffat (MK95) percorre 3 vezes o vetor de frequências para obter apenas o tamanho dos códigos a serem utilizados na árvore canônica, se as frequências já estiverem ordenadas;

- tempo de descompressão - foi reduzido através do acesso direto gerado pelas codificações propostas, já que o código transformado na enumeração correspondente indica diretamente a posição da palavra no vocabulário;

Finalmente, foi desenvolvido o protótipo de compressor xhuff que mostrou tempos de busca de padrão em arquivos comprimidos até 2 vezes mais rápidos que os compressores consgrados gzip e bzip2 pelo fato de não ser necessário descomprimir o arquivo, mas apenas buscar pelo código do padrão no texto comprimido. 


\subsection{Trabalhos Futuros}

Ademais os mapeamentos aqui propostos podem ser utilizados em outras aplicações, não necessariamente ligadas à compressão de dados ou recuperação de informação. Estes mapeamentos podem também ajudar em outras formas de compressão, além das vistas aqui, pois tanto no LZ77 quanto no LZ78 são utilizados inteiros de tamanho variável para representar o bloco referenciado. Em diversas implementações, como a de Navarro e Tarhio (NT00), os inteiros são codificados em bytes, sendo o bit mais significativo utilizado para indicar o último byte da sequência. Esta solução pode ser modificada da mesma forma que a codificação X-Huffman-F generaliza a codificação X-Huffman-128, o que provavelmente deve levar a compressões e descompressões mais eficientes.

Apesar de codificação Huffman ser um assunto antigo e das referências citadas serem, em sua maioria, por volta de 2.000 , os resultados obtidos continuam atuais; um exemplo é o capítulo Search and Retrieval of Compressed Text do livro Advances in Computers, Volume 63 - Parallel, Distributed and Pervasive Computing (Zel05). Este capítulo é fortemente baseado nos artigos de Zhang et al. (ZTSM04; ZTSM05) onde são propostas uma modificação da compressão LZW que se assemelha bastante com a ideia de um "vocabulário" compartilhado pela coleção de documentos, tal como na compressão Huffman, porém neste caso a árvore da compressão LZW que é compartilhada. Mesmo após a proposta de diversas variações na compressão LZW os resultados obtidos são piores do que os conhecidos (WMB99) e Moura et al. (dMNZBY00), o que ressalta ainda mais os resultados obtidos no presente trabalho.

Outro ponto em aberto é a questão de como são feitas as quebras entre palavras e separadores. No caso das URLs provavelmente deve ser melhor utilizar o caracter "/" ou "." como separador implícito e não o espaço em branco, padrão nos textos. Esta é uma dificuldade para a implementação de um compressor Huffman genérico. Após otimizar o compressor xhuff para URLs e repetir o experimento os resultados da tabela 9.1 foram melhorados para uma taxa de compressão de $45,6 \%$ para $28,7 \%$, o tempo de compressão baixou de $126,7 \mathrm{~s}$ para $65,8 \mathrm{~s}$, o tempo de descompressão baixou de $25,9 \mathrm{~s}$ para $21,4 \mathrm{~s}$ e o tempo de busca baixou de $6,5 \mathrm{~s}$ para $3,9 \mathrm{~s}$. Todos os ganhos se devem à geração de um arquivo comprimido bem menor que o obtido sem a otmização para URLs, pois estava utilizando regras de separação de textos. Estes dados mostram o quanto é importante a modelagem da separação do texto comprimido para a codificação Huffman. Uma ideia seria a de procurar dados preliminares no texto, tal como sugerido por Song et al. em (SEN07) onde é utilizado um algoritmo de Ben Stephenson (Ste07) para encontrar a substring que mais "contribui" em um texto. Porém, o algoritmo proposto, se aplicado iterativamente, pode não produzir, por exemplo, as $k$-substrings que mais contribuem. Obviamente estes fatores são de maior preocupação para a compressão do texto, pois para manter o casamento entre busca e compressão é necessário que a separação das palavras na busca e compressão seja a mesma. Caso contrário perde-se a simplicidade de realizar a busca do padrão comprimido no texto comprimido, uma das principais vantagens da arquitetura estudada no presente trabalho.

Finalmente, outro ponto que pode ser explorado é o paralelismo que pode ser obtido através da utilização das novas codificações propostas. O texto pode ser dividido em blocos independentes, de forma que diversos processadores possam realizar simultaneamente a primeira varredura do texto, a fim de se obter as frequências dos símbolos. Depois desta etapa é necessário realizar a junção dos resultados obtidos nos diversos processos somando as frequências dos símbolos iguais, com isto se obtém o vocabulário da coleção. Logo após, deve-se ordenar este vocabulário segundo a 
frequência dos símbolos, e esta operação também pode ser realizada em paralelo novamente. Como não há necessidade de gerar a árvore Huffman para se obter os códigos, outro processamento que é essencialmente sequencial, basta iniciar a codificação do texto, a qual também pode ser realizada em paralelo utilizando os mesmos blocos de texto inicialmente definidos. Ou seja, as codificações aqui propostas eliminam uma parte sequencial significativa no processo paralelo de compressão Huffman. Espera-se que em uma versão futura o xhuff tenha também uma versão paralela para confirmar a real efetividade de tais ganhos teóricos. 


\section{Apêndice A}

\section{Listagens dos Programas em C das Codificações Propostas}

Este apêndice contém as listagens dos programas C discutidos nas seções 7.3 e 7.4.

\section{A.1 Codificação X-Huffman-F}

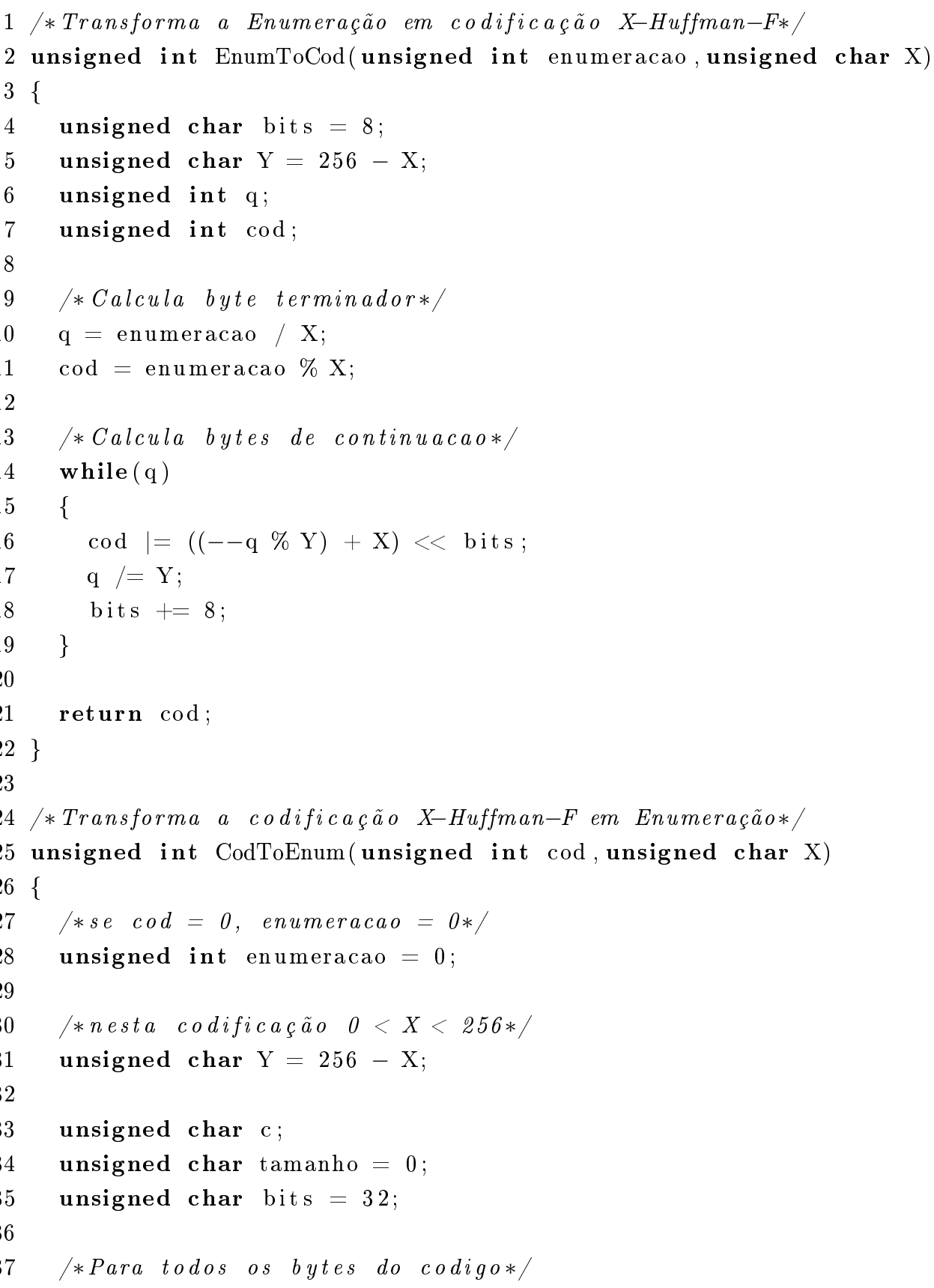




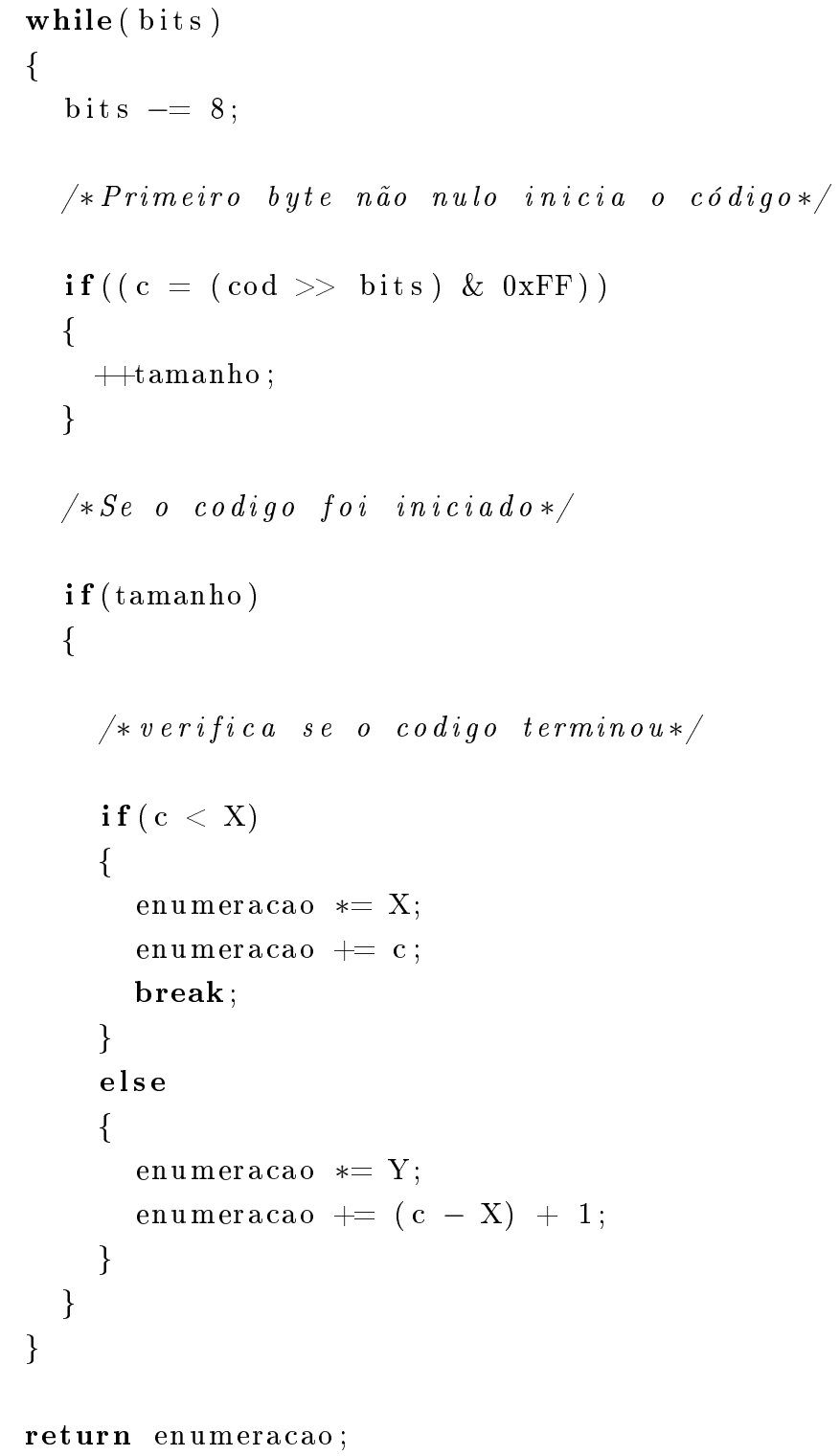

\section{A.2 Codificação X-Huffman-V}

1 /*Transforma a Enumeração em codificação X-Huffman-V*/

2

3 unsigned int EnumToCod(unsigned int enumeracao, unsigned char $* \mathrm{X}$, unsigned int $* \mathrm{k}$, unsigned char 1)

4\{

/*Y tem que ser short, pois X pode ser 0 (zero)*/

unsigned short int $\mathrm{Y}$;

unsigned char tamanho $=0$;

unsigned char ct;

unsigned char bits $=8$;

unsigned int $q$;

unsigned int cod;

/*Determina o tamanho do codigo*/ 


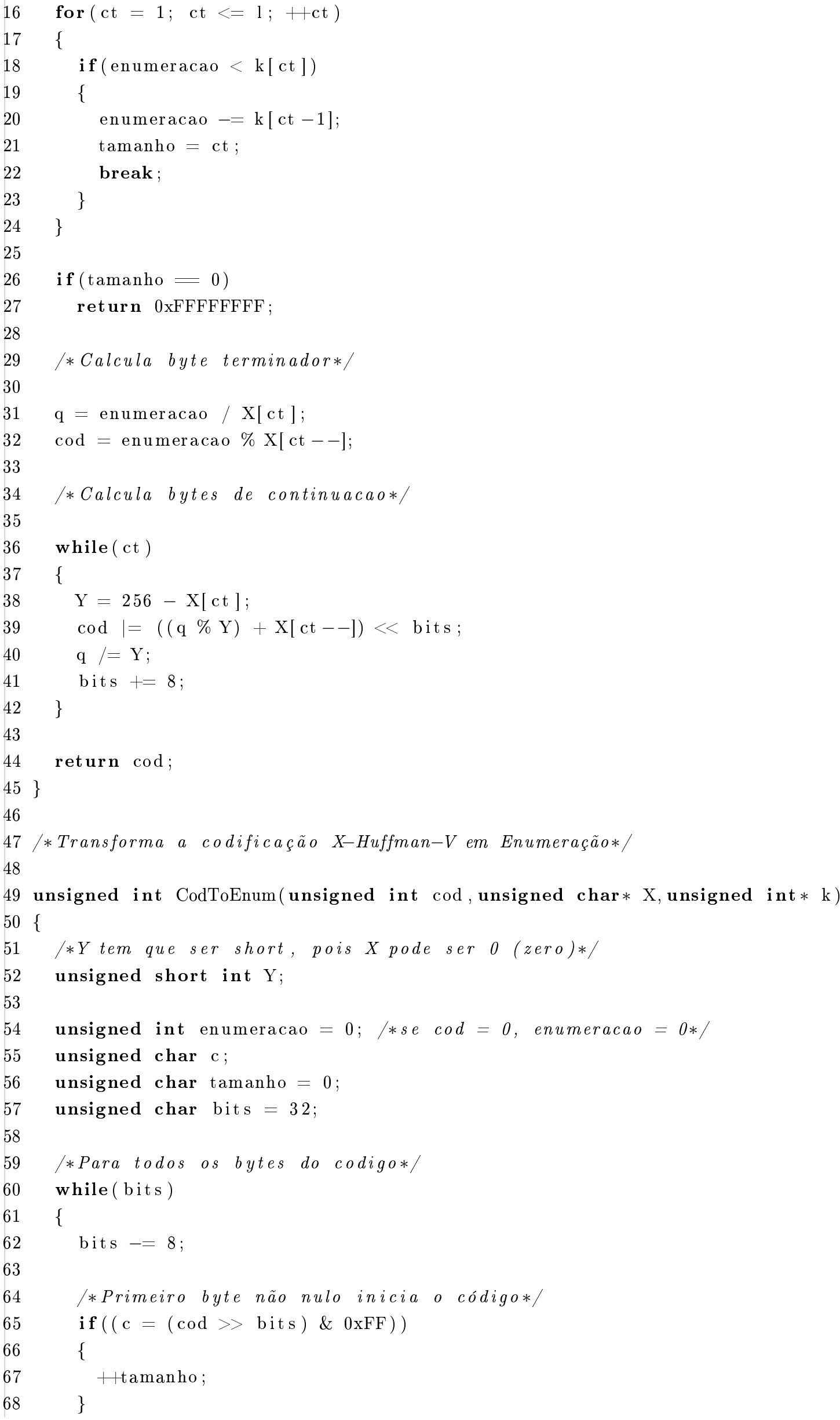


69

$70 \quad / *$ Se o codigo foi iniciado*/

71 if (tamanho)

$72 \quad$ \{

73

74

75

76

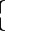




\section{Apêndice B}

\section{Suporte das Codificações Propostas para 64 bits}

A arquitetura 64 bits está expandindo seu mercado, desta forma, são apresentadas as versões 64 bits para as codificações X-Huffman-128, X-Huffman-F e X-Huffman-V.

\section{B.1 Codificação X-Huffman-128}

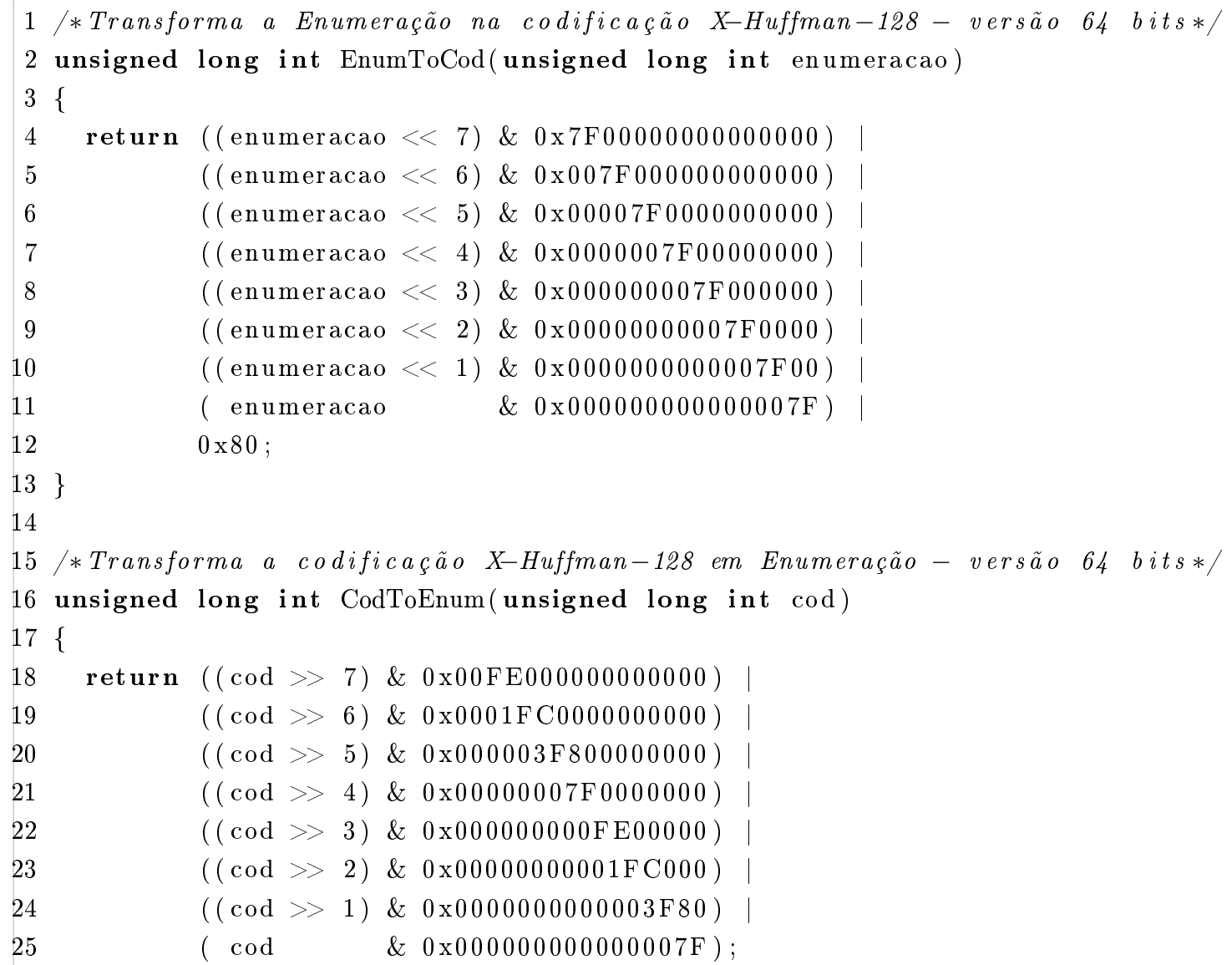

\section{B.2 Codificação X-Huffman-F}

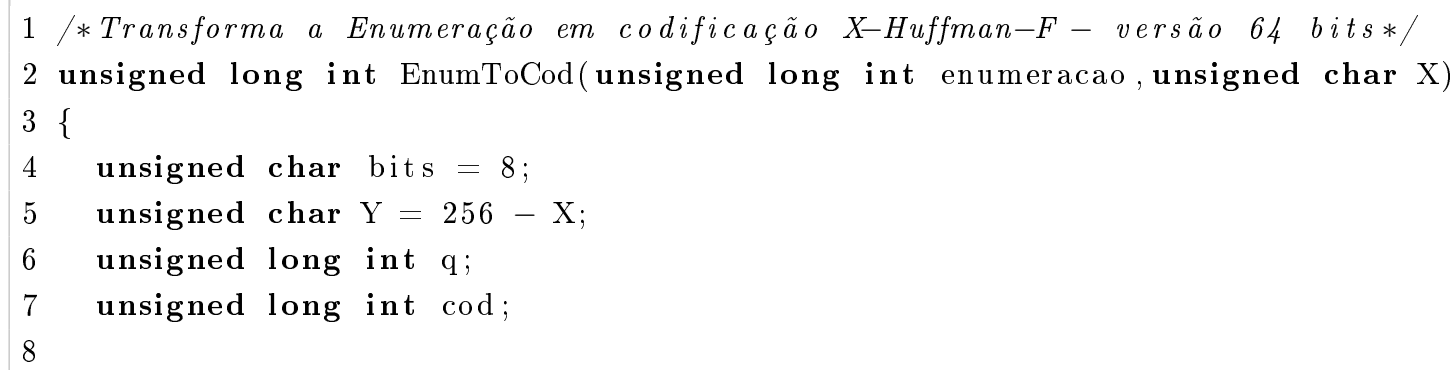




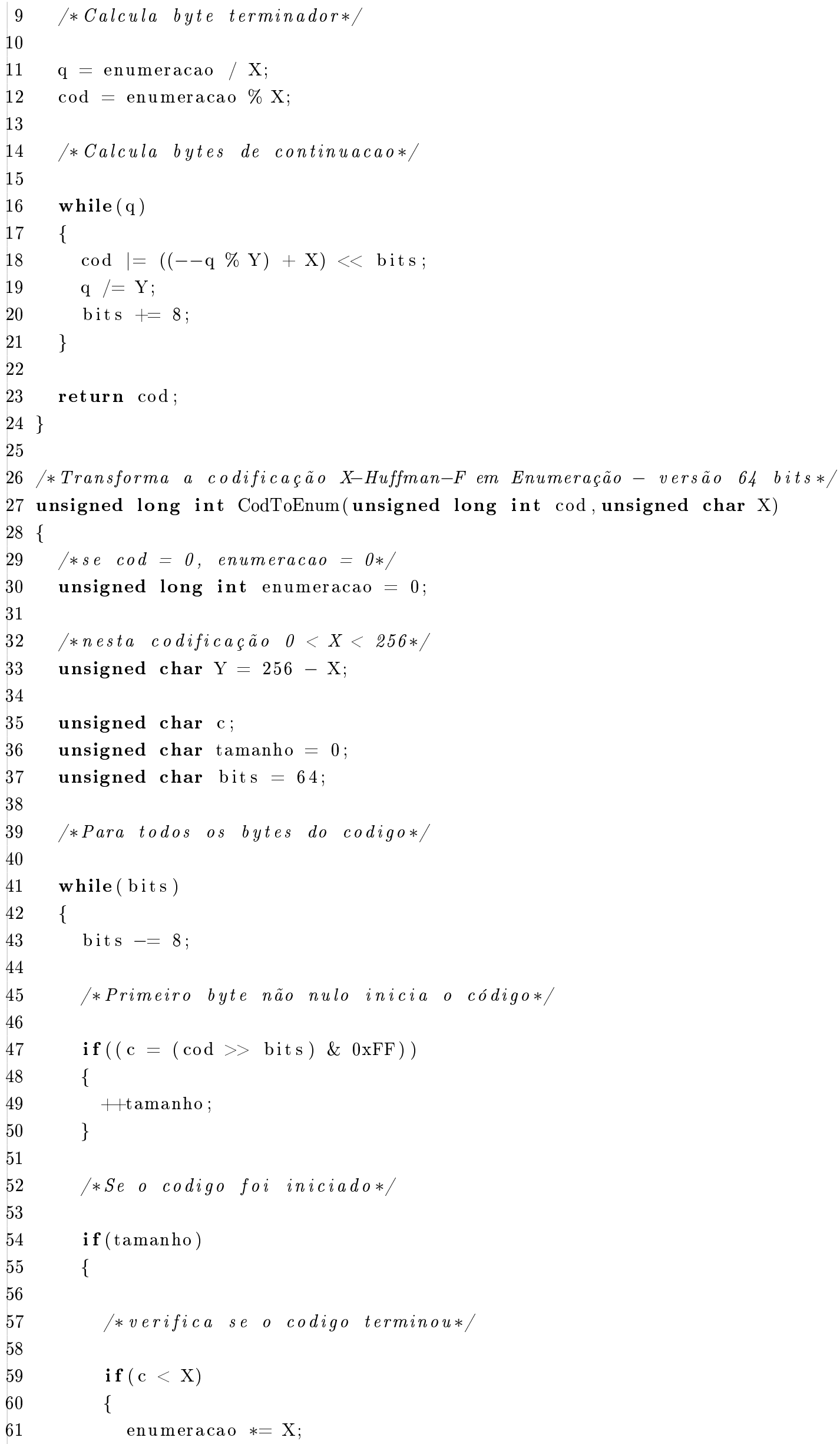




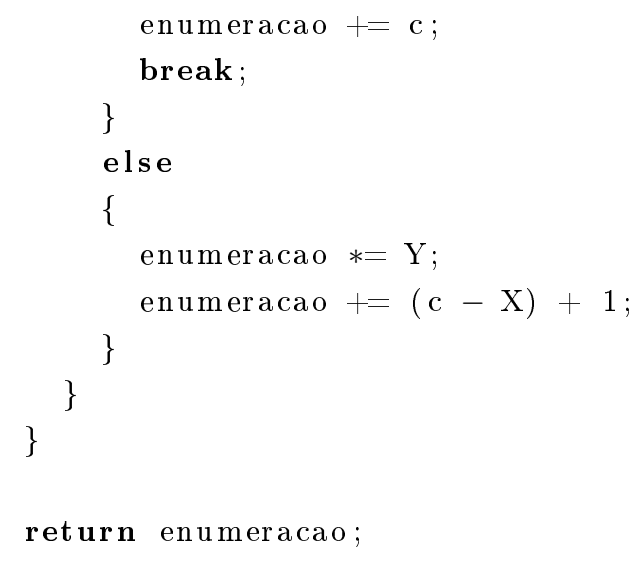

\section{B.3 Codificação X-Huffman-V}

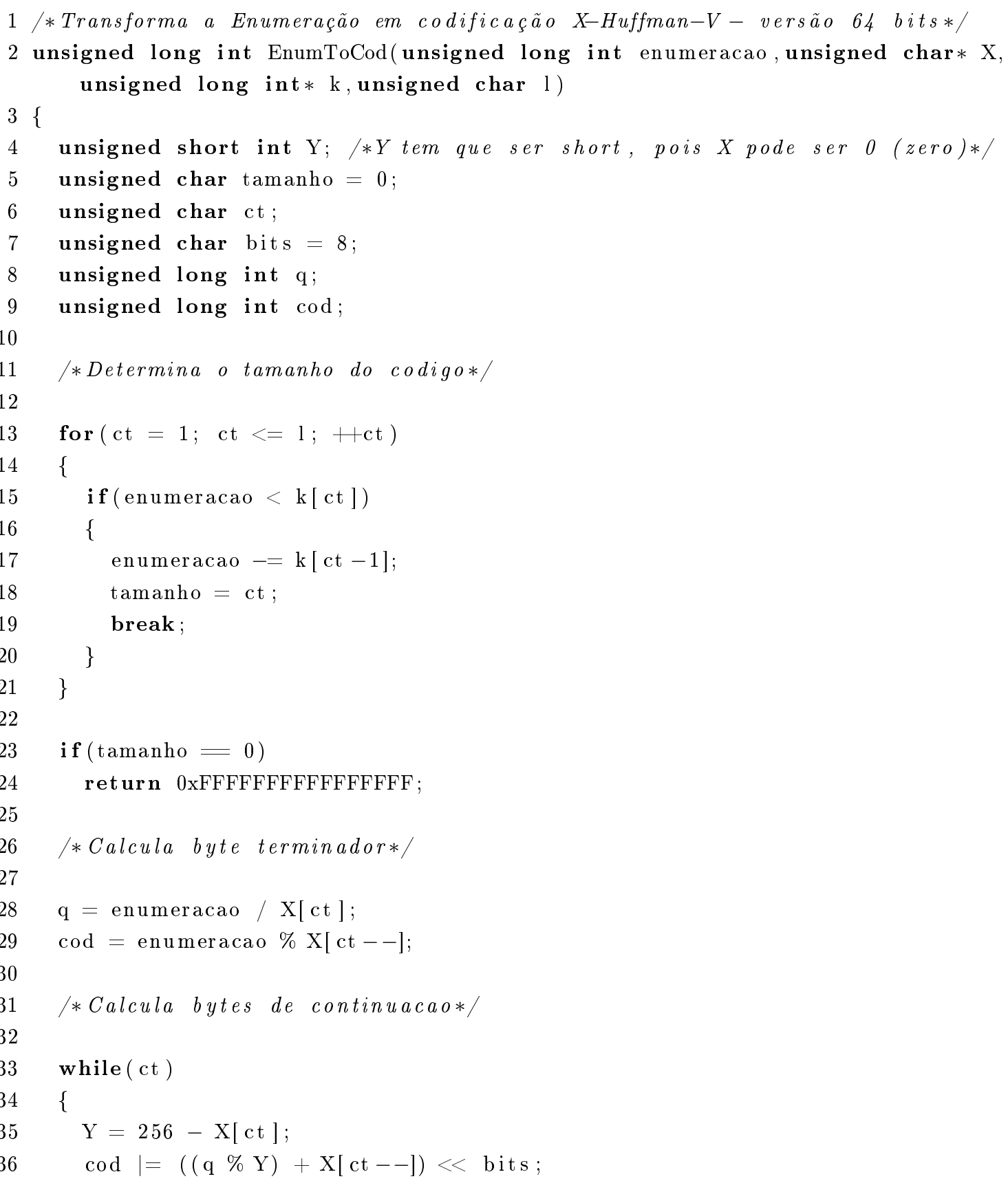




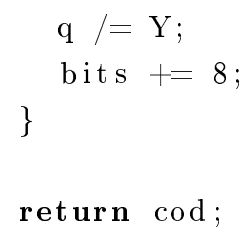




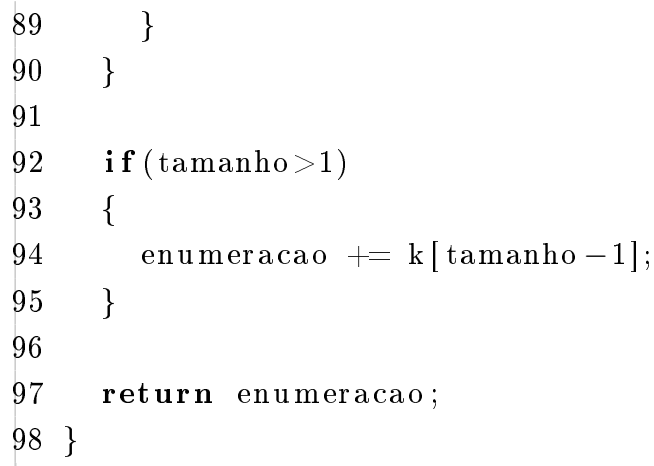


APÊNDICE B 


\section{Apêndice C}

\section{Otimização da compressão para X-Huffman-V}

Neste apêndice são apresentadas algumas figuras para ilustrar a superfície a ser percorrida na busca por gradiente a fim de encontrar a solução ótima da otimização da compressão para a codificação X-Huffman-V. A solução da otimização para a codificação X-Huffman-F utilizando a "força-bruta" foi bastante viável nos testes realizados com o compressor xhuff, pois o cálculo das 255 possibilidades nos arquivos testados no capítulo 9 foi de menos de 0,1s. Já para a codificação $\mathrm{X}$-Huffman-V, mesmo em arquivos pequenos a geração de cerca de 65.500 possibilidades chega a demorar 5s. Foram realizados testes para busca por gradiente, mas mesmo assim os resultados não foram satisfatórios devido a planaridade da superfície próxima ao ponto ótimo.

Para a visualização de um exemplo desta superfície foi gerada uma distribuição com $v=5.000$, $t=25.000$ e $\theta=1,5$ de forma a ser possível ter várias combinações de dois níveis que consigam uma quantidade de códigos suficiente para esta distribuição. A figura C.1 mostra a variação do tamanho do arquivo com $\left(X_{1}, X_{2}\right)$, sendo que $X_{1}=X_{2}$. A figura C.2 mostra a representação plana do tamanho do arquivo comprimdo para todas as combinações de $X_{1}$ e $X_{2}$ e a figura C.3 é a representação tridimensional do mesmo gráfico. Este problema ainda merece mais estudo a fim de se obter uma melhor solução, uma das idéias originadas pelo estudo é utilizar a diagonal do hipercubo de dimensão igual ao tamanho do código mais comprido e de aresta 256 para obter um melhor ponto inicial na busca por gradiente. 
Variação do tamanho do arquivo comprimido por $(\mathrm{X} 1, \mathrm{X} 2)$

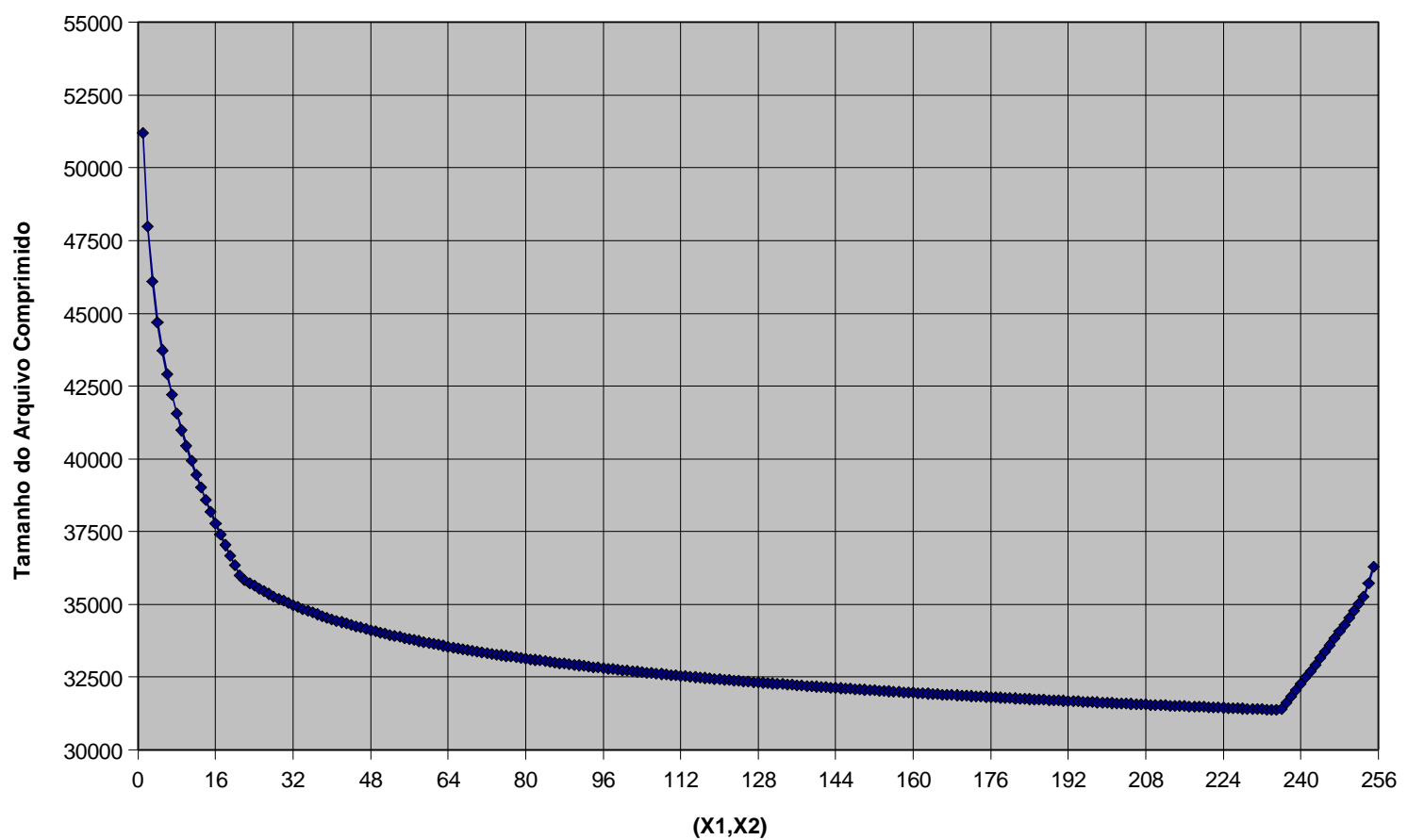

Figura C.1: Diagonal da superfície do tamanho do arquivo por $\left(X_{1}, X_{2}\right)$ para $v=5.000, t=25.000 e$ $\theta=1,5$ 


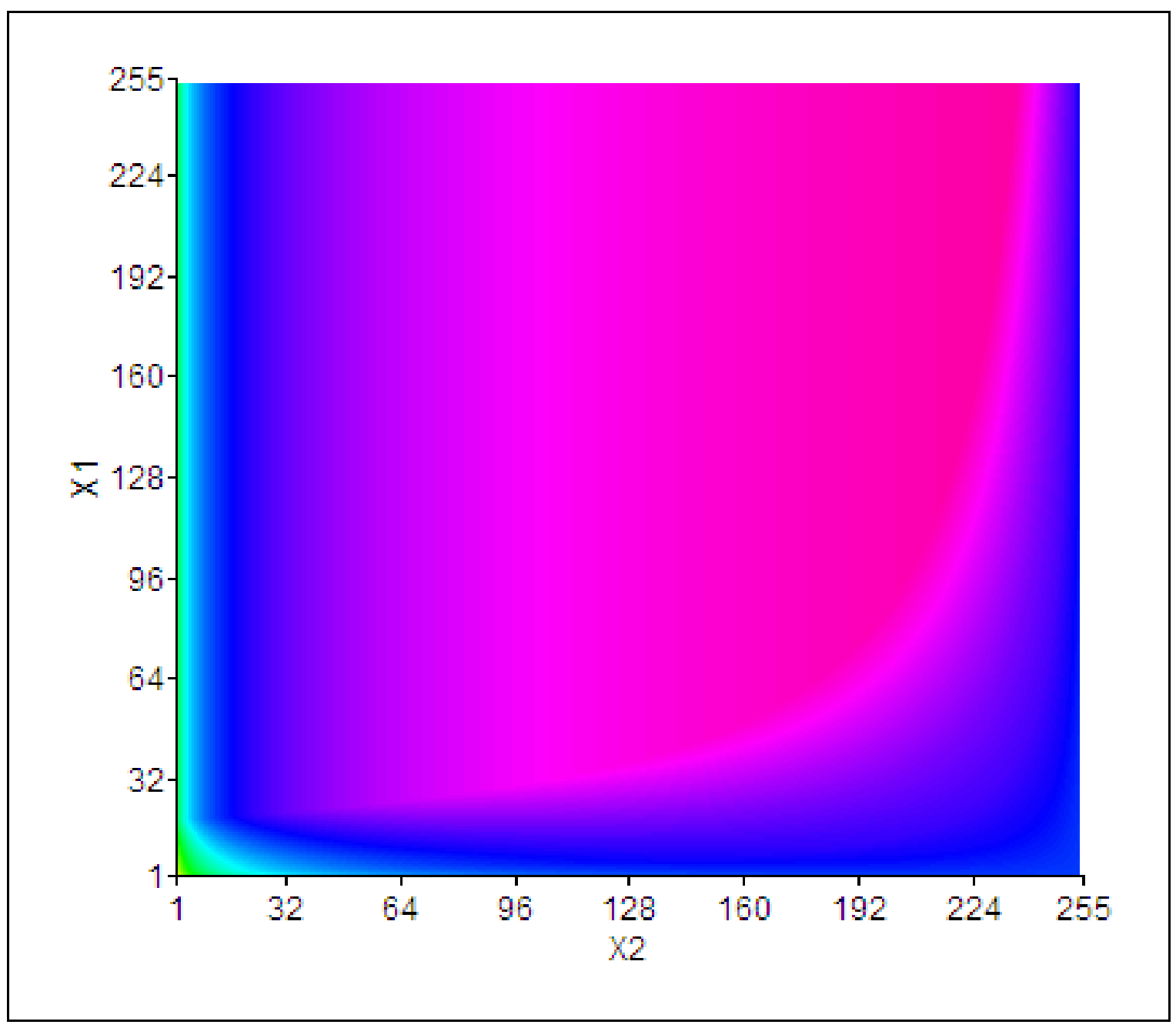

Figura C.2: Visualização plana da superfície do tamanho do arquivo por $\left(X_{1}, X_{2}\right)$ para $v=5.000, t=25.000$ e $\theta=1,5$ 


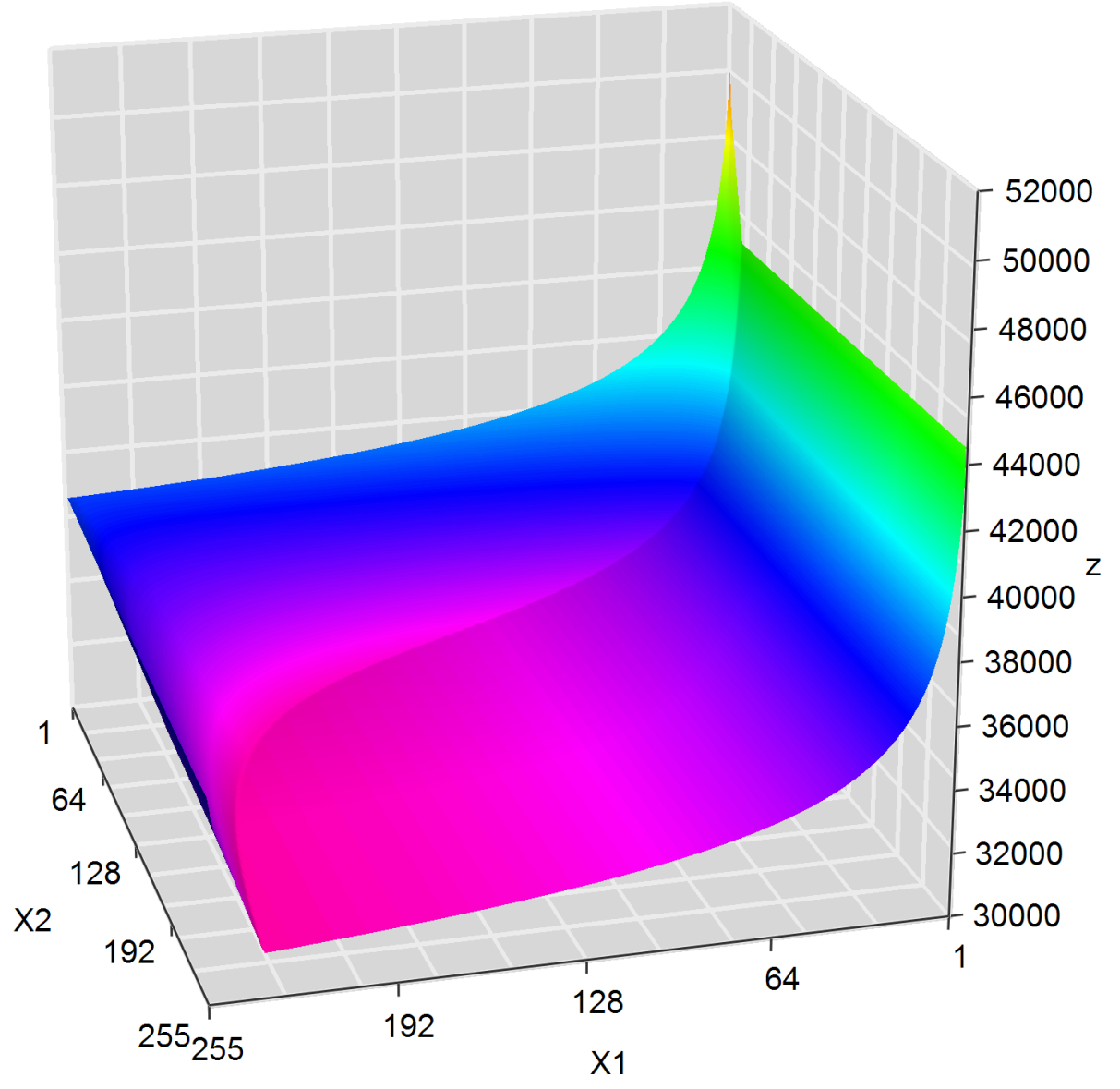

Figura C.3: Visualização tridimensional da superfície do tamanho do arquivo por $\left(X_{1}, X_{2}\right)$ para $v=5.000$, $t=25.000$ e $\theta=1,5$ 


\section{Referências Bibliográficas}

[AC75] Alfred V. Aho e Margaret J. Corasick. Efficient string matching: An aid to bibliographic search. Commun. ACM, 18(6):333-340, 1975. 13, 24

[BCW90] Timothy C. Bell, John G. Cleary, e Ian H. Witten. Text Compression (Prentice Hall Advanced Reference Series). Prentice Hall, January 1990. 9

[BM77] Robert S. Boyer e J. Strother Moore. A fast string searching algorithm. Commun. ACM, 20(10):762-772, 1977. 11

[BSTW86] Jon Louis Bentley, Daniel D. Sleator, Robert E. Tarjan, e Victor K. Wei. A locally adaptive data compression scheme. Commun. ACM, 29(4):320-330, 1986. 21

[BW94] Michael Burrows e David Wheeler. A block-sorting lossless data compression algorithm. Relatório Técnico 124, Digital SRC Research Report, 1994. 7

[BYG92] Ricardo A. Baeza-Yates e Gaston H. Gonnet. A new approach to text searching. Commun. ACM, 35(10):74-82, 1992. 24

[BYN97] Ricardo A. Baeza-Yates e Gonzalo Navarro. Block addressing indices for approximate text retrieval. Em Forouzan Golshani e Kia Makki, editors, CIKM, páginas 1-8. ACM, 1997. 5

[BYRN99] Ricardo Baeza-Yates e Berthier Ribeiro-Neto. Modern Information Retrieval. ACM Press, New York, 1999. xv, 17, 18, 20, 21, 59

[CH87] G. V. Cormack e R. N. S. Horspool. Data compression using dynamic markov modelling. The Computer Journal, 30(6):541-550, 1987. 8

[CW84] John G. Cleary e Ian H. Witten. Data compression using adaptive coding and partial string matching. IEEE Transactions on Communications, 32(4):396-402, April 1984. 7

[dLS03] Alair Pereira do Lago e Imre Simon. Tópicos em algoritmos sobre seqüências. Publicações Matemáticas do IMPA. [IMPA Mathematical Publications]. Instituto de Matemática Pura e Aplicada (IMPA), Rio de Janeiro, 2003. 24o Colóquio Brasileiro de Matemática. [24th Brazilian Mathematics Colloquium]. 3

[dMNZBY00] Edleno Silva de Moura, Gonzalo Navarro, Nivio Ziviani, e Ricardo A. Baeza-Yates. Fast and flexible word searching on compressed text. ACM Trans. Inf. Syst., 18(2):113-139, 2000. xv, xvii, 17, 18, 20, 21, 22, 23, 25, 27, 43, 48, 52, 59, 60

[FT03] Kimmo Fredriksson e Jorma Tarhio. Processing of huffman compressed texts with a super-alphabet. Em Mario A. Nascimento, Edleno Silva de Moura, e Arlindo L. Oliveira, editors, SPIRE, volume 2857 of Lecture Notes in Computer Science, páginas 108-121. Springer, 2003. 24

[Gag07] Travis Gagie. Dynamic shannon coding. Inf. Process. Lett., 102(2-3):113-117, 2007. 23 
[Gus07] Dan Gusfield. Algorithms on strings, trees, and sequences : computer science and computational biology. Cambridge Univ. Press, January 2007. 3

[Huf52] David A. Huffman. A method for the construction of minimum-redundancy codes. Proceedings of the Institute of Radio Engineers, 40(9):1098-1101, September 1952. 17

[Knu85] Donald E. Knuth. Dynamic huffman coding. J. Algorithms, 6(2):163-180, 1985. 23

[Kur99] Stefan Kurtz. Reducing the space requirement of suffix trees. Softw. Pract. Exper., 29(13):1149-1171, 1999. 3

[Man97] Udi Manber. A text compression scheme that allows fast searching directly in the compressed file. ACM Trans. Inf. Syst., 15(2):124-136, 1997. 24

[MK95] Alistair Moffat e Jyrki Katajainen. In-place calculation of minimum-redundancy codes. Em Selim G. Akl, Frank K. H. A. Dehne, Jörg-Rüdiger Sack, e Nicola Santoro, editors, WADS, volume 955 of Lecture Notes in Computer Science, páginas 393-402. Springer, 1995. 31, 59

[MNZ97] E. Moura, G. Navarro, e N. Ziviani. Indexing compressed text. Em Proc. 4th South American Workshop on String Processing (WSP), páginas 95-111. Carleton University Press, 1997. 17, 59

[Mof89] A. Moffat. Word-based text compression. Softw. Pract. Exper., 19(2):185-198, 1989. 21

[Mye99] Gene Myers. A fast bit-vector algorithm for approximate string matching based on dynamic programming. J. ACM, 46(3):395-415, 1999. 14

[NBY99] Gonzalo Navarro e Ricardo Baeza-Yates. Very fast and simple approximate string matching. Inf. Process. Lett., 72(1-2):65-70, 1999. 14

$\left[\mathrm{NKT}^{+}\right.$01] Gonzalo Navarro, Takuya Kida, Masayuki Takeda, Ayumi Shinohara, e Setsuo Arikawa. Faster approximate string matching over compressed text. Em Data Compression Conference, páginas 459-468, 2001. xv, 11, 12, 13, 14

[NR99] Gonzalo Navarro e Mathieu Raffinot. A general practical approach to pattern matching over ziv-lempel compressed text. Em Maxime Crochemore e Mike Paterson, editors, CPM, volume 1645 of Lecture Notes in Computer Science, páginas 14-36. Springer, 1999. 11, 12, 13

[NT00] Gonzalo Navarro e Jorma Tarhio. Boyer-moore string matching over ziv-lempel compressed text. Em COM '00: Proceedings of the 11th Annual Symposium on Combinatorial Pattern Matching, volume 1848 of Lecture Notes in Computer Science, páginas 166-180, London, UK, 2000. Springer-Verlag. xvii, 11, 12, 13, 60

[SEN07] Il Yeal Song, Johann Eder, e Tho Manh Nguyen, editors. Data Warehousing and Knowledge Discovery, 9th International Conference, DaWaK 2007, Regensburg, Germany, September 3-7, 2007, Proceedings, volume 4654 of Lecture Notes in Computer Science. Springer, 2007. 60, 78

[Ste07] Ben Stephenson. An efficient algorithm for identifying the most contributory substring. Em Song et al. (SEN07), páginas 272-282. 60

[Vit85] Jeffrey Scott Vitter. Design and analysis of dynamic huffman coding (extended abstract). Em FOCS, páginas 293-302. IEEE, 1985. 23 
[Wel84] T. A. Welch. A technique for high-performance data compression. Computer, 17(6):819, 1984. 11

[WM92] Sun Wu e Udi Manber. Fast text searching allowing errors. Commun. ACM, 35(10):83-91, $1992 . \quad 12$

[WMB99] Ian H. Witten, Alistair Moffat, e Timothy C. Bell. Managing Gigabytes: Compressing and Indexing Documents and Images. Morgan Kaufmann, Maio 1999. 8, 21, 59, 60

[YY02] Chunxuan Ye e Raymond W. Yeung. A simple upper bound on the redundancy of huffman codes. IEEE Transactions on Information Theory, 48(7):2132-2138, 2002. 23

[Ze105] Marvin Zelkowitz. Advances in Computers: Parallel, Distributed, and Pervasive Computing. Academic Press, Inc., Orlando, FL, USA, 2005. 60

[Zip49] George K. Zipf. Human Behavior and the Principle of Least Effort. Addison-Wesley (Reading MA), 1949. 39

[ZL77] Jacob Ziv e Abraham Lempel. A universal algorithm for sequential data compression. IEEE Transactions on Information Theory, 23(3):337-343, 1977. 9

[ZL78] Jacob Ziv e Abraham Lempel. Compression of individual sequences via variable-rate coding. IEEE Transactions on Information Theory, 24(5):530-536, 1978. 9

[ZTSM04] Nan Zhang, Tao Tao, Ravi Vijaya Satya, e Amar Mukherjee. Modified lzw algorithm for efficient compressed text retrieval. Em ITCC '04: Proceedings of the International Conference on Information Technology: Coding and Computing (ITCC'04) Volume 2, página 224, Washington, DC, USA, 2004. IEEE Computer Society. 60

[ZTSM05] Nan Zhang, Tao Tao, Ravi Vijaya Satya, e Amar Mukherjee. A flexible compressed text retrieval system using a modified lzw algorithm. Em DCC '05: Proceedings of the Data Compression Conference, páginas 493-493, Washington, DC, USA, 2005. IEEE Computer Society. 60 